\title{
Antimycobacterial Rufomycin Analogues from Streptomyces atratus Strain MJM3502
}

Bin Zhou, ${ }^{\dagger, \ddagger}$ Gauri Shetye, ${ }^{\ddagger}$ Yang Yu, ${ }^{\dagger}$ Bernard D. Santarsiero, ${ }^{\dagger, \perp}$ Larry L. Klein, ${ }^{\dagger, \neq}$ Cele Abad-Zapatero, ${ }^{\ddagger \perp}$ Nina M. Wolf, ${ }^{\ddagger}$ Jinhua Cheng,,${ }^{\S} \#$ Y Yingyu Jin, ${ }^{\S}$ Hanki Lee,,

Joo-Won Suh, ${ }^{\S}$ Hyun Lee, ${ }^{\dagger, \ddagger \perp \perp}$ Jonathan Bisson, ${ }^{\dagger, \neq}$ James B. McAlpine, ${ }^{\dagger, \neq}$ Shao-Nong Chen, ${ }^{\dagger, \ddagger}$ Sang-Hyun Cho, ${ }^{\dagger, \ddagger}$ Scott G. Franzblau, ${ }^{\dagger, \ddagger}$ and Guido F. Pauli ${ }^{*}+, \neq$

${ }^{\dagger}$ Department of Pharmaceutical Sciences, University of Illinois at Chicago, 833 S. Wood Street, Chicago, Illinois 60612, United States

‡Institute for Tuberculosis Research, College of Pharmacy, University of Illinois at Chicago, 833

S. Wood Street, Chicago, Illinois 60612, United States

${ }^{\perp}$ Center for Biomolecular Sciences, College of Pharmacy, University of Illinois at Chicago, $900 \mathrm{~S}$. Ashland Street, Chicago, Illinois 60612, United States

${ }^{\S}$ Center for Nutraceutical and Pharmaceutical Materials, Myongji University, Cheoin-gu, Yonginsi, Gyeonggi-do, Republic of Korea

\#Division of Bioscience and Bioinformatics, College of Natural Science, Myongii University, Cheoin-gu, Yongin-si, Gyeonggi-do, Republic of Korea

\section{-SUPPORTING INFORMATION}




\section{- TABLE OF CONTENTS}

SI-1. Preparation of L- and D-FDLA derivatives of amino acid standards $\quad 1$

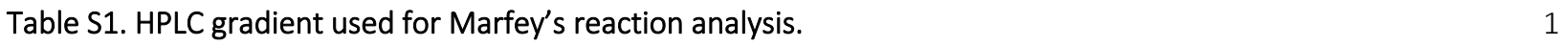

Table S2. Retention time and MS of observed L/D-FDLA-AA standards. $\quad 1$

Figure S1. LC-ESIMS chromatograms of L- and D-FDLA derivatized AA standards. 1

SI-2. Crystal Structure Analysis $\quad 2$

SI-3. NMR (400 MHz ${ }^{1} \mathrm{H}$ ), IR, LC-HRESIMS and LC-MS chromatograms of Marfey's derivatization products for 1-8 3

Figure S2. ${ }^{1} \mathrm{H}$ NMR spectrum of 1 in $\mathrm{CD}_{3} \mathrm{OD}$ at $400 \mathrm{MHz}$

Figure $\mathrm{S} 3 .{ }^{13} \mathrm{C}$ NMR spectrum of 1 in $\mathrm{CD}_{3} \mathrm{OD}$ at $100 \mathrm{MHz}$

Figure S4. COSY spectrum of 1 in $\mathrm{CD}_{3} \mathrm{OD}(400 \mathrm{MHz}) \quad 4$

Figure S5. TOCSY spectrum of 1 in $\mathrm{CD}_{3} \mathrm{OD}(400 \mathrm{MHz})$

Figure S6. $\mathrm{HSQC}$ spectrum of 1 in $\mathrm{CD}_{3} \mathrm{OD}\left(400 \mathrm{MHz}^{1} \mathrm{H}\right)$

Figure S7. $\mathrm{HMBC}$ spectrum of 1 in $\mathrm{CD}_{3} \mathrm{OD}\left(400 \mathrm{MHz}^{1} \mathrm{H}\right)$

Figure S8. (+)-HRESIMS spectrum of $1 \quad 6$

$\begin{array}{ll}\text { Figure S9. IR spectrum of } 1 & 6\end{array}$

Figure S10. Tandem MS/MS fragmentation of 1

Figure S11. ${ }^{1} \mathrm{H}$ NMR spectrum of 2 in $\mathrm{CD}_{3} \mathrm{OD}$ at $400 \mathrm{MHz}$

Figure S12. ${ }^{13} \mathrm{C}$ NMR spectrum of 2 in $\mathrm{CD}_{3} \mathrm{OD}$ at $100 \mathrm{MHz}$

Figure S13. COSY spectrum of 2 in $\mathrm{CD}_{3} \mathrm{OD}(400 \mathrm{MHz}) \quad 9$

Figure S14. TOCSY spectrum of 2 in $\mathrm{CD}_{3} \mathrm{OD}(400 \mathrm{MHz}) \quad 9$

Figure S15. HSQC spectrum of 2 in $\mathrm{CD}_{3} \mathrm{OD}\left(400 \mathrm{MHz}^{1} \mathrm{H}\right)$

Figure $\mathrm{S} 16 . \mathrm{HMBC}$ spectrum of 2 in $\mathrm{CD}_{3} \mathrm{OD}\left(400 \mathrm{MHz}{ }^{1} \mathrm{H}\right)$

Figure S17. (+)-HRESIMS spectrum of 2

Figure S18. IR spectrum of $2 \quad 11$

Figure S19. LC-ESIMS chromatograms of a total hydrolysate of 2 after derivatization with D/L-FDLA 12

Figure S2O. ${ }^{1} \mathrm{H}$ NMR spectrum of 3 in $\mathrm{CD}_{3} \mathrm{OD}$ at $400 \mathrm{MHz}$

Figure $\mathrm{S} 21 .{ }^{13} \mathrm{C}$ NMR spectrum of 3 in $\mathrm{CD}_{3} \mathrm{OD}$ at $100 \mathrm{MHz}$

Figure S22. COSY spectrum of 3 in $\mathrm{CD}_{3} \mathrm{OD}(400 \mathrm{MHz}) \quad 14$

Figure S23. TOCSY spectrum of 3 in $\mathrm{CD}_{3} \mathrm{OD}(400 \mathrm{MHz}) \quad 14$

Figure S24. $\mathrm{HSQC}$ spectrum of 3 in $\mathrm{CD}_{3} \mathrm{OD}\left(400 \mathrm{MHz}^{1} \mathrm{H}\right)$

Figure S25. $\mathrm{HMBC}$ spectrum of 3 in $\mathrm{CD}_{3} \mathrm{OD}\left(400 \mathrm{MHz}^{1} \mathrm{H}\right) \quad 15$

Figure S26. (+)-HRESIMS spectrum of $3 \quad 16$

Figure S27. IR spectrum of $3 \quad 16$

Figure S28. LC-ESIMS chromatograms of a total hydrolysate of 3 after derivatization with D/L-FDLA 17

Figure S29. ${ }^{1} \mathrm{H}$ NMR spectrum of 4 in $\mathrm{CD}_{3} \mathrm{OD}$ at $400 \mathrm{MHz}$ 
Figure $\mathrm{S} 30 .{ }^{13} \mathrm{C}$ NMR spectrum of 4 in $\mathrm{CD}_{3} \mathrm{OD}$ at $100 \mathrm{MHz}$

Figure S31. COSY spectrum of 4 in $\mathrm{CD}_{3} \mathrm{OD}(400 \mathrm{MHz}) \quad 19$

Figure S32. TOCSY spectrum of 4 in $\mathrm{CD}_{3} \mathrm{OD}(400 \mathrm{MHz}) \quad 19$

Figure S33. $\mathrm{HSQC}$ spectrum of 4 in $\mathrm{CD}_{3} \mathrm{OD}\left(400 \mathrm{MHz}^{1} \mathrm{H}\right)$

Figure S34. $\mathrm{HMBC}$ spectrum of 4 in $\mathrm{CD}_{3} \mathrm{OD}\left(400 \mathrm{MHz}^{1} \mathrm{H}\right)$

Figure S35. (+)-HRESIMS spectrum of 4

Figure S36. IR spectrum of $4 \quad 21$

Figure S37. LC-ESIMS chromatograms of a total hydrolysate of 4 after derivatization with D/L-FDLA 22

Figure S38. ${ }^{1} \mathrm{H}$ NMR spectrum of 5 in $\mathrm{CD}_{3} \mathrm{OD}$ at $400 \mathrm{MHz}$

Figure S39. ${ }^{13} \mathrm{C}$ NMR spectrum of 5 in $\mathrm{CD}_{3} \mathrm{OD}$ at $100 \mathrm{MHz}$

Figure S40. COSY spectrum of 5 in $\mathrm{CD}_{3} \mathrm{OD}(400 \mathrm{MHz}) \quad 24$

Figure S41. TOCSY spectrum of 5 in $\mathrm{CD}_{3} \mathrm{OD}(400 \mathrm{MHz}) \quad 24$

Figure S42. $\mathrm{HSQC}$ spectrum of 5 in $\mathrm{CD}_{3} \mathrm{OD}\left(400 \mathrm{MHz}^{1} \mathrm{H}\right)$

Figure S43. $\mathrm{HMBC}$ spectrum of 5 in $\mathrm{CD}_{3} \mathrm{OD}\left(400 \mathrm{MHz}{ }^{1} \mathrm{H}\right)$

Figure S44. (+)-HRESIMS spectrum of $5 \quad 26$

Figure S45. IR spectrum of $5 \quad 26$

Figure S46. LC-ESIMS chromatograms of a total hydrolysate of 5 after derivatization with D/L-FDLA 27

Figure S47. ${ }^{1} \mathrm{H}$ NMR spectrum of 6 in $\mathrm{CD}_{3} \mathrm{OD}$ at $400 \mathrm{MHz}$

Figure S48. ${ }^{13} \mathrm{C}$ NMR spectrum of 6 in $\mathrm{CD}_{3} \mathrm{OD}$ at $100 \mathrm{MHz}$

Figure S49. TOCSY spectrum of 6 in $\mathrm{CD}_{3} \mathrm{OD}(400 \mathrm{MHz}) \quad 29$

Figure S50. $\mathrm{HSQC}$ spectrum of 6 in $\mathrm{CD}_{3} \mathrm{OD}\left(400 \mathrm{MHz}^{1} \mathrm{H}\right)$

Figure $\mathrm{S} 51$. $\mathrm{HMBC}$ spectrum of 6 in $\mathrm{CD}_{3} \mathrm{OD}\left(400 \mathrm{MHz}^{1} \mathrm{H}\right)$

Figure S52. (+)-HRESIMS spectrum of $6 \quad 30$

Figure S53. IR spectrum of $6 \quad 31$

Figure S54. LC-ESIMS chromatograms of a total hydrolysate of 6 after derivatization with D/L-FDLA 31

Figure S55. ${ }^{1} \mathrm{H}$ NMR spectrum of 7 in $\mathrm{CD}_{3} \mathrm{OD}$ at $400 \mathrm{MHz}$

Figure $556 .{ }^{13} \mathrm{C}$ NMR spectrum of 7 in $\mathrm{CD}_{3} \mathrm{OD}$ at $100 \mathrm{MHz}$

Figure S57. COSY spectrum of 7 in $\mathrm{CD}_{3} \mathrm{OD}(400 \mathrm{MHz})$

Figure S58. TOCSY spectrum of 7 in $\mathrm{CD}_{3} \mathrm{OD}(400 \mathrm{MHz})$

Figure S59. HSQC spectrum of 7 in $\mathrm{CD}_{3} \mathrm{OD}\left(400 \mathrm{MHz}^{1} \mathrm{H}\right)$

Figure S60. $\mathrm{HMBC}$ spectrum of 7 in $\mathrm{CD}_{3} \mathrm{OD}\left(400 \mathrm{MHz}{ }^{1} \mathrm{H}\right)$

Figure S61. NOESY spectrum of 7 in $\mathrm{CD}_{3} \mathrm{OD}(400 \mathrm{MHz})$

Figure S62. (+)-HRESIMS spectrum of 7

Figure S63. IR spectrum of $7 \quad 36$

Figure S64. LC-ESIMS chromatograms of a total hydrolysate of 7 after derivatization with D/L-FDLA 36 
Figure S65. ${ }^{1} \mathrm{H}$ NMR spectrum of 8 in $\mathrm{CD}_{3} \mathrm{OD}$ at $400 \mathrm{MHz}$

Figure S68. TOCSY spectrum of 8 in $\mathrm{CD}_{3} \mathrm{OD}(400 \mathrm{MHz})$

Figure S69. HSQC spectrum of 8 in $\mathrm{CD}_{3} \mathrm{OD}\left(400 \mathrm{MHz}^{1} \mathrm{H}\right)$

Figure S70. HMBC spectrum of 8 in $\mathrm{CD}_{3} \mathrm{OD}\left(400 \mathrm{MHz}{ }^{1} \mathrm{H}\right)$

Figure S71. NOESY spectrum of $8(400 \mathrm{MHz})$

Figure S72. (+)-HRESIMS spectrum of 8

Figure S73. IR spectrum of 8

Figure S74. LC-ESIMS chromatograms of the hydrolysate of 8 after derivatization with D/L-FDLA

Figure S75.UHPLC chromatograms for isolates 1-13 (extracted at $254 \mathrm{~nm}$ )

Figure S76. UV spectra of 1

Figure S77. UV spectra of 2

Figure S78. UV spectra of 3

Figure S79. UV spectra of 4

Figure S80. UV spectra of 5

Figure S81. UV spectra of 6

Figure S82. UV spectra of 7

Figure S83. UV spectra of 8 


\section{SI-1. Preparation of L- and D-FDLA derivatives of amino acid standards}

$50 \mathrm{mM}$ L-amino acids (L-Leu, L-Ala, L-Tyr, and L-NMeLeu) dissolved in $\mathrm{H}_{2} \mathrm{O}(50 \mu \mathrm{L})$ were treated with $1 \mathrm{M} \mathrm{NaHCO}_{3}(20 \mu \mathrm{L})$ and L- or D-FDLA (1\% solution in acetone, $\left.100 \mu \mathrm{L}\right)$ at $40{ }^{\circ} \mathrm{C}$ for $1 \mathrm{~h}$. After cooling to rt, the contents were neutralized with $1 \mathrm{M} \mathrm{HCl}(20 \mu \mathrm{L})$ and diluted with $\operatorname{MeCN}(500 \mu \mathrm{L})$. An aliquot (5 $\mu \mathrm{L}$ ) of filtered hydrolysate was analyzed by LC-MS selected ion chromatography on a reversed-phase column (Waters CORTECS C18, $2.7 \mu \mathrm{m}, 3.0 \times 100 \mathrm{~mm}$ ) with an HPLC gradient method as following table:

Table S1. HPLC gradient used for Marfey's reaction analysis.

\begin{tabular}{ll}
\hline Time (min) & $\mathbf{\%}_{\mathbf{C H}} \mathbf{C N}$ \\
\hline 1.0 & 10 \\
3.0 & 30 \\
13.0 & 40 \\
18.0 & 40 \\
28.0 & 50 \\
38.0 & 60 \\
40.0 & 100 \\
43.0 & 100 \\
44.0 & 10 \\
\hline
\end{tabular}

Table S2. Retention time and MS of observed L/D-FDLA-AA standards.

\begin{tabular}{llll}
\hline L-AA & L-FDLA-L-AA $(\mathrm{t}, \min )$ & D-FDLA-L-AA $(\mathrm{t}, \min )$ & $\mathrm{MS}(\mathrm{m} / \mathrm{z})$ \\
\hline Leu & 10.2 & 16.8 & $426.2[\mathrm{M}+\mathrm{H}]$ \\
$N$ MeLeu & 12.7 & 15.5 & $462.2[\mathrm{M}+\mathrm{Na}]$ \\
$\mathrm{Ala}$ & 6.1 & 8.2 & $384.2[\mathrm{M}+\mathrm{H}]$ \\
$m \mathrm{NO}_{2} \mathrm{Tyr}$ & 9.5 & 12.5 & $521.2[\mathrm{M}+\mathrm{H}]$ \\
\hline
\end{tabular}

Figure S1. LC-ESIMS chromatograms of L- and D-FDLA derivatized AA standards.

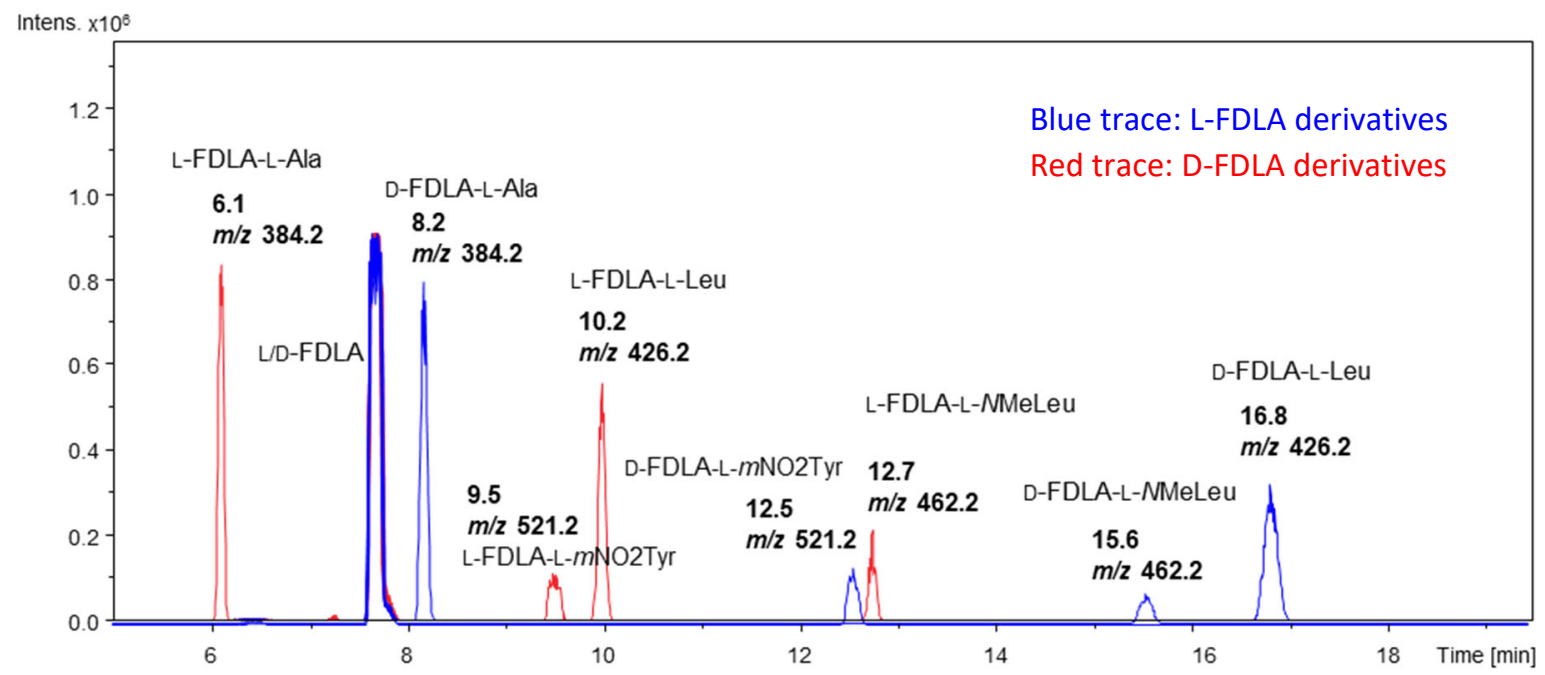




\section{SI-2. Crystal Structure Analysis}

A crystal measuring roughly $20 \times 20 \times 50 \mathrm{~mm}$ was selected for data collection. It was encased in silicon oil, transferred to a nylon loop, and cooled to $100 \mathrm{~K}$. Data collection was carried out at beam line 21-ID-D, LS-CAT, Advanced Photon Source, Argonne National Laboratory, using a Eiger 9M Detector, with a wavelength of $0.68877 \AA$ and a crystal-to-detector distance of $100 \mathrm{~mm}$. Integration of the data with XDS resulted in a total of 46012 accepted reflections, and an averaged set of 26510 unique reflections to a resolution of $0.75 \AA$. The unit cell was identified as monoclinic, space group P2 (No. 4), with two molecules in the asymmetric unit. The structure was solved by SHELXS and refined with SHELXL-2014. All hydrogen atoms were placed and restrained to ride on the adjacent atom at fixed bond lengths. Three water molecules were included in the model with no hydrogen atoms; two of the water molecules were considered disordered. Some atoms exhibited high vibrational motion and were modeled by restraints on distances and anisotropic Gaussian displacement parameters. The final agreement is $\mathrm{R} 1=0.1166$ for reflections with Fo $>$ $4 \mathrm{~s}(\mathrm{Fo})$, and 0.1249 for all 26475 data, with goodness-of-fit $=1.63$. Bijvoet analysis suggests that this absolute structure is reasonable: $\mathrm{P} 2($ true $)=0.999, \mathrm{P} 3$ (false) $=0.003$, Hooft $\mathrm{y}=0.26(18)$, Flack parameter $\mathrm{x}=0.3(3)$; for the inverted structure, $\mathrm{P} 2$ (true) $=0.001, \mathrm{P} 3$ (false) $=0.477$, Hooft $\mathrm{y}=0.73(18)$, Flack parameter $\mathrm{x}=0.7(3)$. The absolute structure is assigned with $\mathrm{C} 11 \mathrm{~A}(\mathrm{~S}), \mathrm{C} 11 \mathrm{P}(\mathrm{S})$, C12A(S), C13A(S), C14A(S), C14C(S), C15A(S), C16A(S), C17A(S) in molecule A, and C21A(S), C21P(S), C22A(S), C23A(S), C24A(S), C24C(S), C25A(S), C26A(S), C27A(S) in molecule B. 
SI-3. NMR (400 MHz $\left.{ }^{1} \mathrm{H}\right)$, IR, LC-HRESIMS and LC-MS chromatograms of Marfey's derivatization products for $1-8$

Figure S2. ${ }^{1} \mathrm{H}$ NMR spectrum of 1 in $\mathrm{CD}_{3} \mathrm{OD}$ at $400 \mathrm{MHz}$

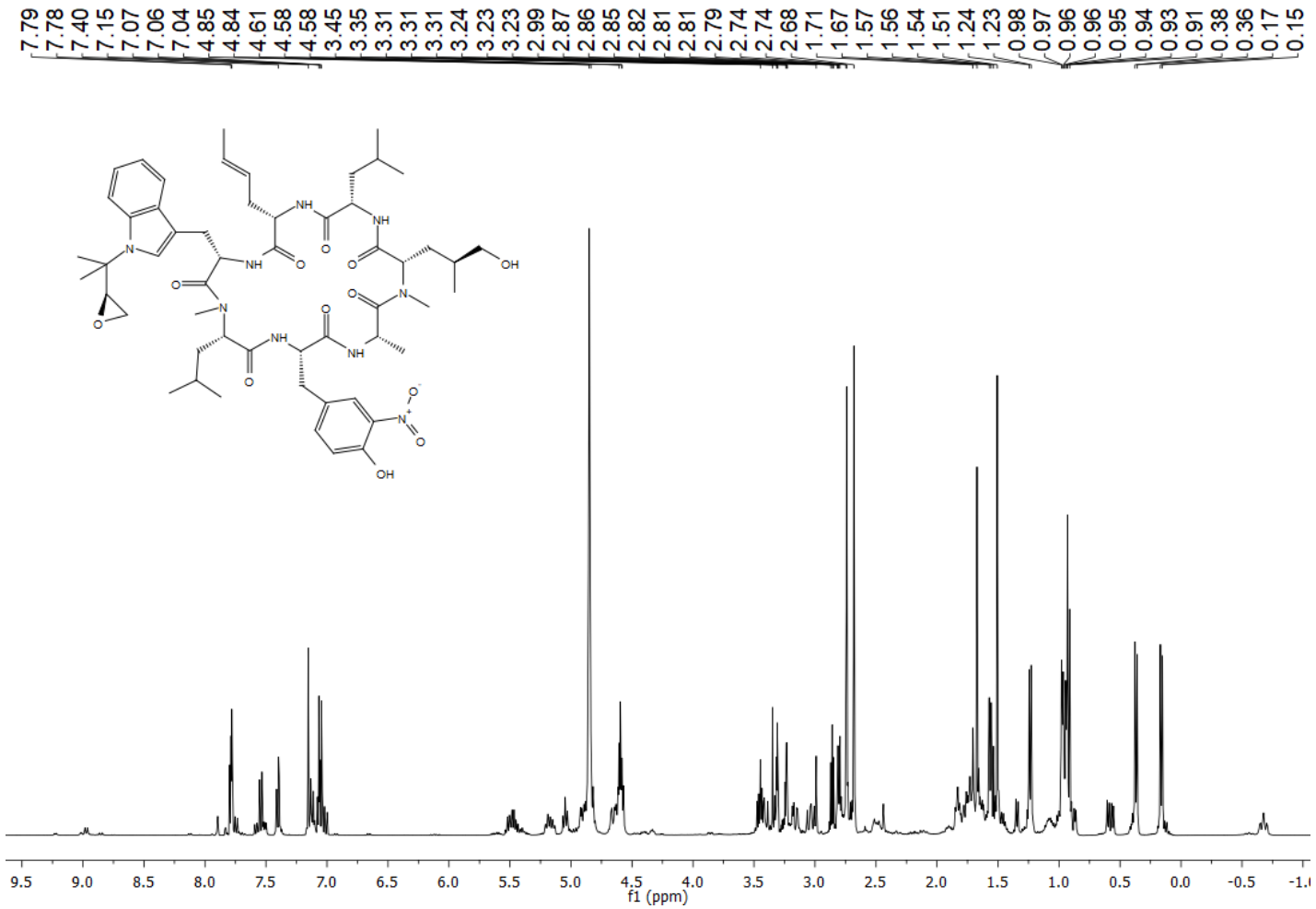

Figure S3. ${ }^{13} \mathrm{C}$ NMR spectrum of 1 in $\mathrm{CD}_{3} \mathrm{OD}$ at $100 \mathrm{MHz}$

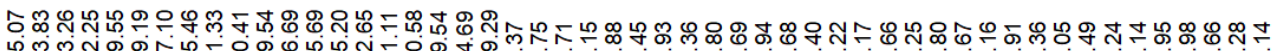

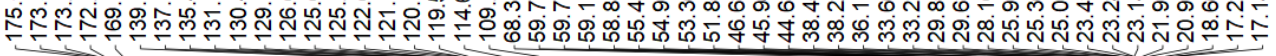
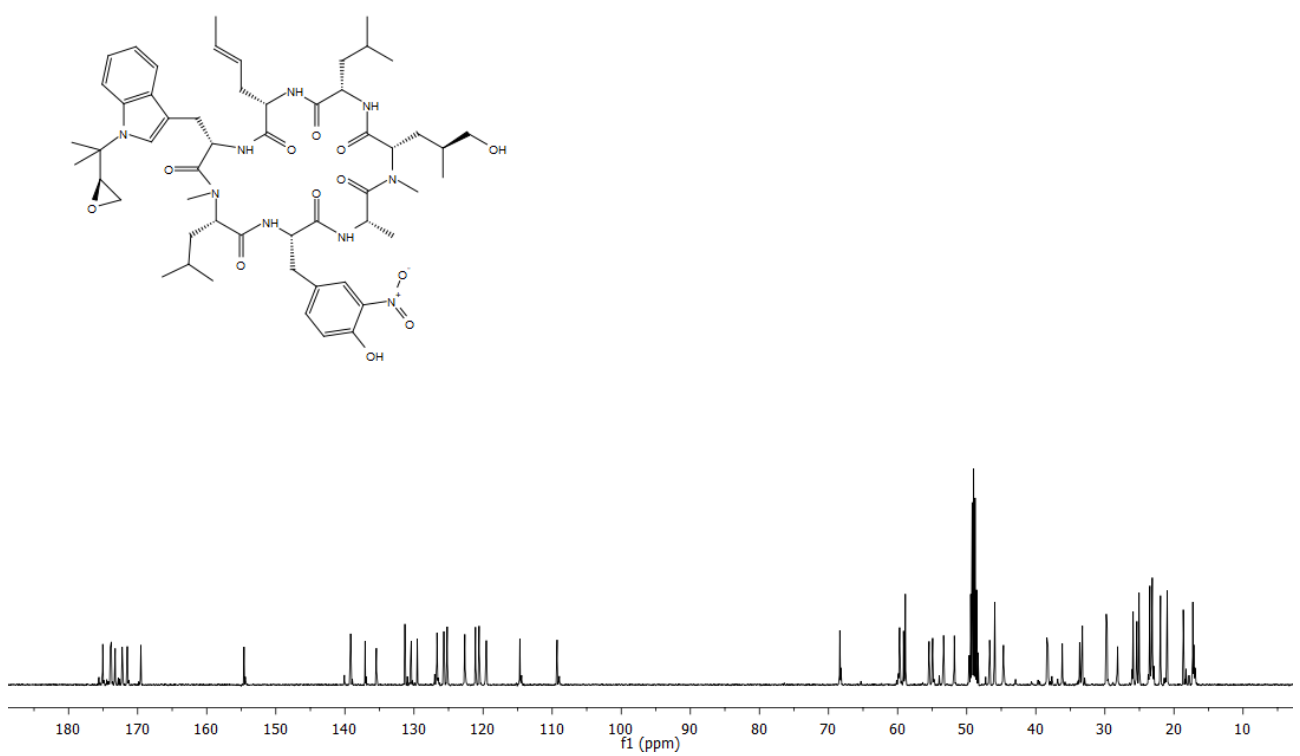
Figure S4. COSY spectrum of 1 in $\mathrm{CD}_{3} \mathrm{OD}(400 \mathrm{MHz})$

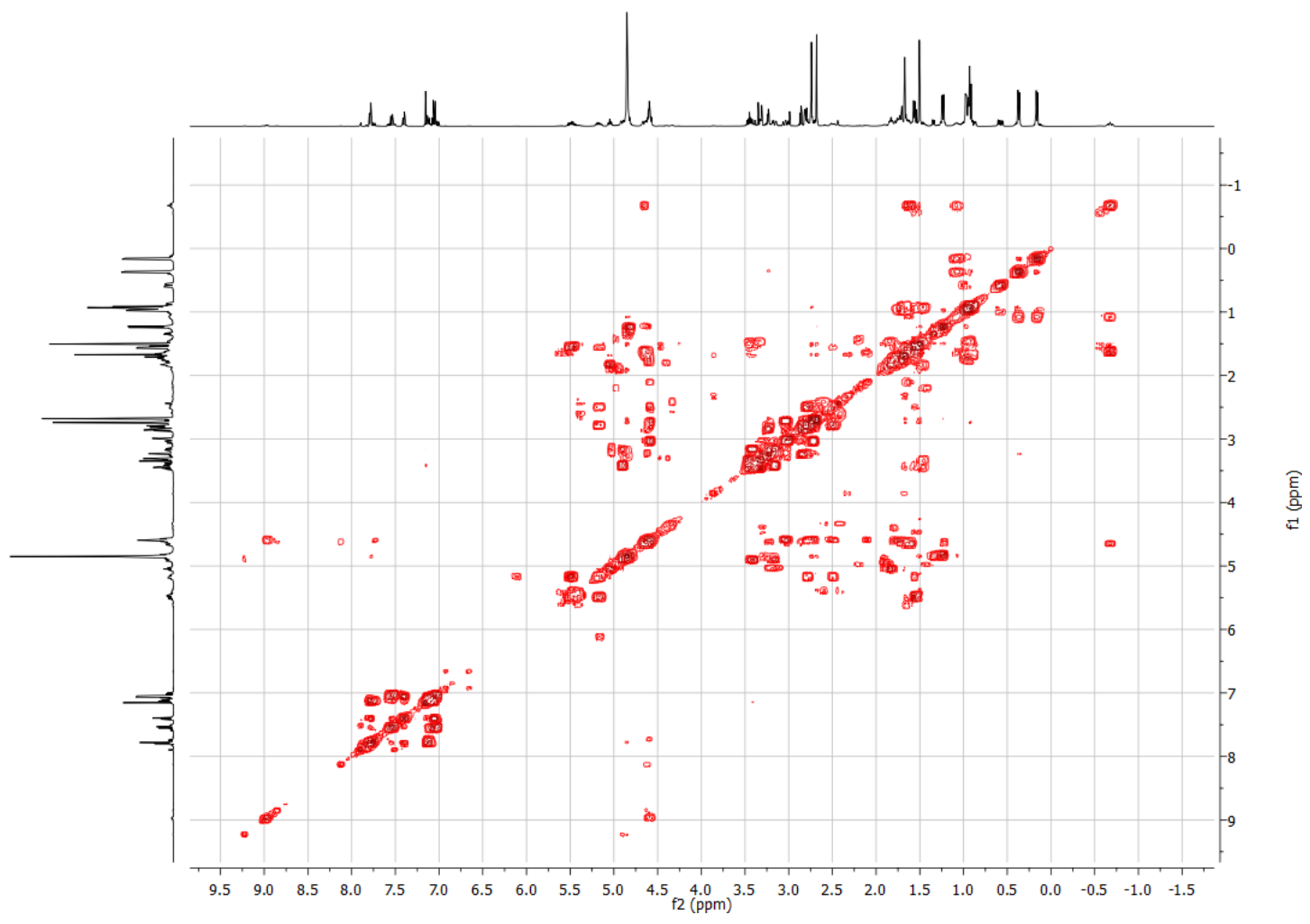

Figure S5. TOCSY spectrum of 1 in $\mathrm{CD}_{3} \mathrm{OD}(400 \mathrm{MHz})$

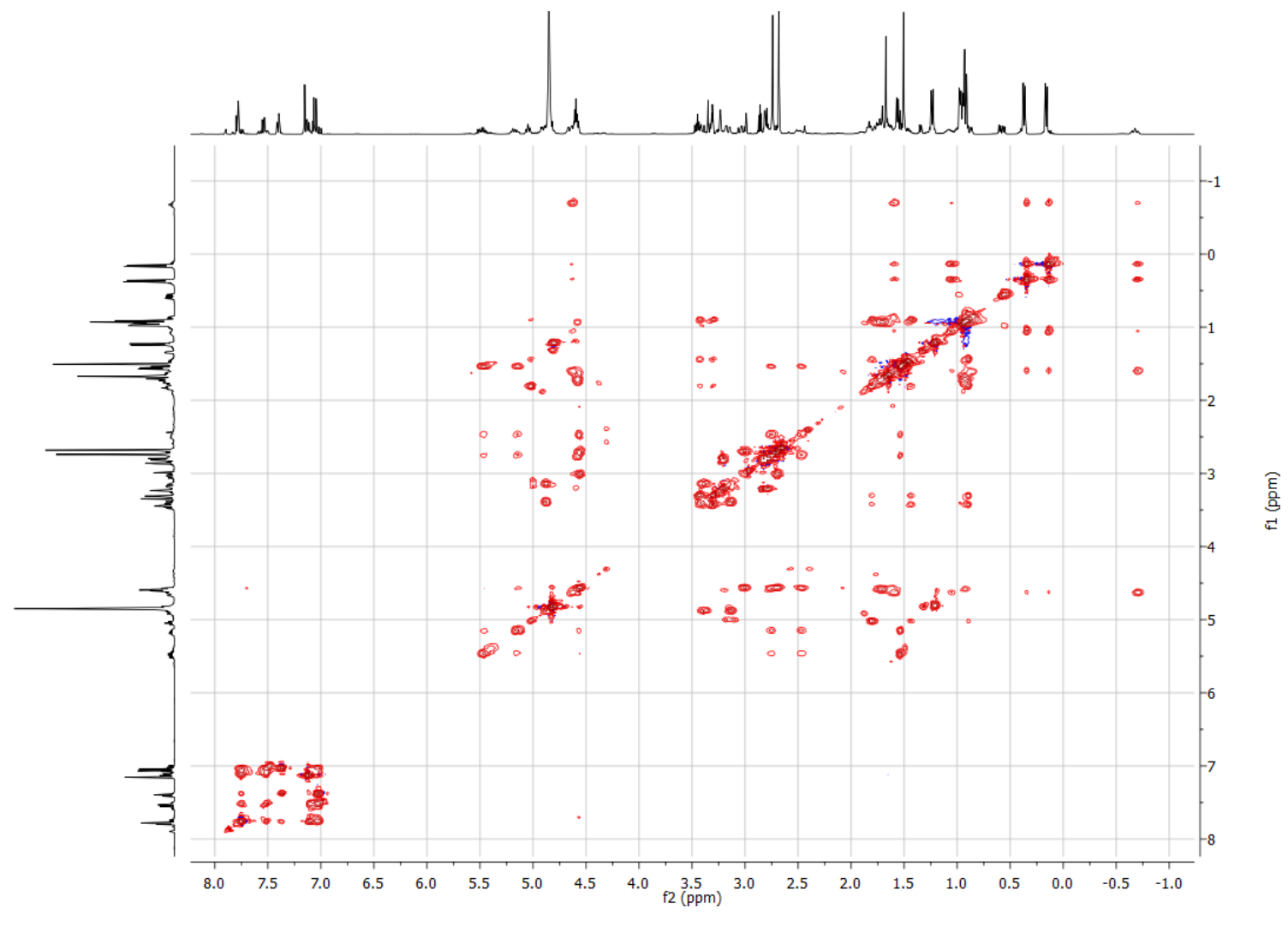


Figure S6. HSQC spectrum of 1 in $\mathrm{CD}_{3} \mathrm{OD}\left(400 \mathrm{MHz}^{1} \mathrm{H}\right)$

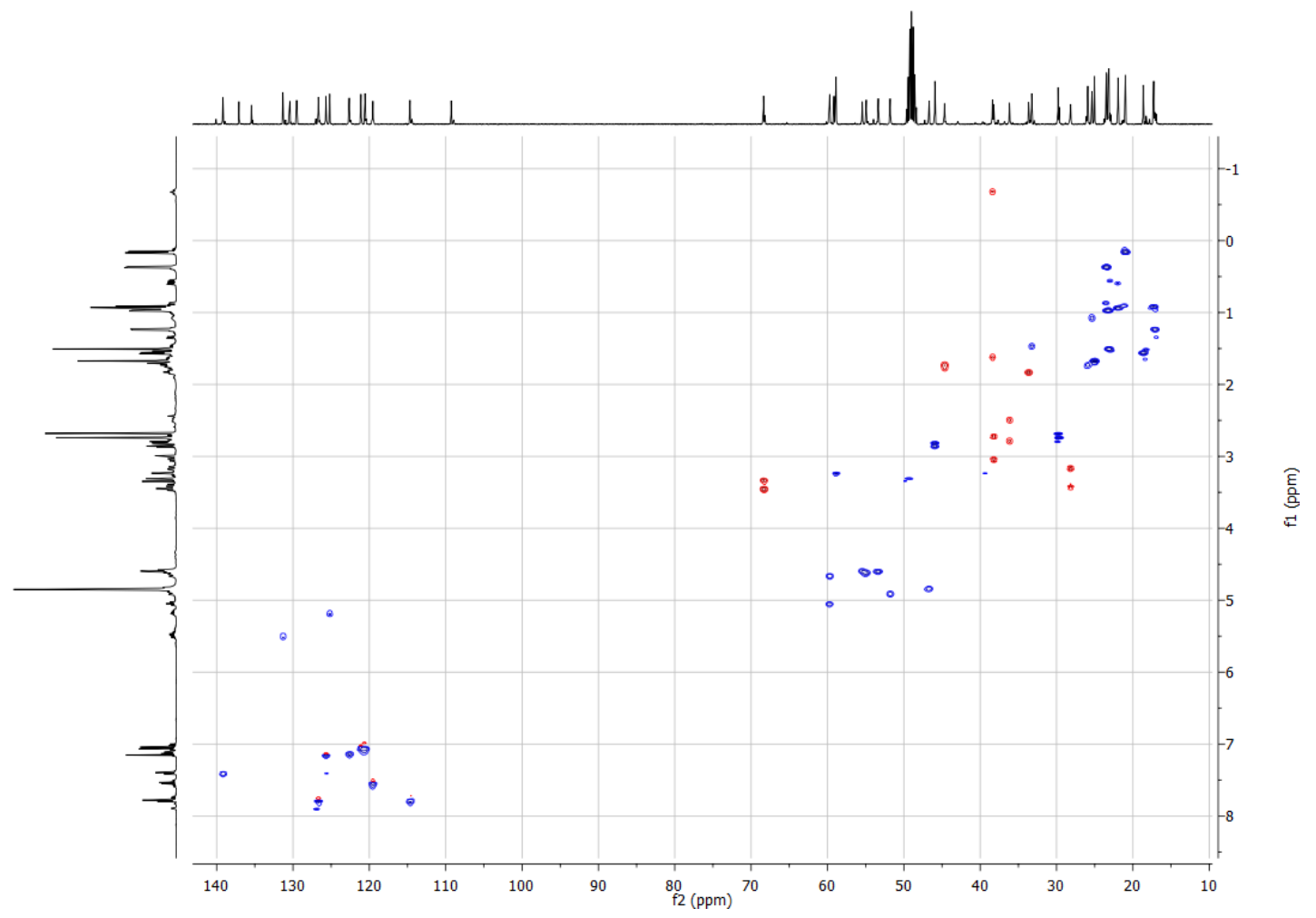

Figure S7. HMBC spectrum of 1 in $\mathrm{CD}_{3} \mathrm{OD}\left(400 \mathrm{MHz}^{1} \mathrm{H}\right)$

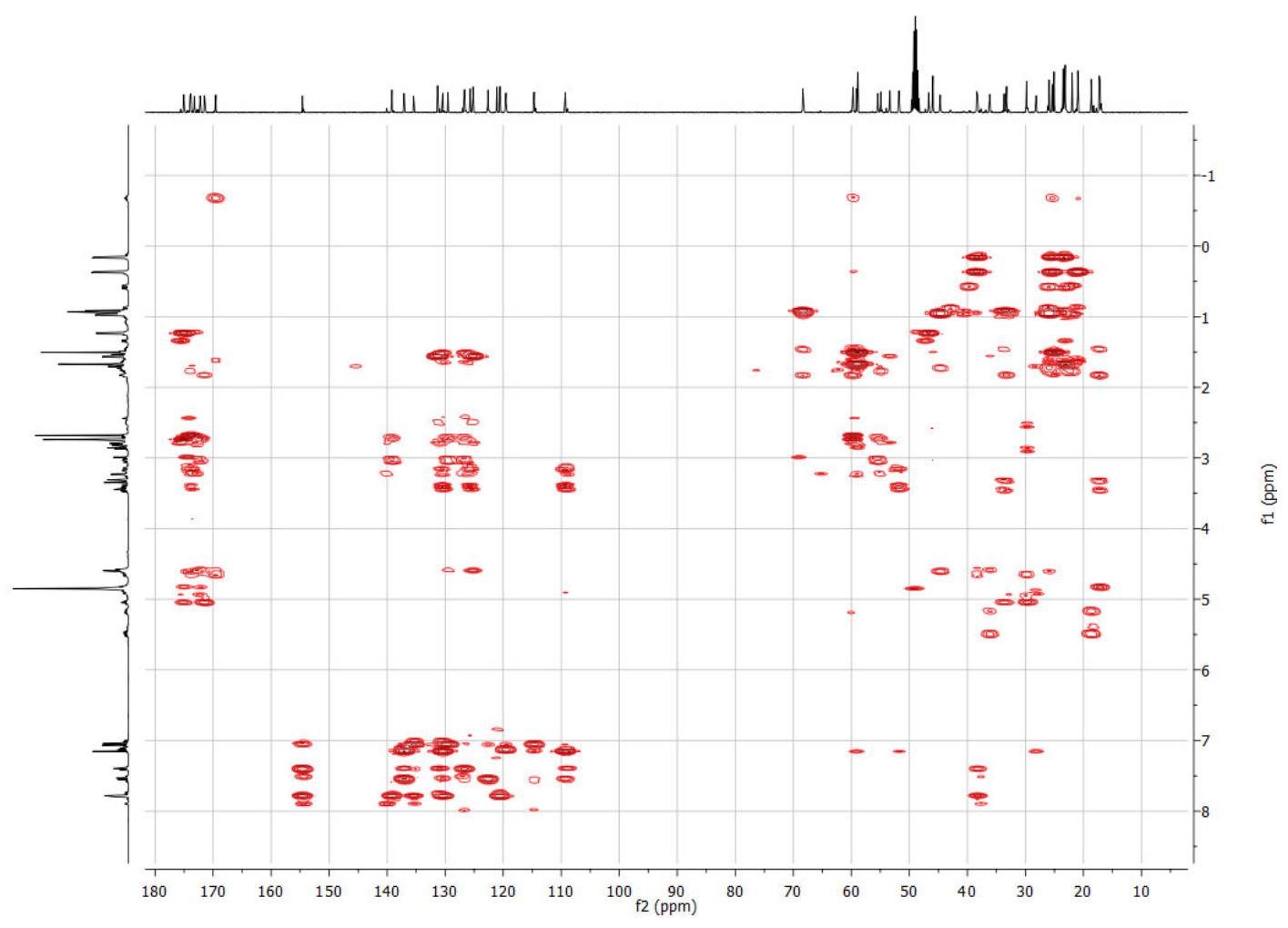


Figure S8. (+)-HRESIMS spectrum of 1
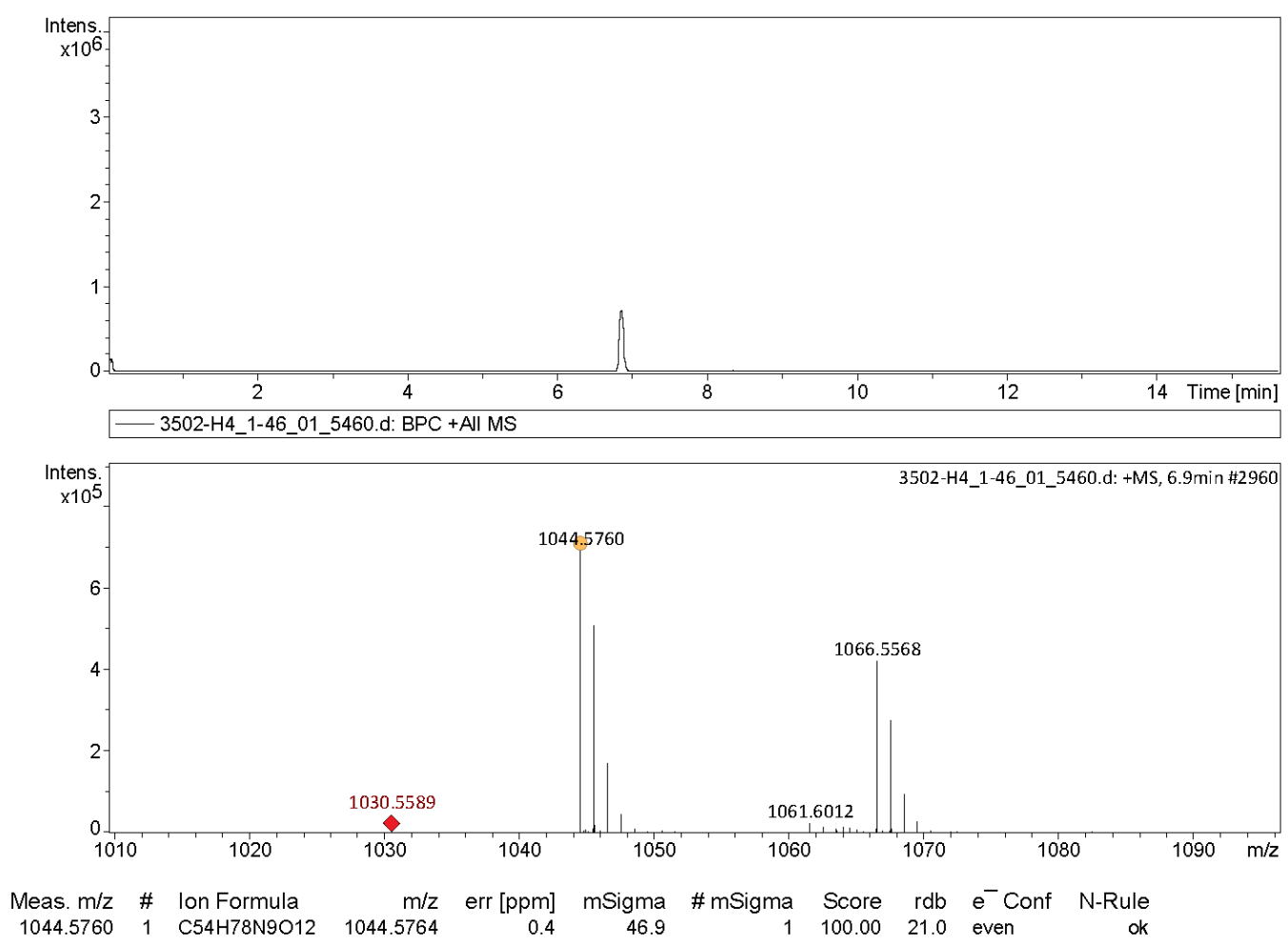

\section{Figure S9. IR spectrum of 1}

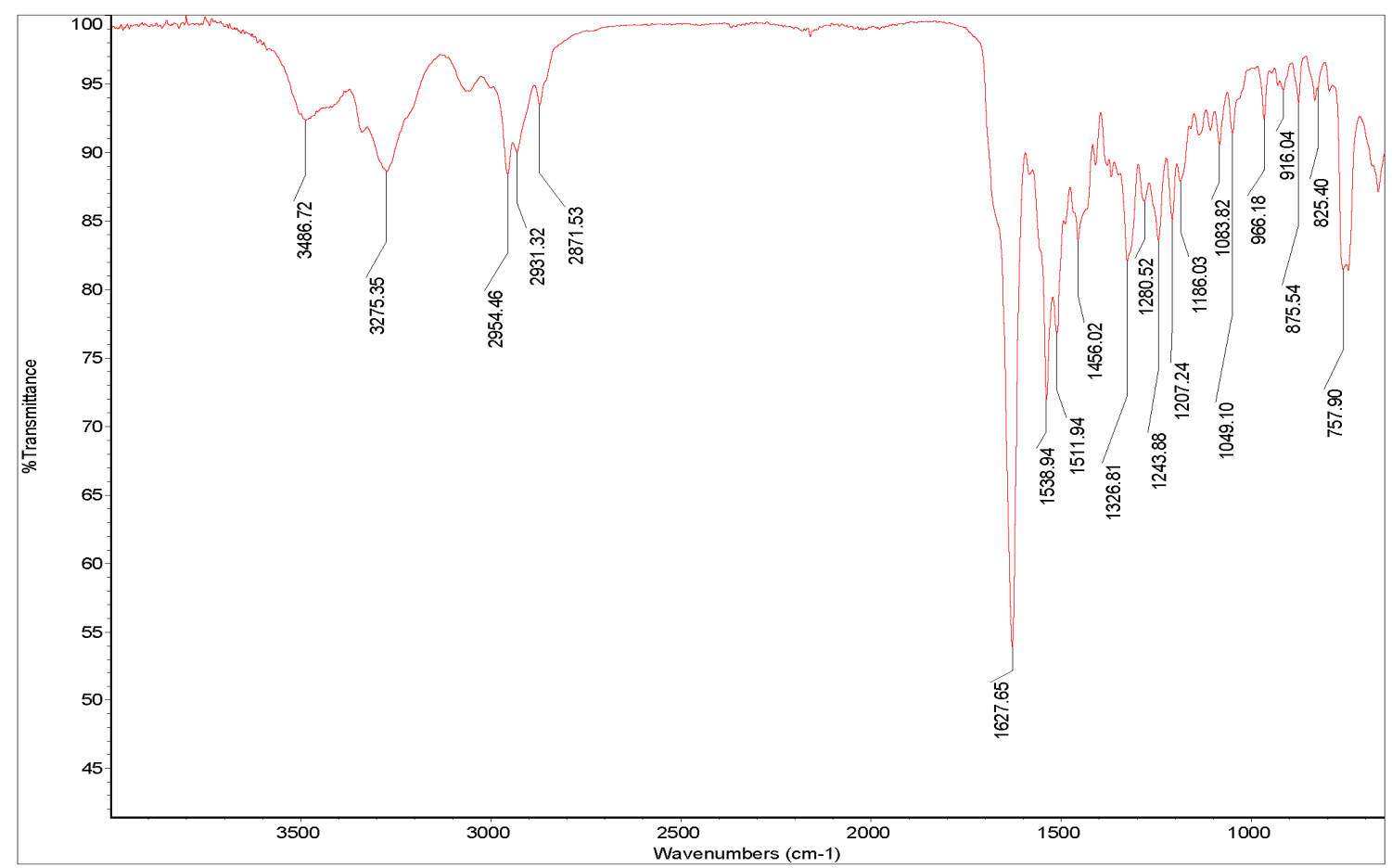


Figure S10. Tandem MS/MS fragmentation of 1

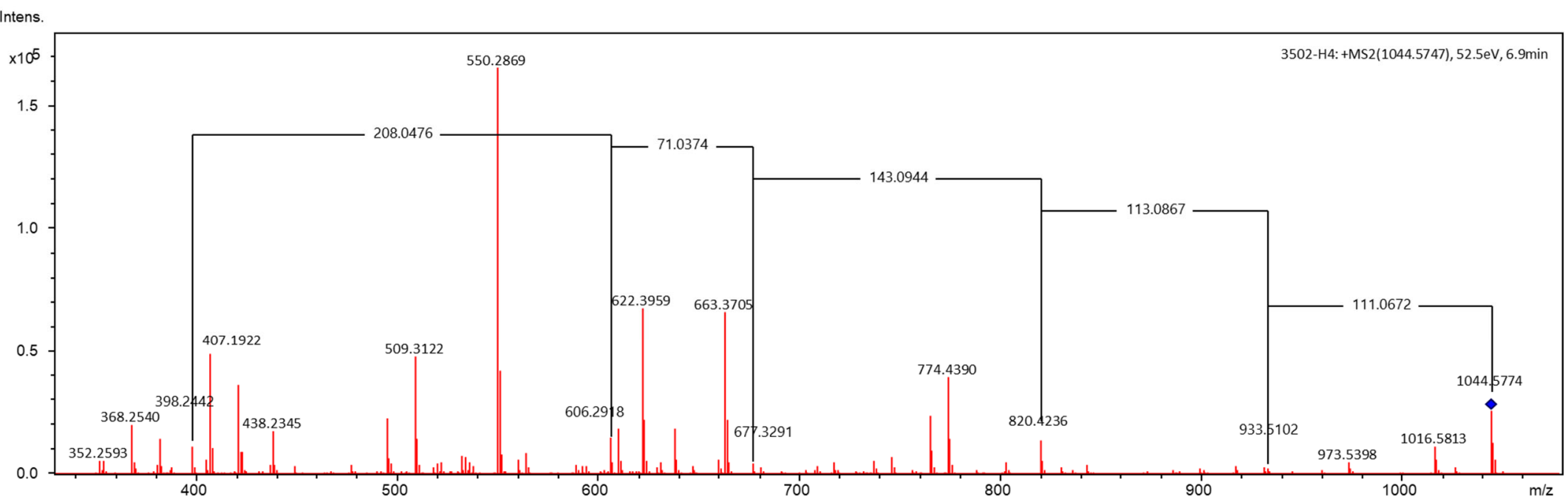


Figure S11. ${ }^{1} \mathrm{H}$ NMR spectrum of 2 in $\mathrm{CD}_{3} \mathrm{OD}$ at $400 \mathrm{MHz}$
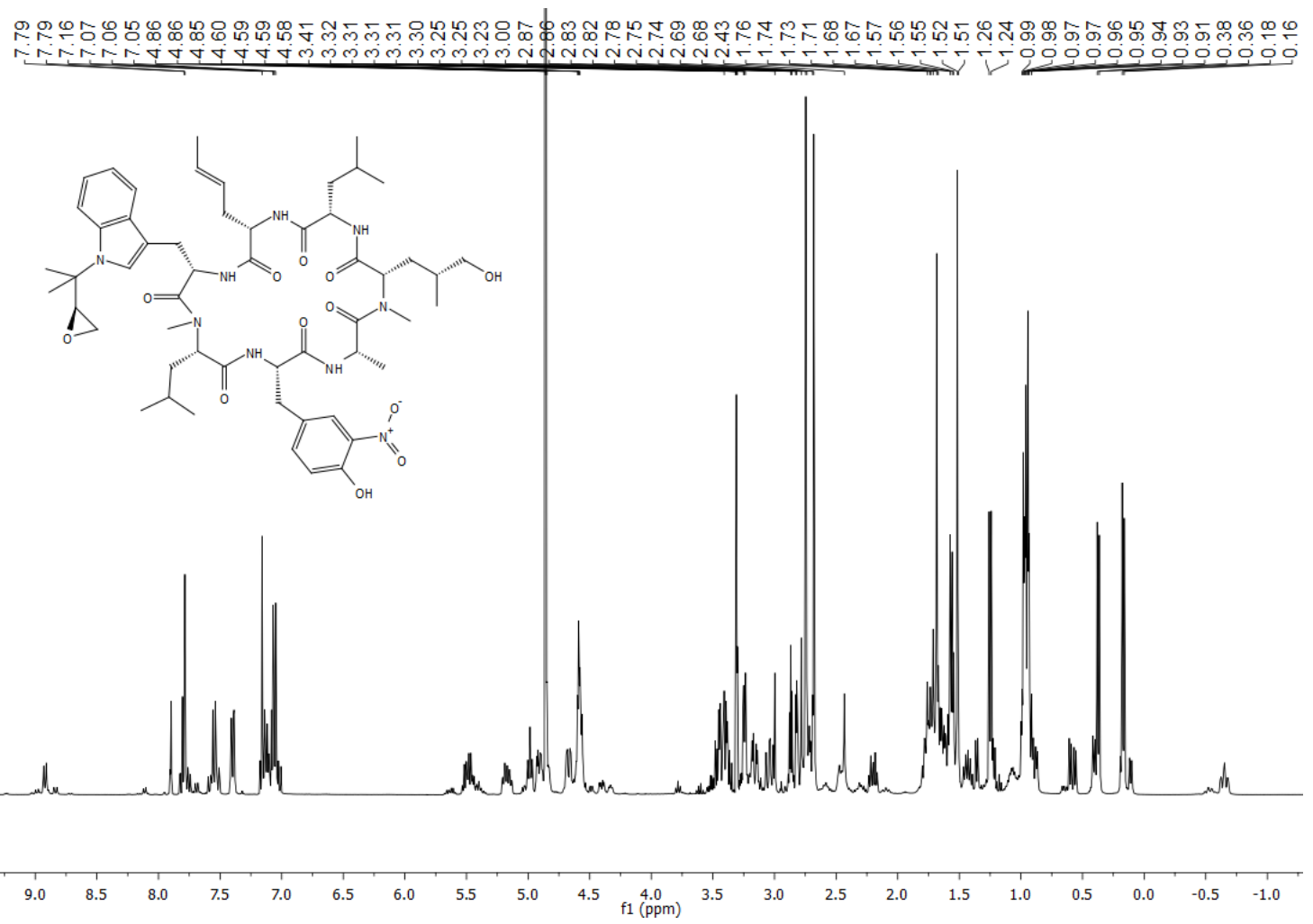

Figure S12. ${ }^{13} \mathrm{C}$ NMR spectrum of 2 in $\mathrm{CD}_{3} \mathrm{OD}$ at $100 \mathrm{MHz}$

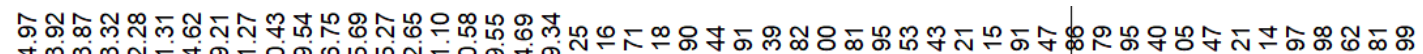

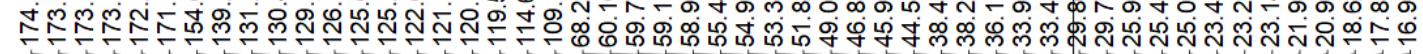
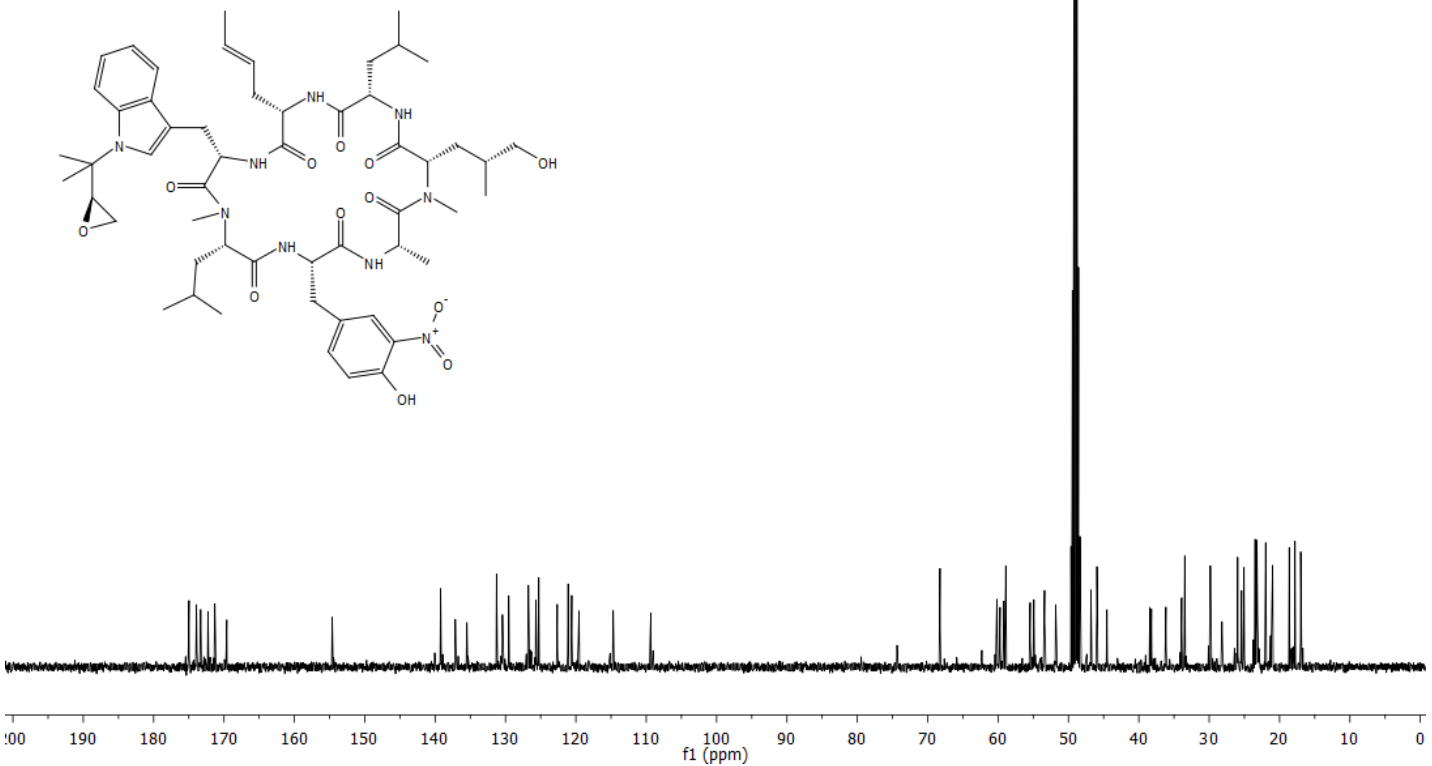
Figure S13. COSY spectrum of 2 in $\mathrm{CD}_{3} \mathrm{OD}(400 \mathrm{MHz})$

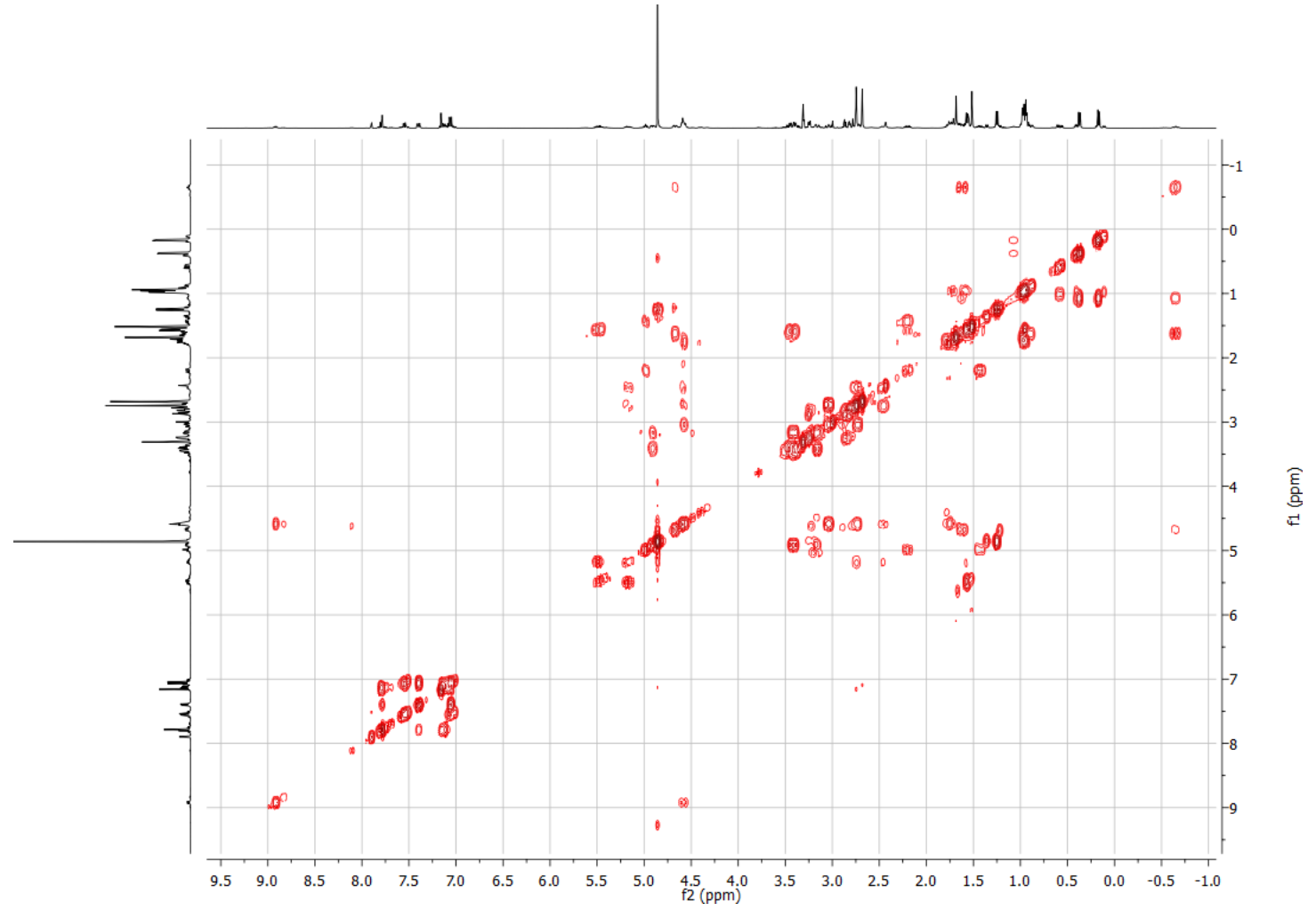

Figure S14. TOCSY spectrum of 2 in $\mathrm{CD}_{3} \mathrm{OD}(400 \mathrm{MHz})$

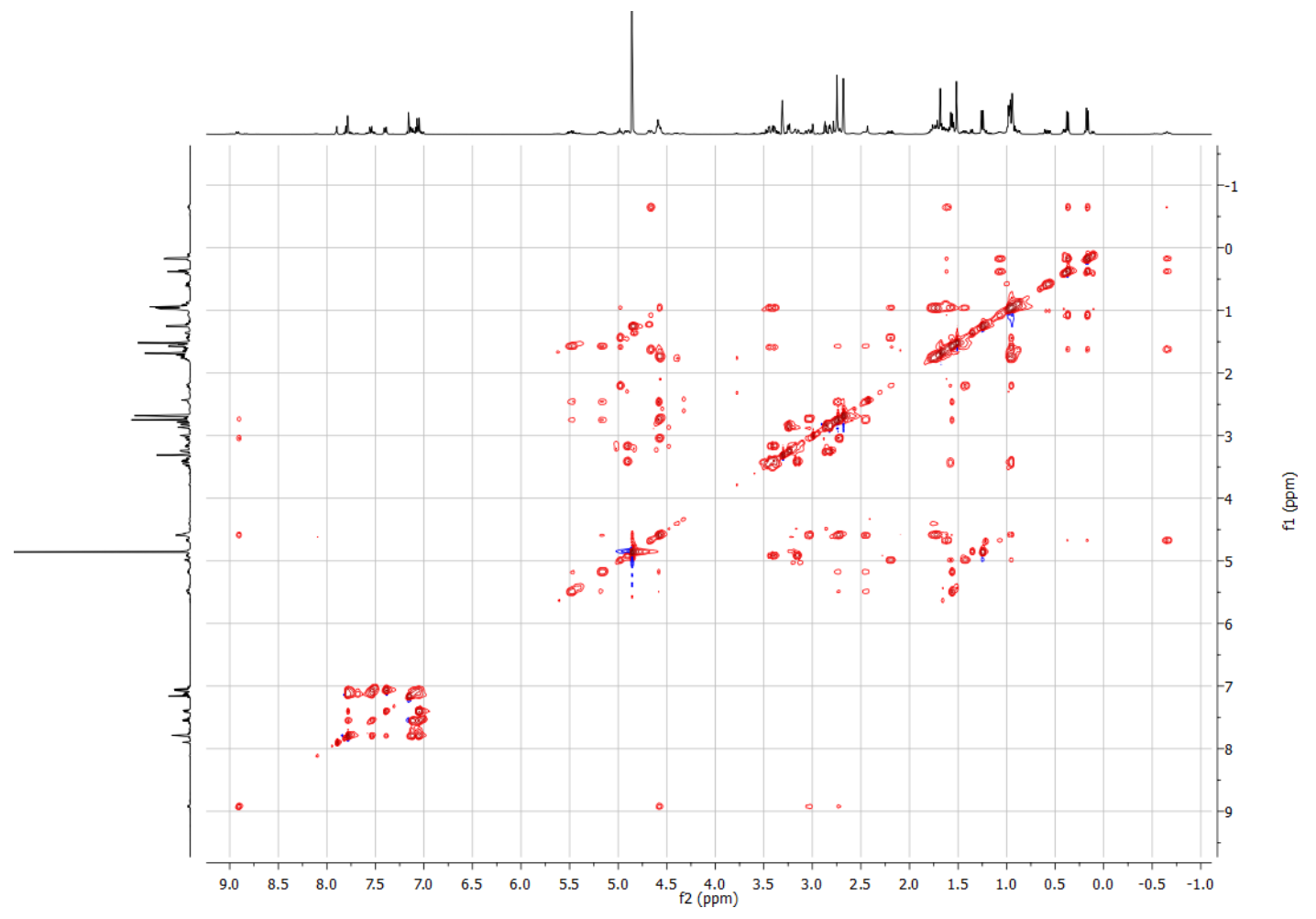


Figure S15. HSQC spectrum of 2 in $\mathrm{CD}_{3} \mathrm{OD}\left(400 \mathrm{MHz}^{1} \mathrm{H}\right)$

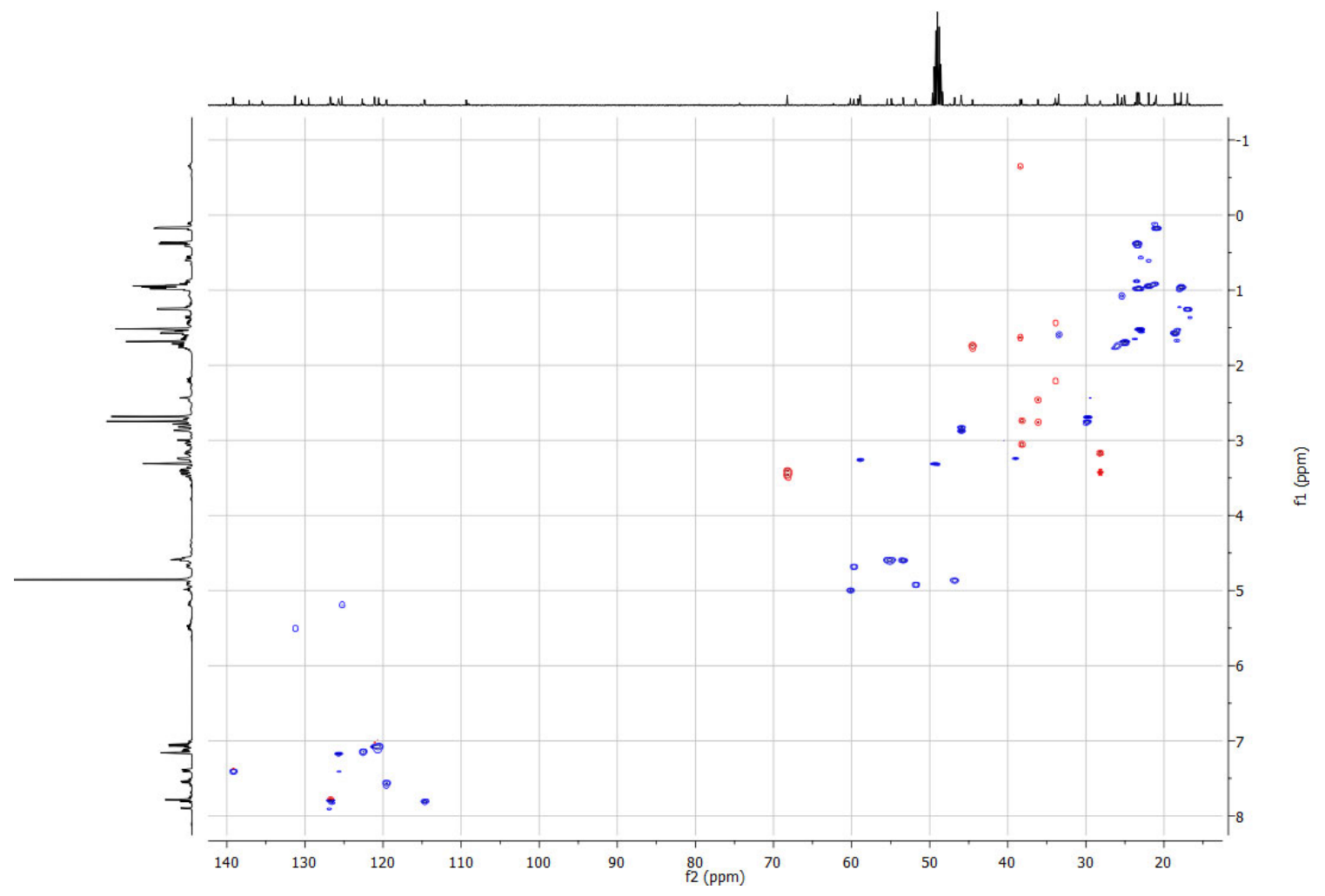

Figure S16. HMBC spectrum of 2 in $\mathrm{CD}_{3} \mathrm{OD}\left(400 \mathrm{MHz}^{1} \mathrm{H}\right)$

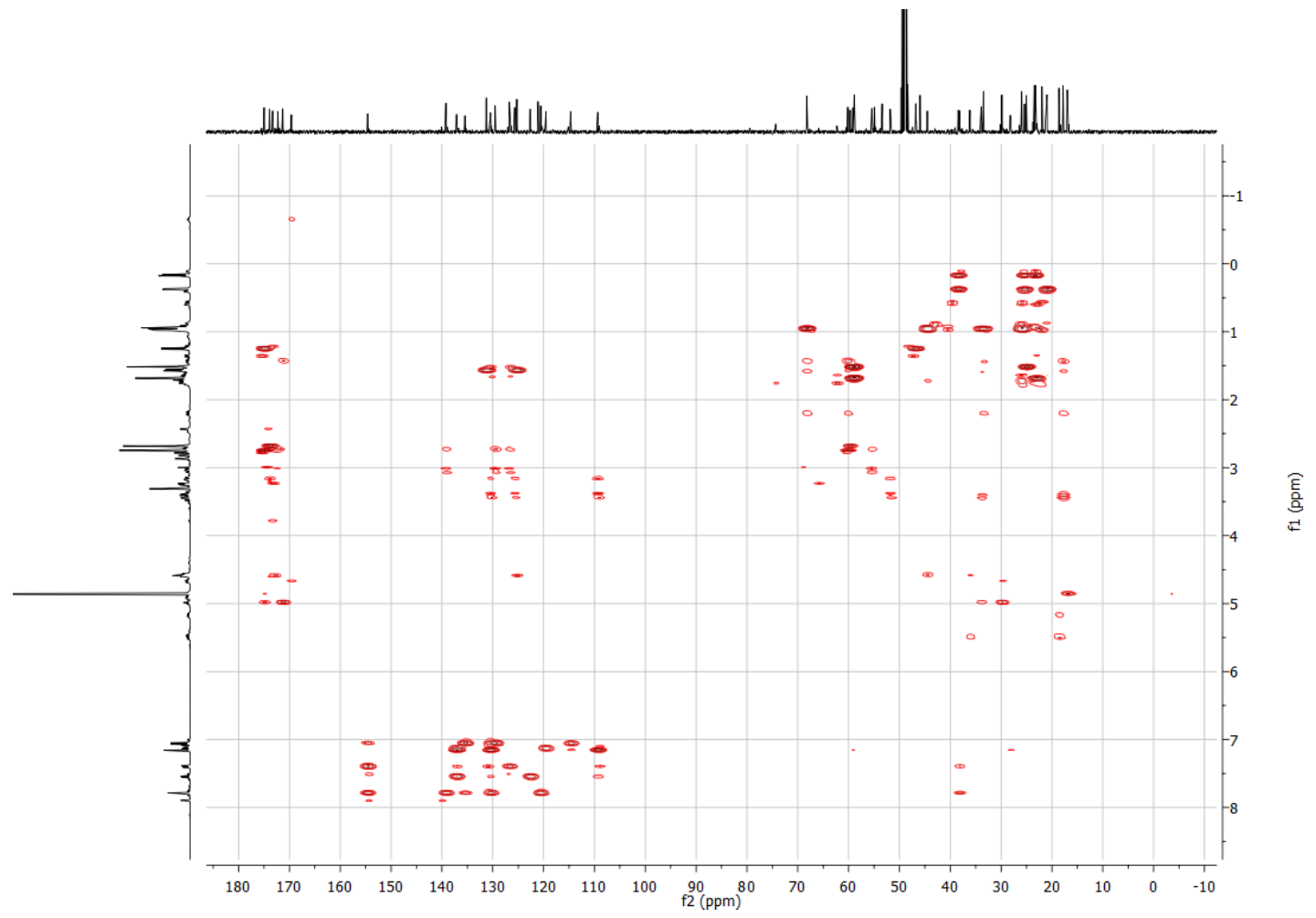


Figure S17. (+)-HRESIMS spectrum of 2
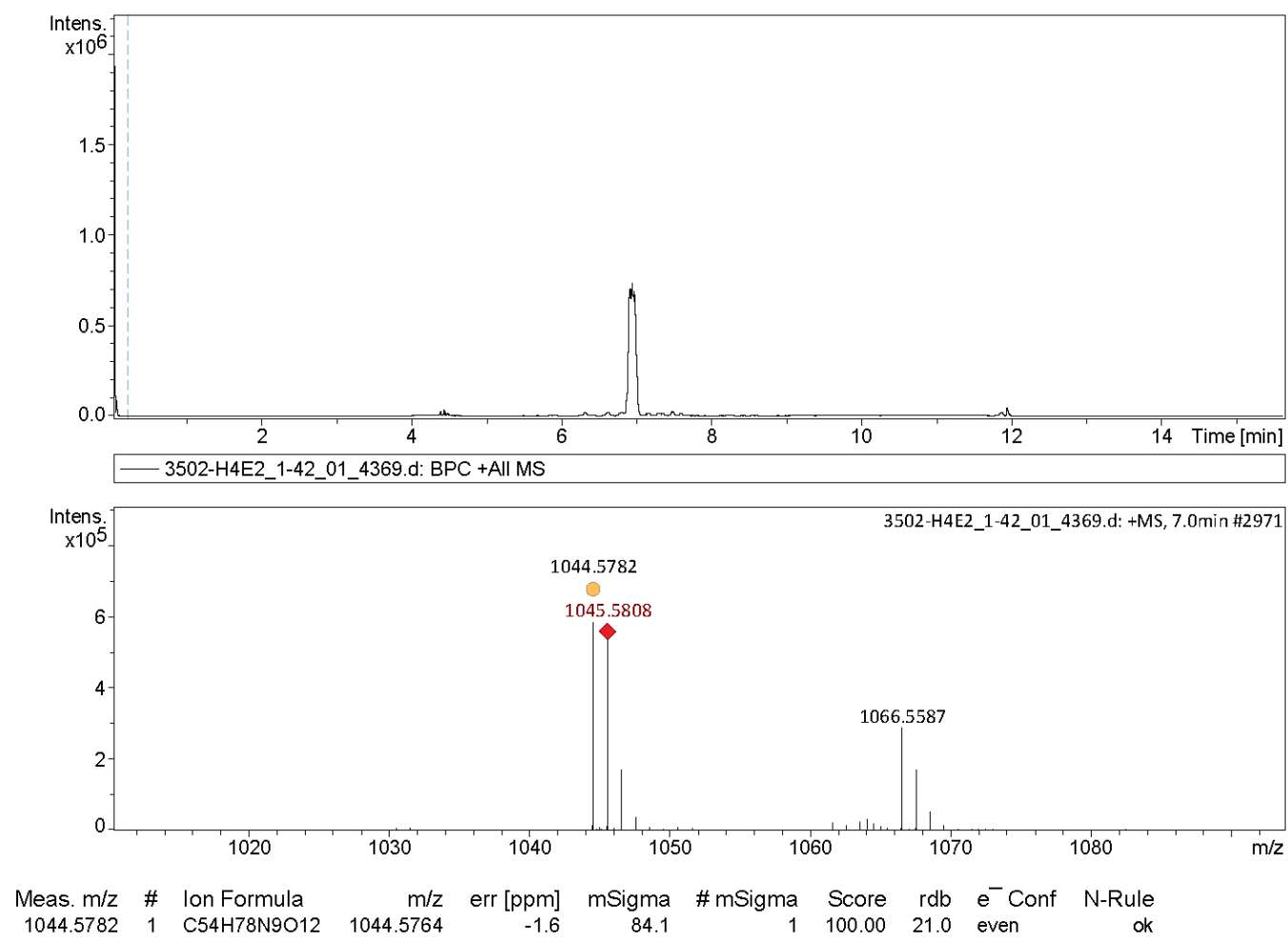

Figure S18. IR spectrum of 2

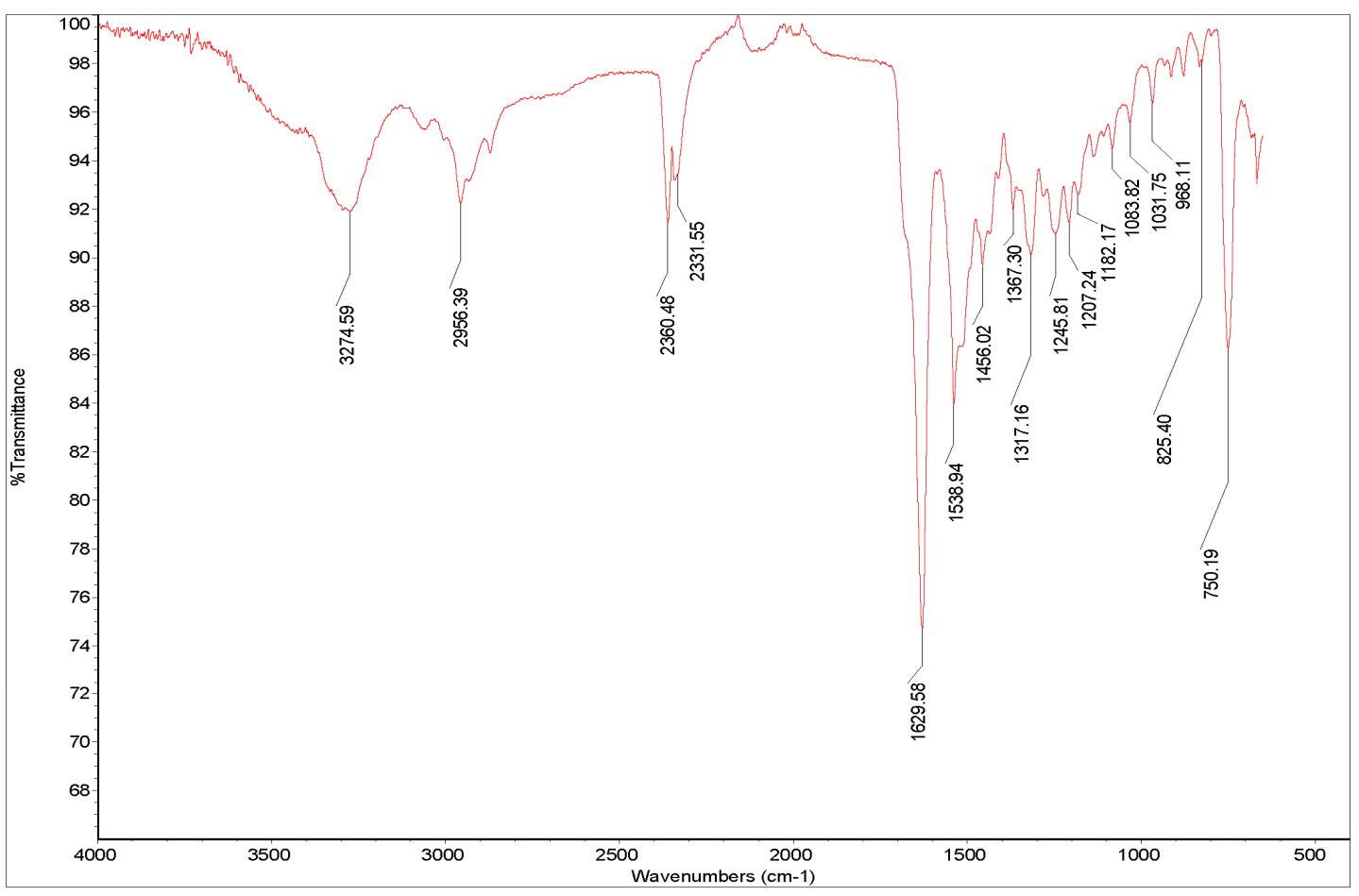


Figure S19. LC-ESIMS chromatograms of a total hydrolysate of 2 after derivatization with D/L-FDLA

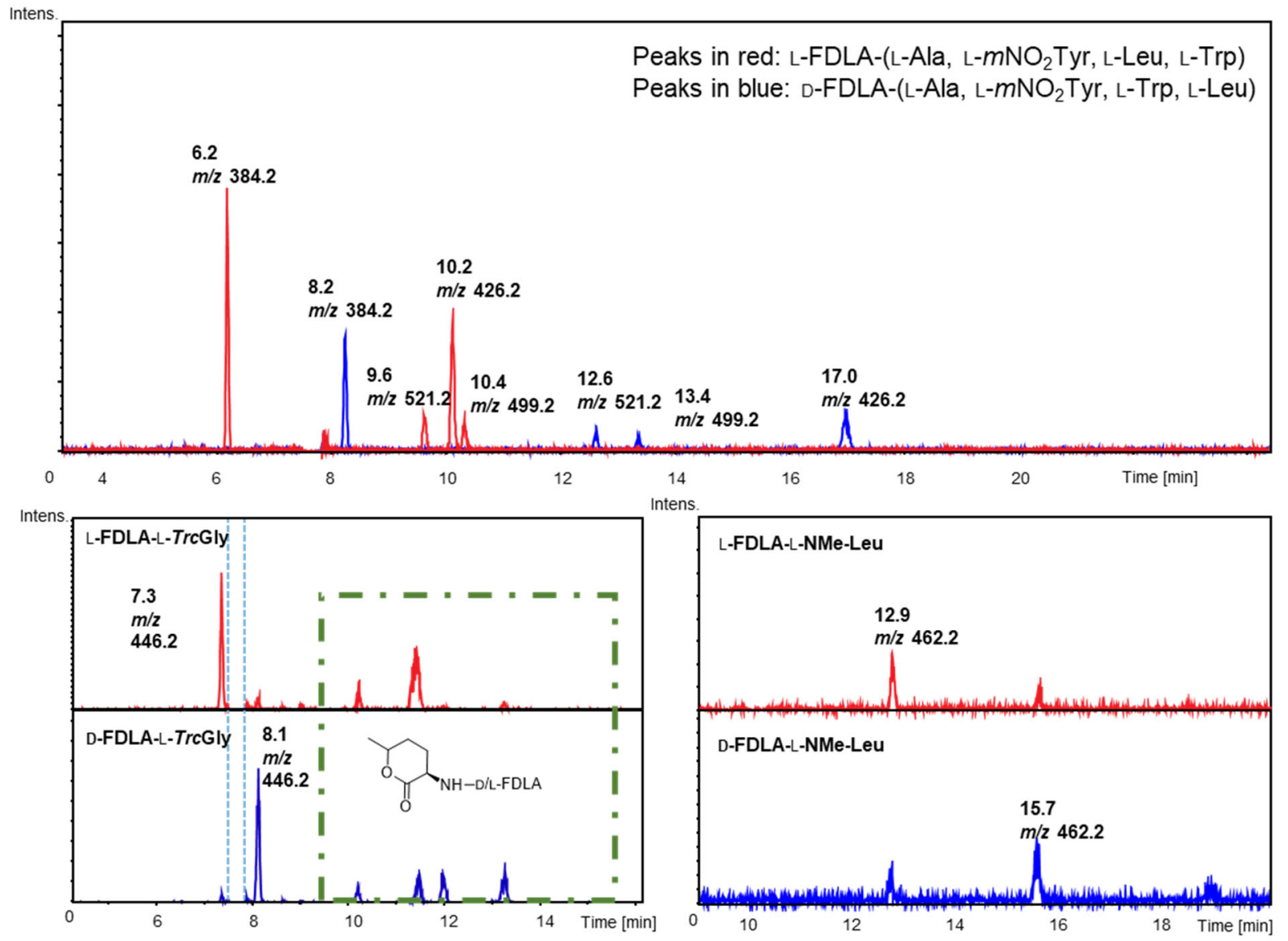




\section{Figure S20. ${ }^{1} \mathrm{H}$ NMR spectrum of 3 in $\mathrm{CD}_{3} \mathrm{OD}$ at $400 \mathrm{MHz}$}

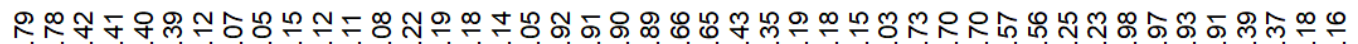

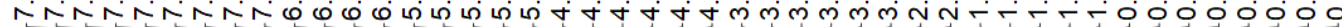
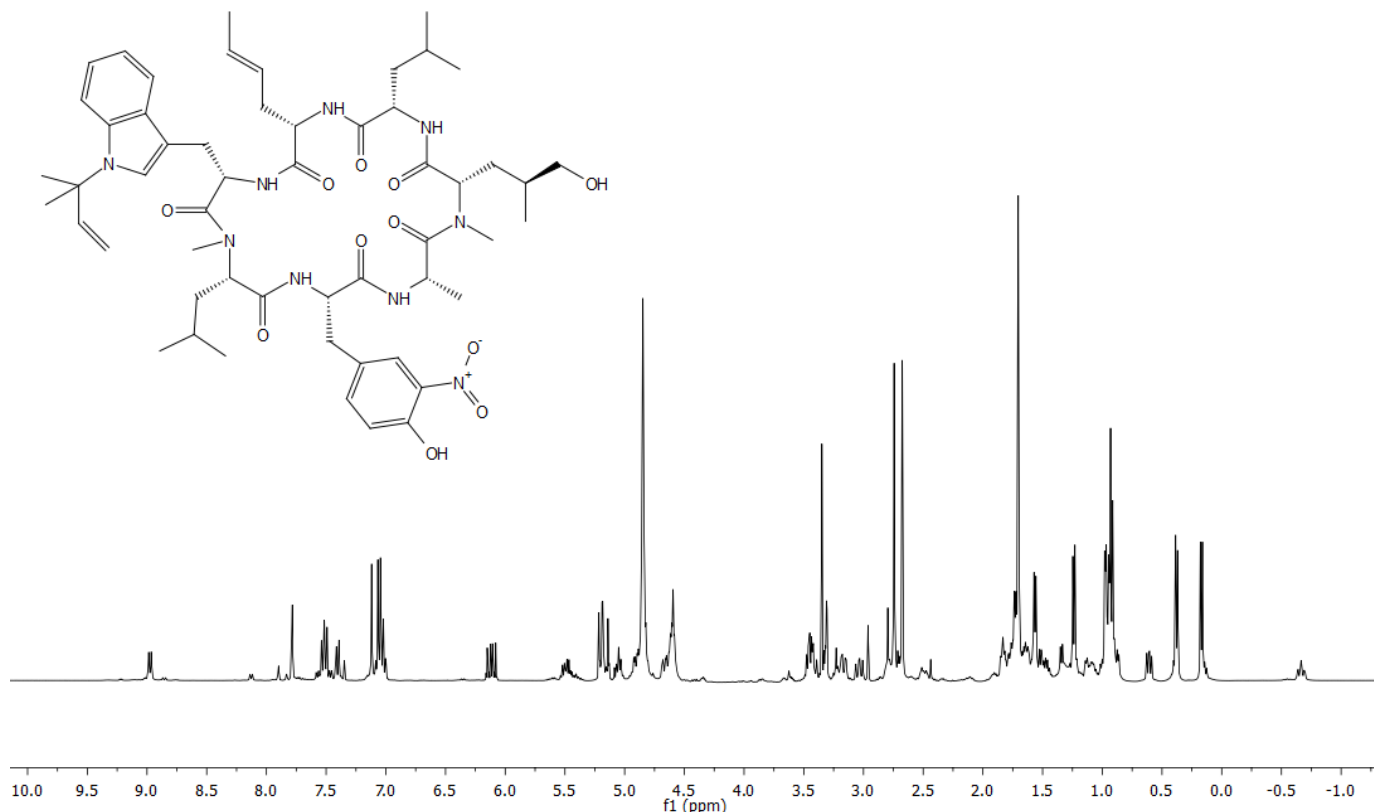

Figure S21. ${ }^{13} \mathrm{C}$ NMR spectrum of 3 in $\mathrm{CD}_{3} \mathrm{OD}$ at $100 \mathrm{MHz}$

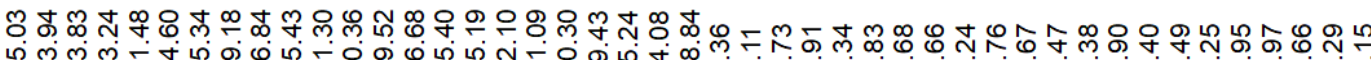

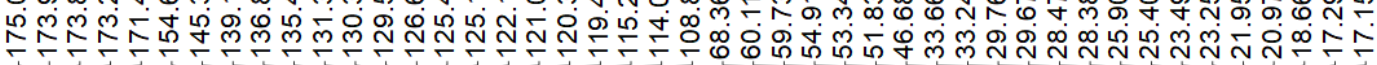

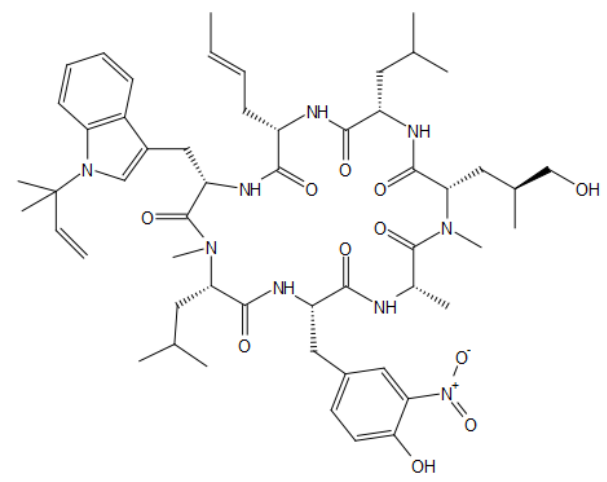

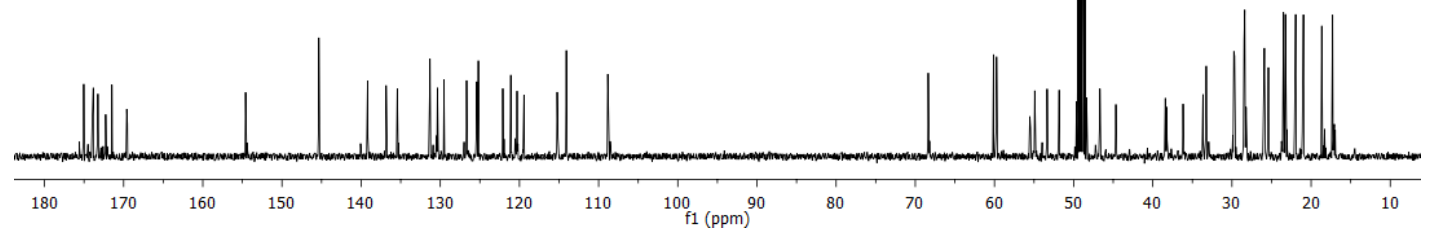


Figure S22. COSY spectrum of 3 in $\mathrm{CD}_{3} \mathrm{OD}(400 \mathrm{MHz})$

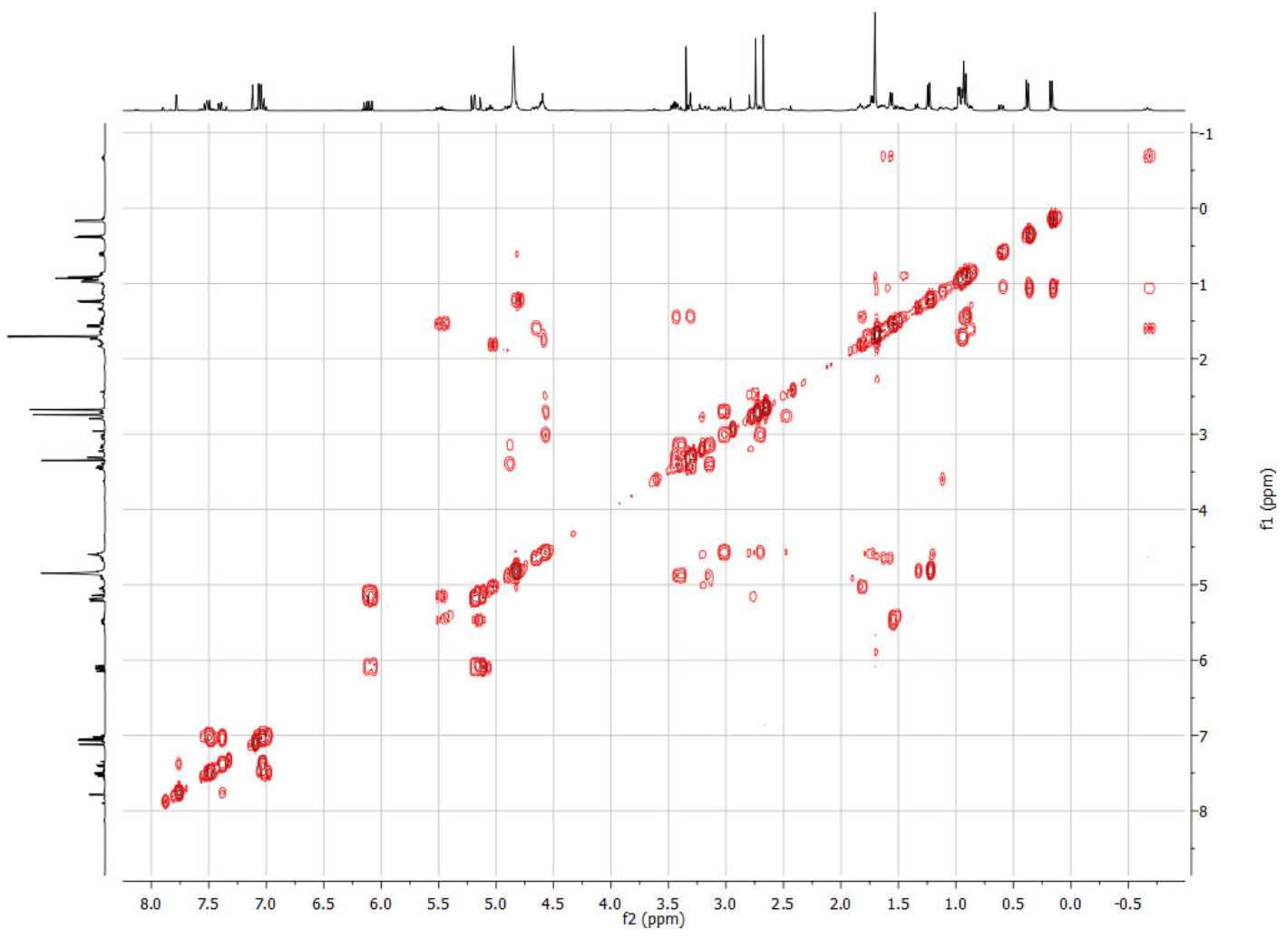

Figure S23. TOCSY spectrum of 3 in $\mathrm{CD}_{3} \mathrm{OD}(400 \mathrm{MHz})$

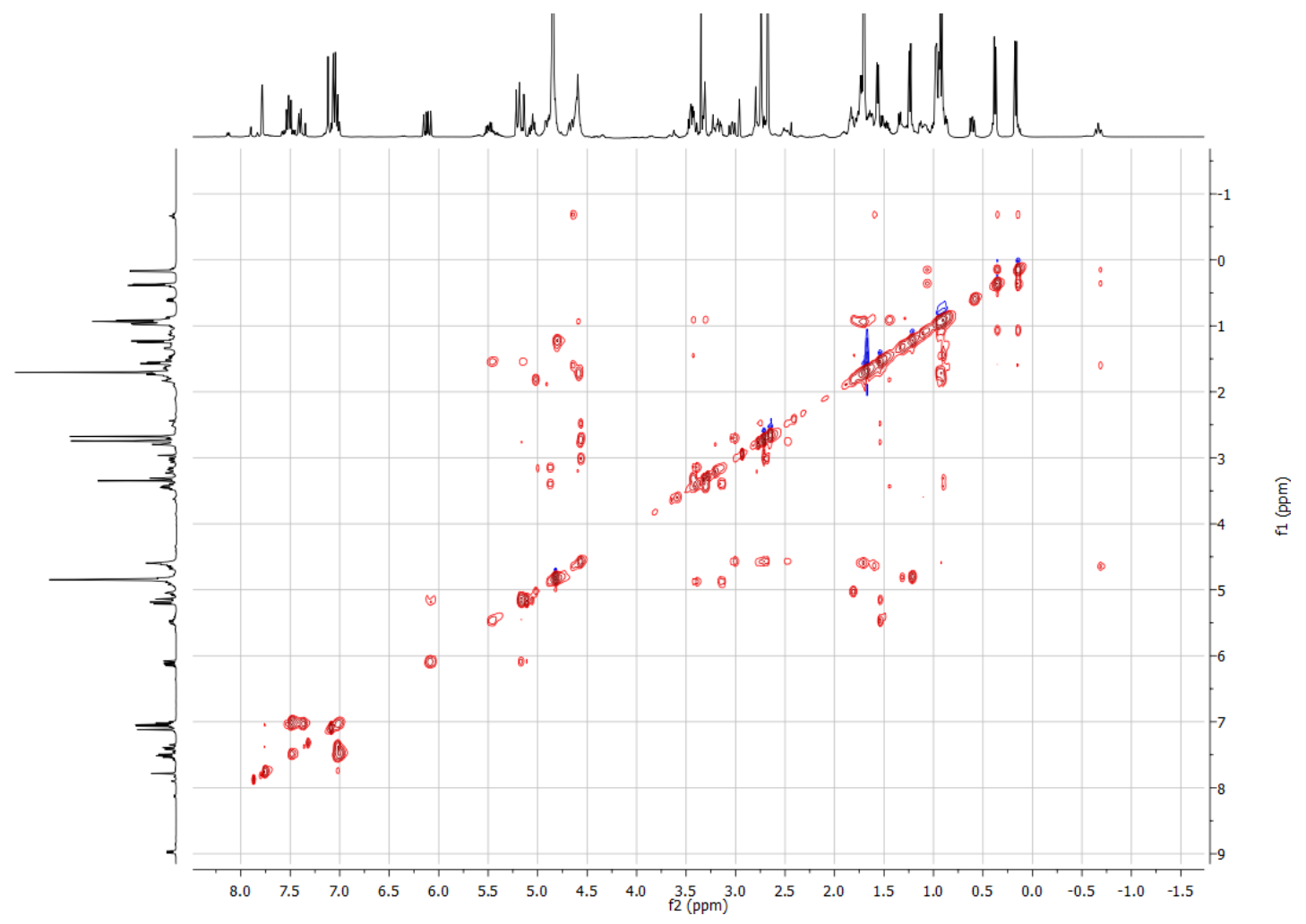


Figure S24. HSQC spectrum of 3 in $\mathrm{CD}_{3} \mathrm{OD}\left(400 \mathrm{MHz}^{1} \mathrm{H}\right)$

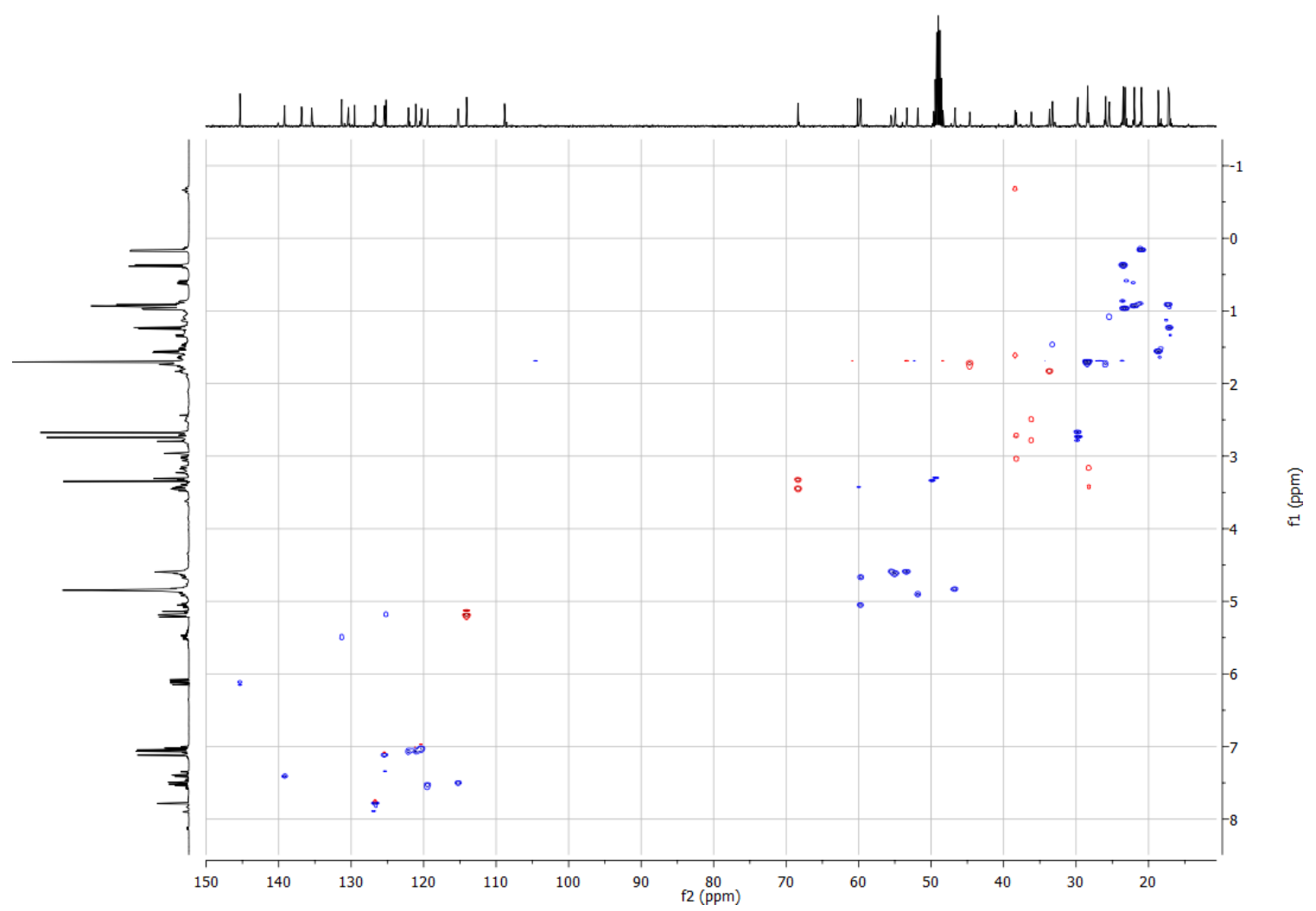

Figure S25. HMBC spectrum of 3 in $\mathrm{CD}_{3} \mathrm{OD}\left(400 \mathrm{MHz}{ }^{1} \mathrm{H}\right)$

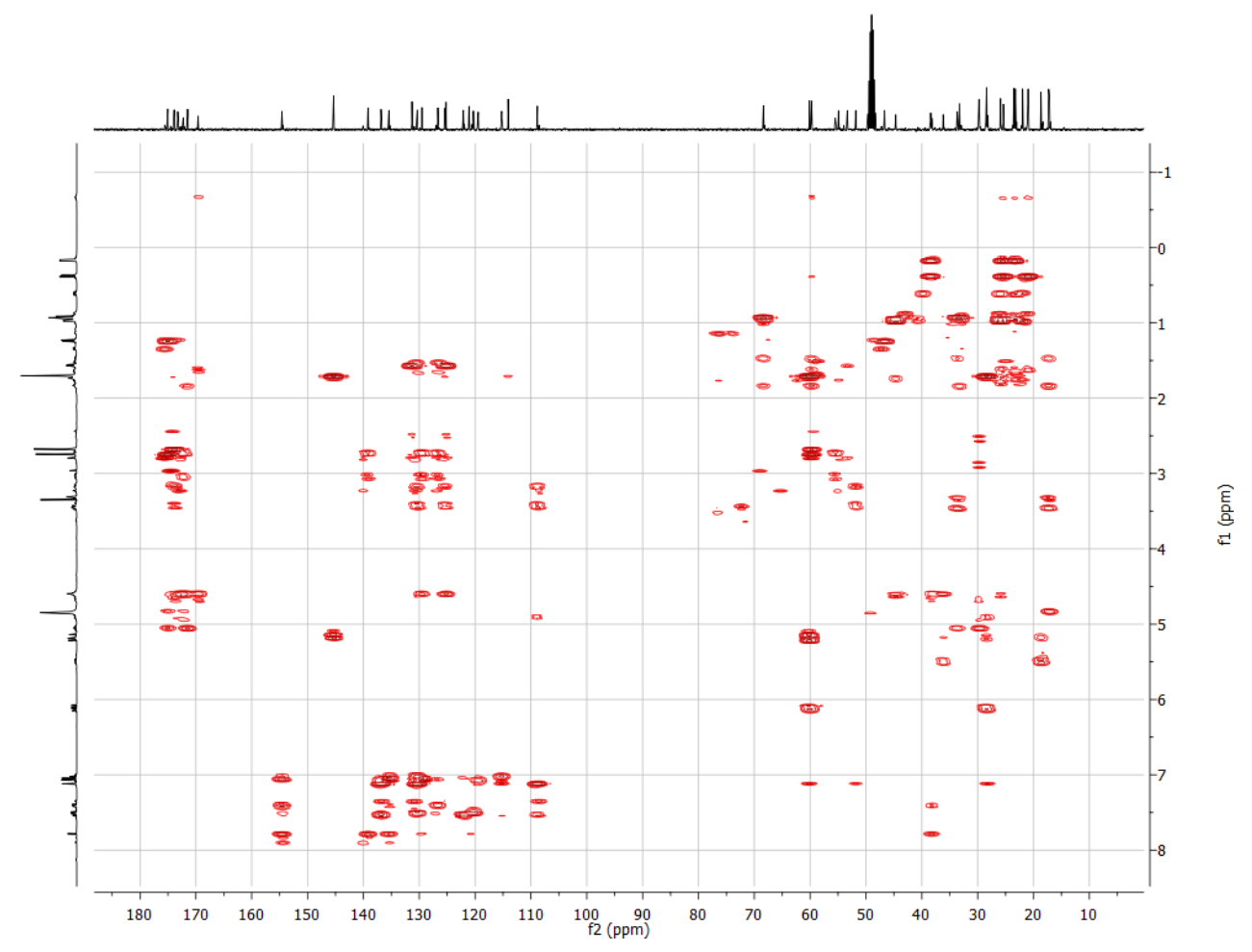


Figure S26. (+)-HRESIMS spectrum of 3
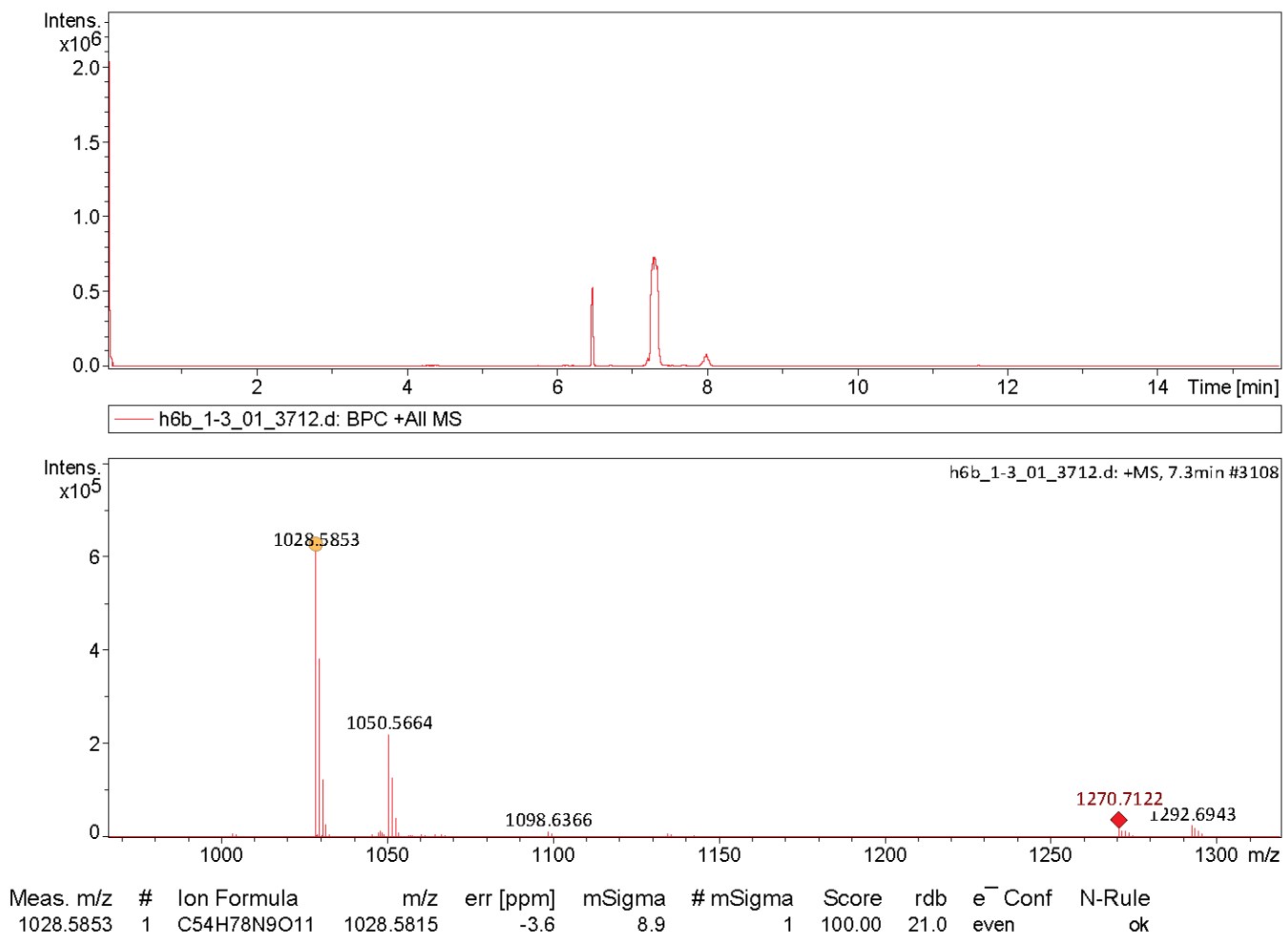

Figure S27. IR spectrum of 3

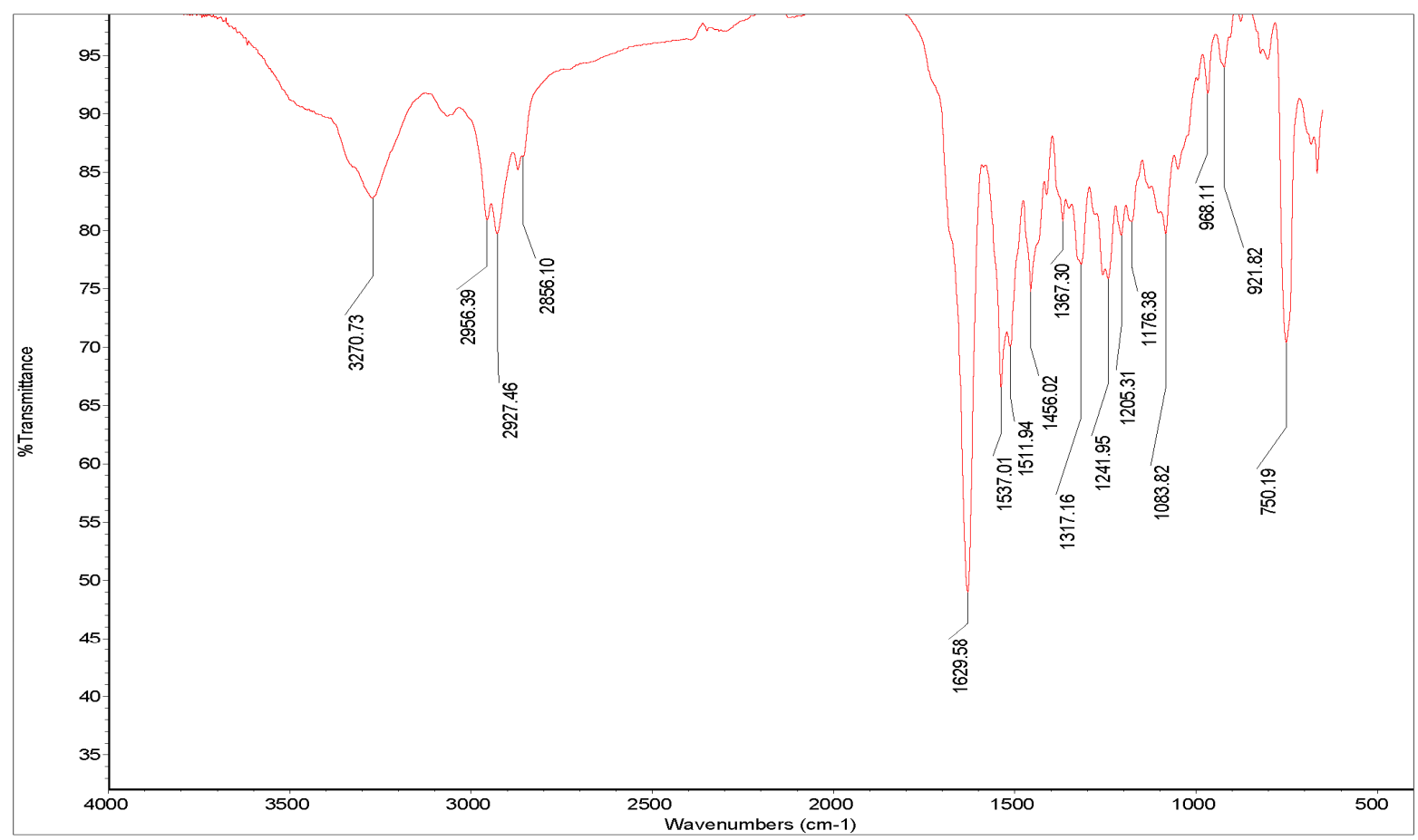


Figure S28. LC-ESIMS chromatograms of a total hydrolysate of 3 after derivatization with D/L-FDLA

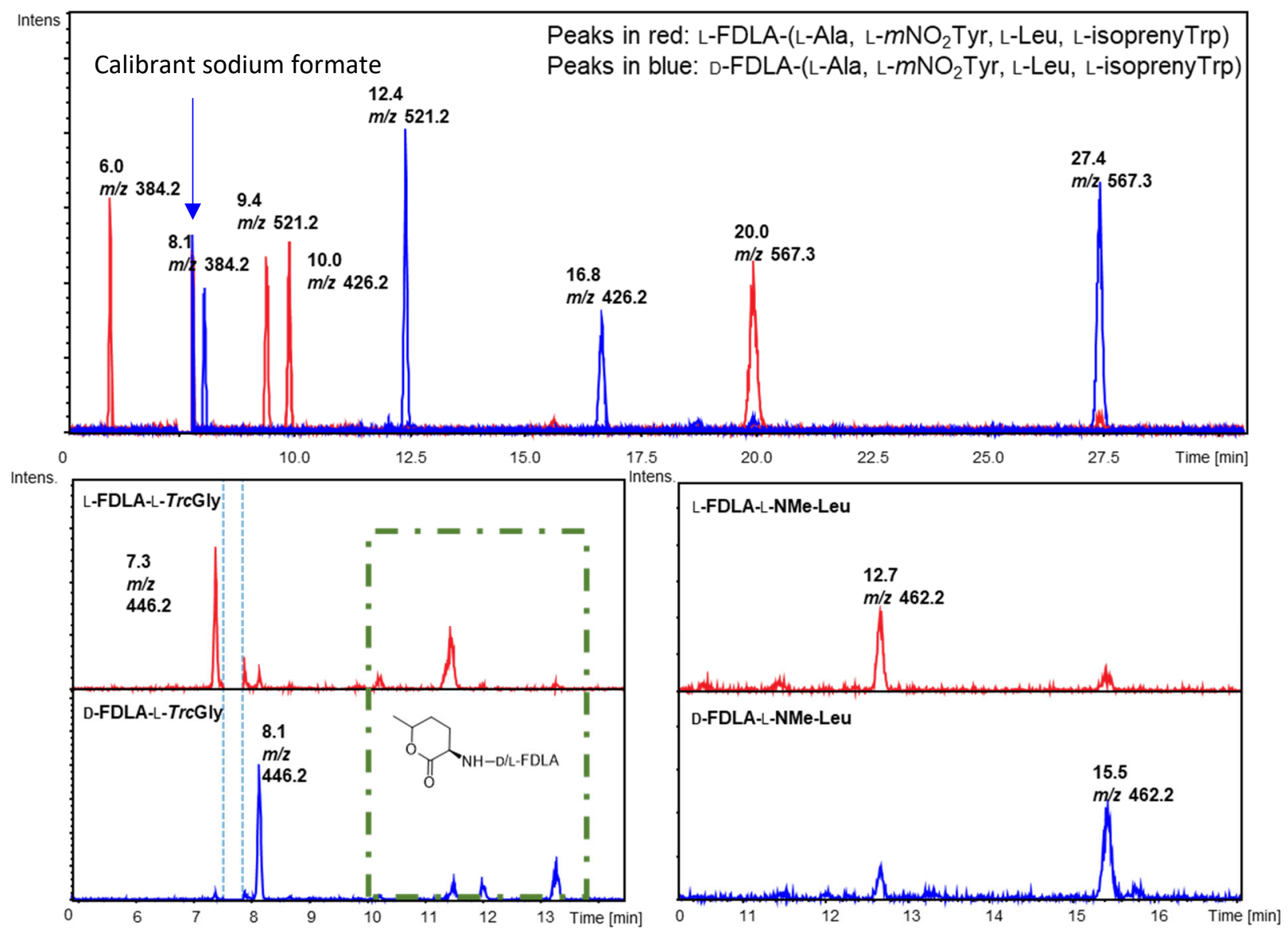


Figure S29. ${ }^{1} \mathrm{H}$ NMR spectrum of 4 in $\mathrm{CD}_{3} \mathrm{OD}$ at $400 \mathrm{MHz}$

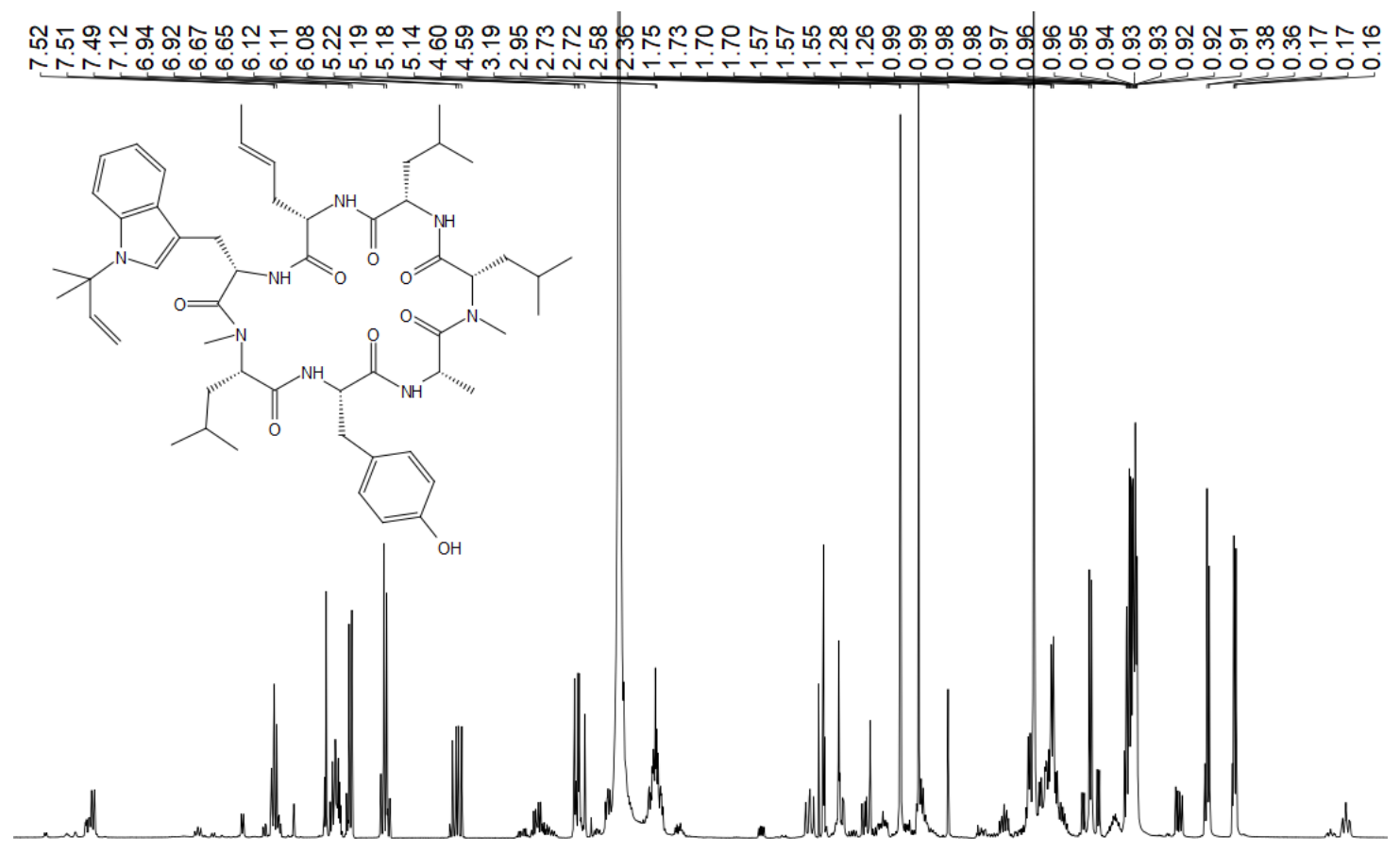

\begin{tabular}{|llllllllllllllllllllll}
5 & 9.0 & 8.5 & 8.0 & 7.5 & 7.0 & 6.5 & 6.0 & 5.5 & 5.0 & 4.5 & 4.0 & 3.5 & 3.0 & 2.5 & 2.0 & 1.5 & 1.0 & 0.5 & 0.0 & -0.5 & -1
\end{tabular}

Figure S30. ${ }^{13} \mathrm{C}$ NMR spectrum of 4 in $\mathrm{CD}_{3} \mathrm{OD}$ at $100 \mathrm{MHz}$

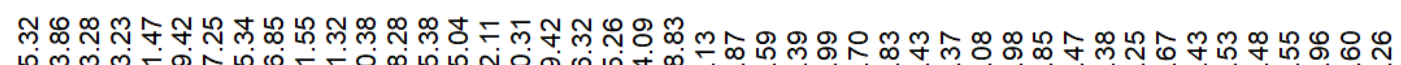

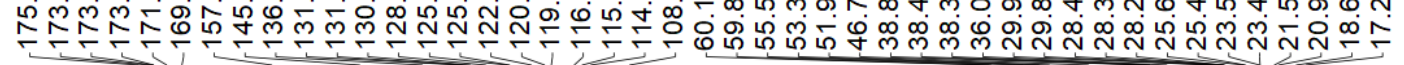
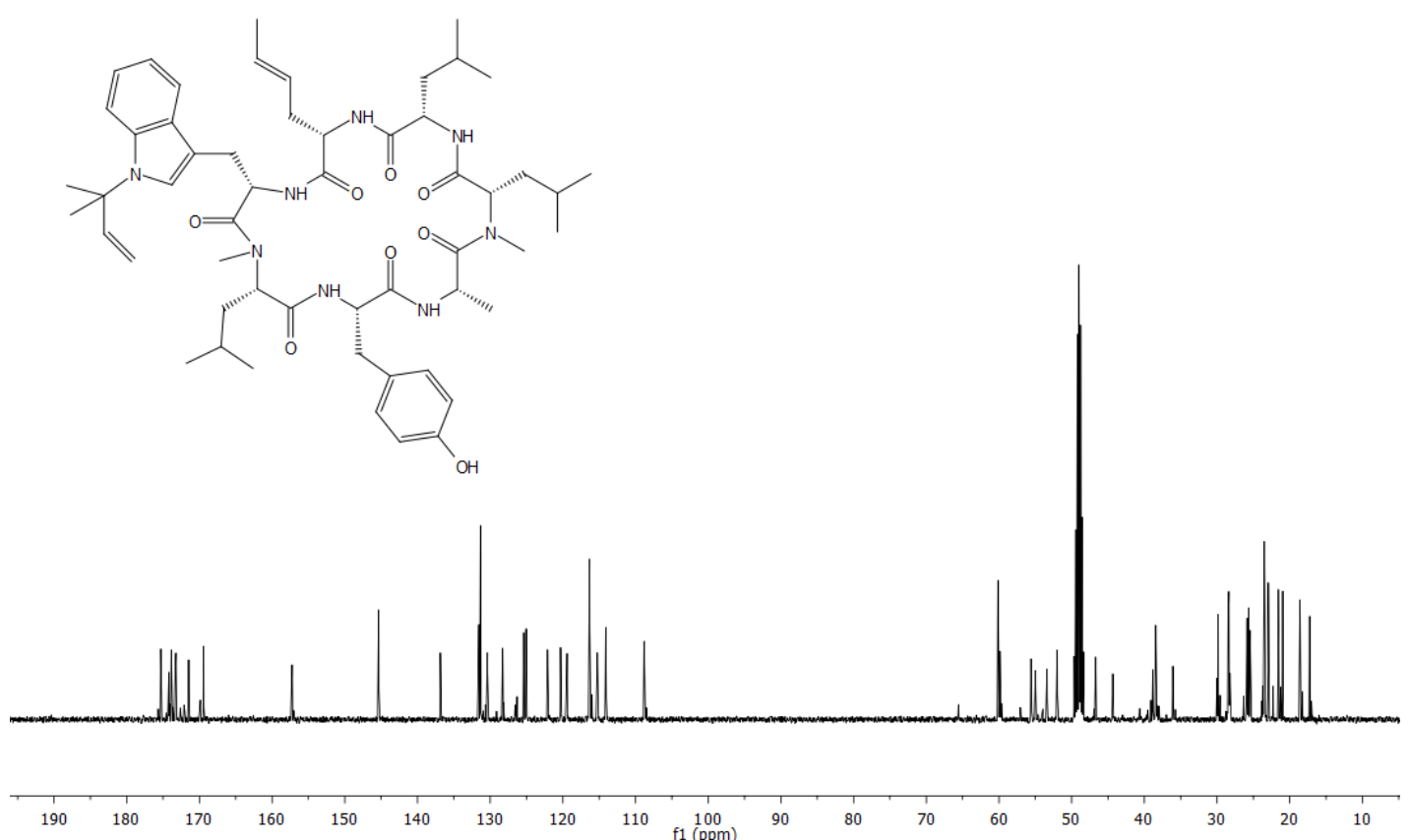
Figure S31. COSY spectrum of 4 in $\mathrm{CD}_{3} \mathrm{OD}(400 \mathrm{MHz})$

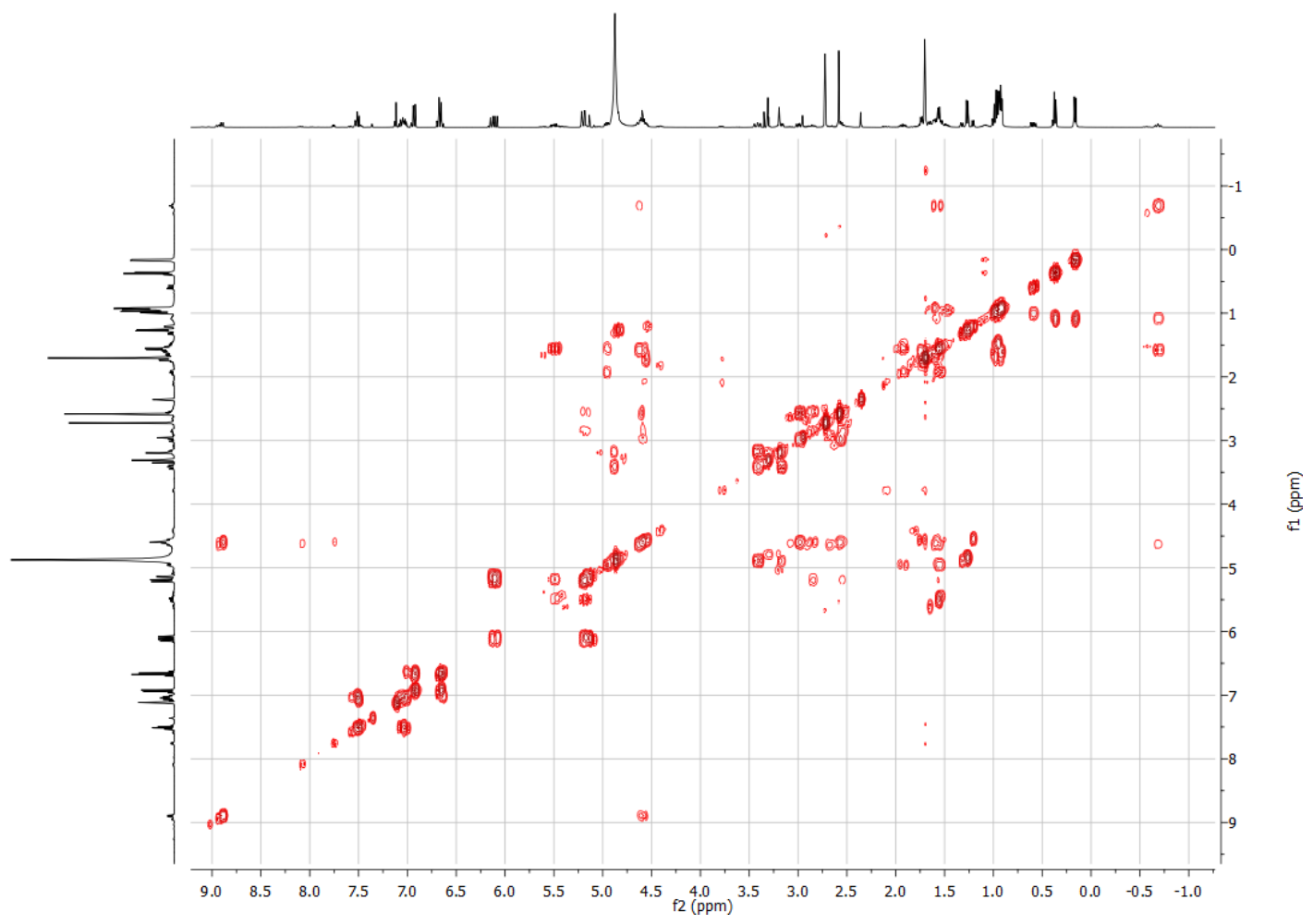

Figure S32. TOCSY spectrum of 4 in $\mathrm{CD}_{3} \mathrm{OD}(400 \mathrm{MHz})$

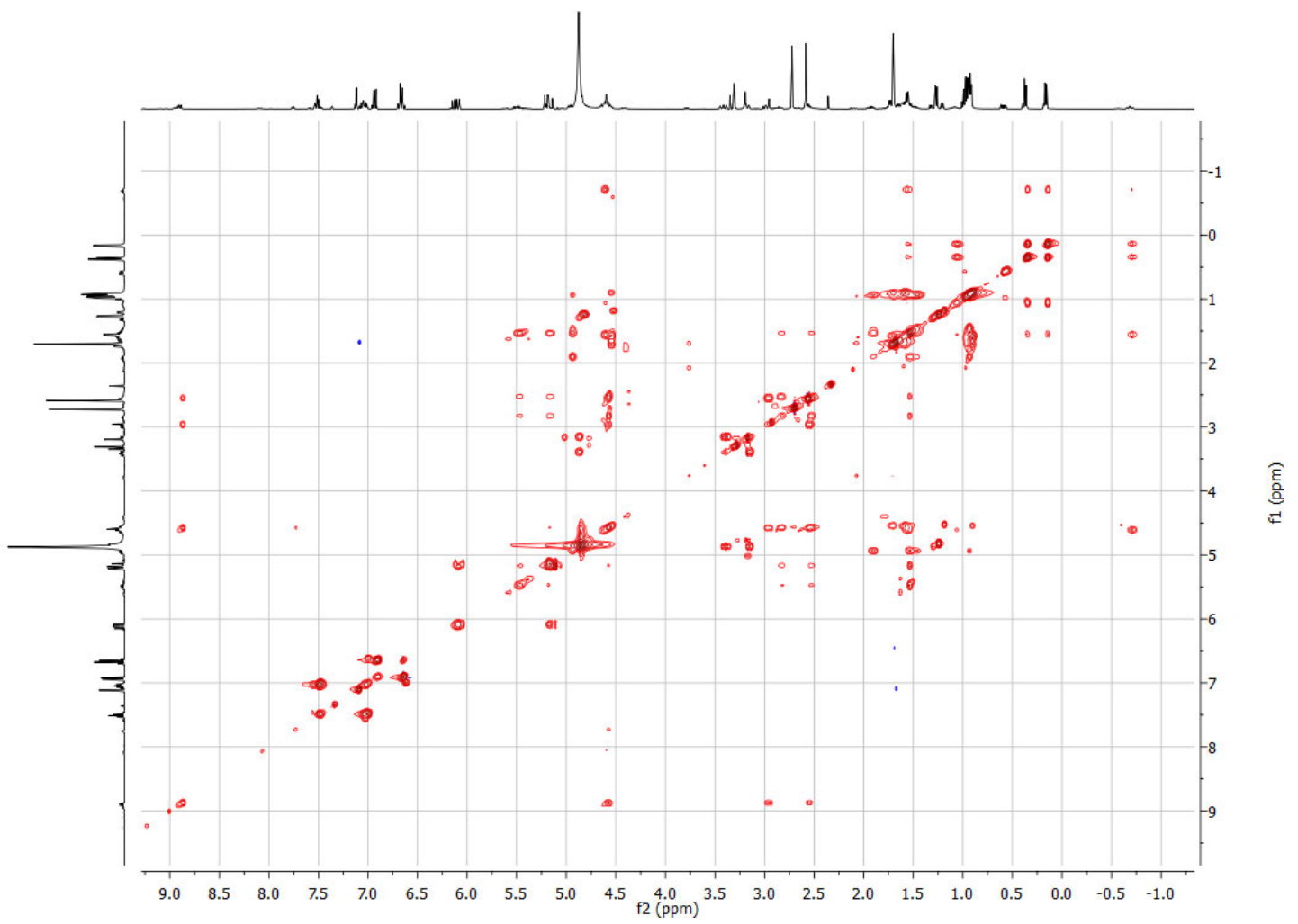


Figure S33. HSQC spectrum of 4 in $\mathrm{CD}_{3} \mathrm{OD}\left(400 \mathrm{MHz}^{1} \mathrm{H}\right)$

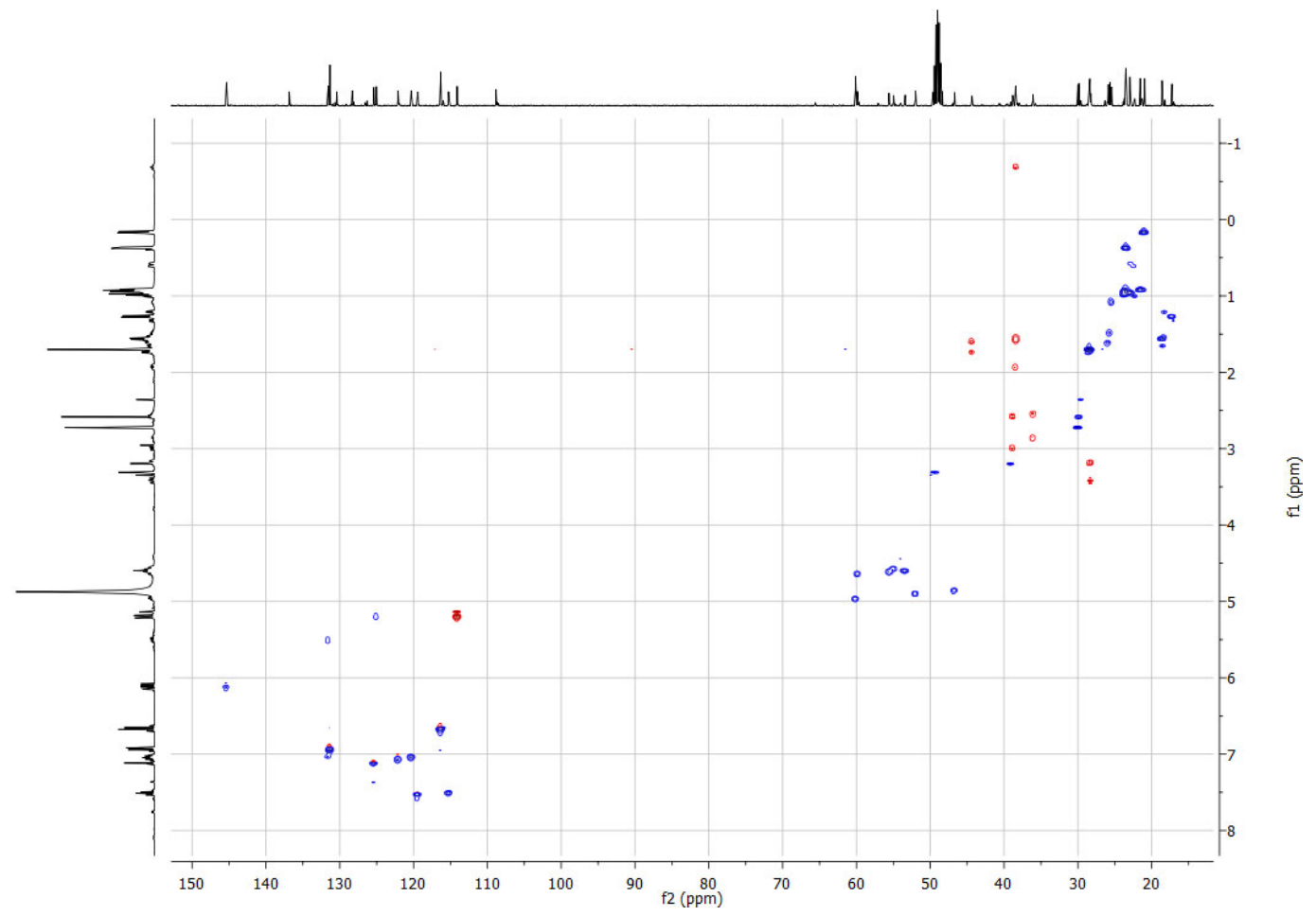

Figure S34. HMBC spectrum of 4 in $\mathrm{CD}_{3} \mathrm{OD}\left(400 \mathrm{MHz}^{1} \mathrm{H}\right)$

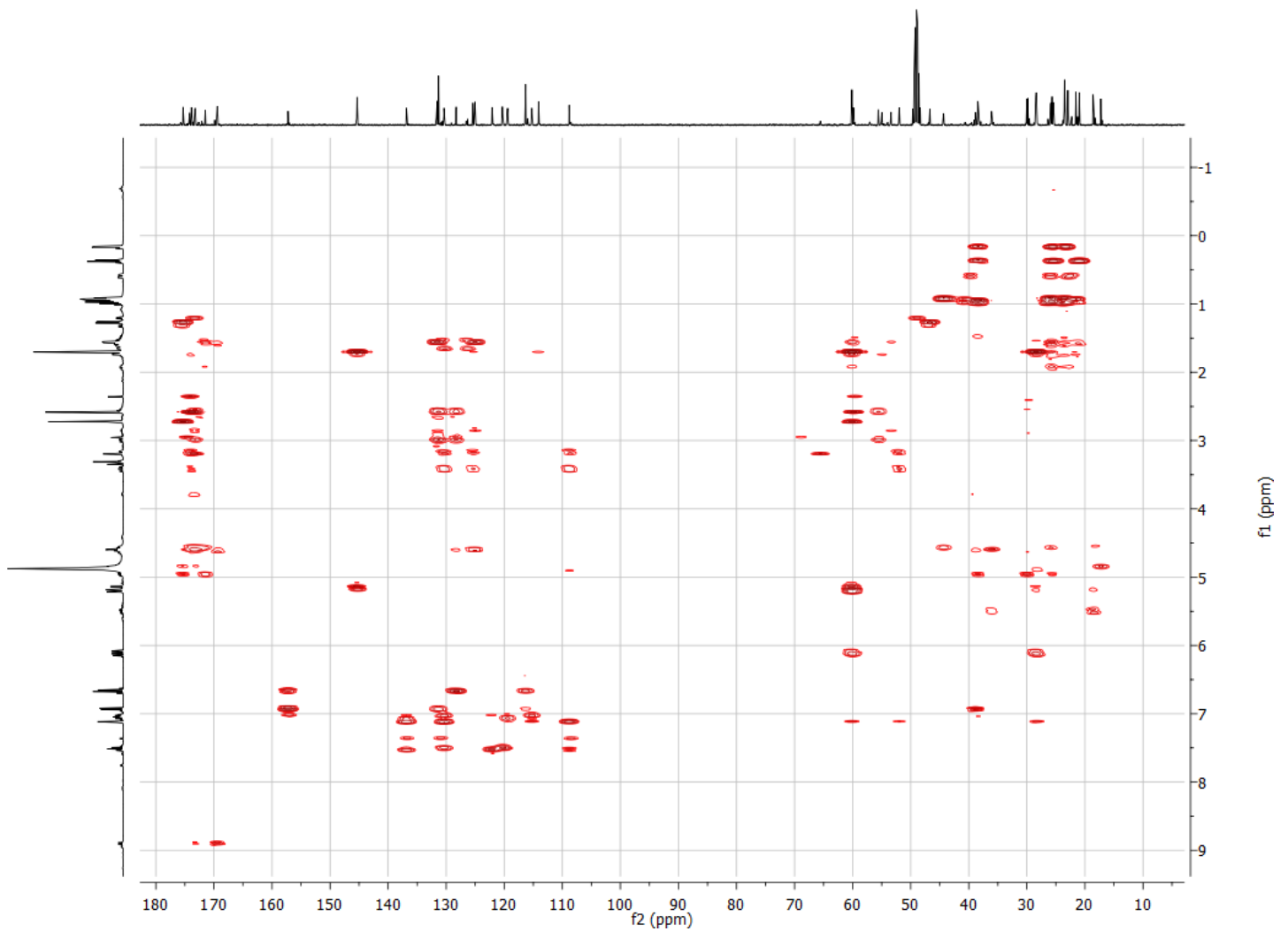


Figure S35. (+)-HRESIMS spectrum of 4

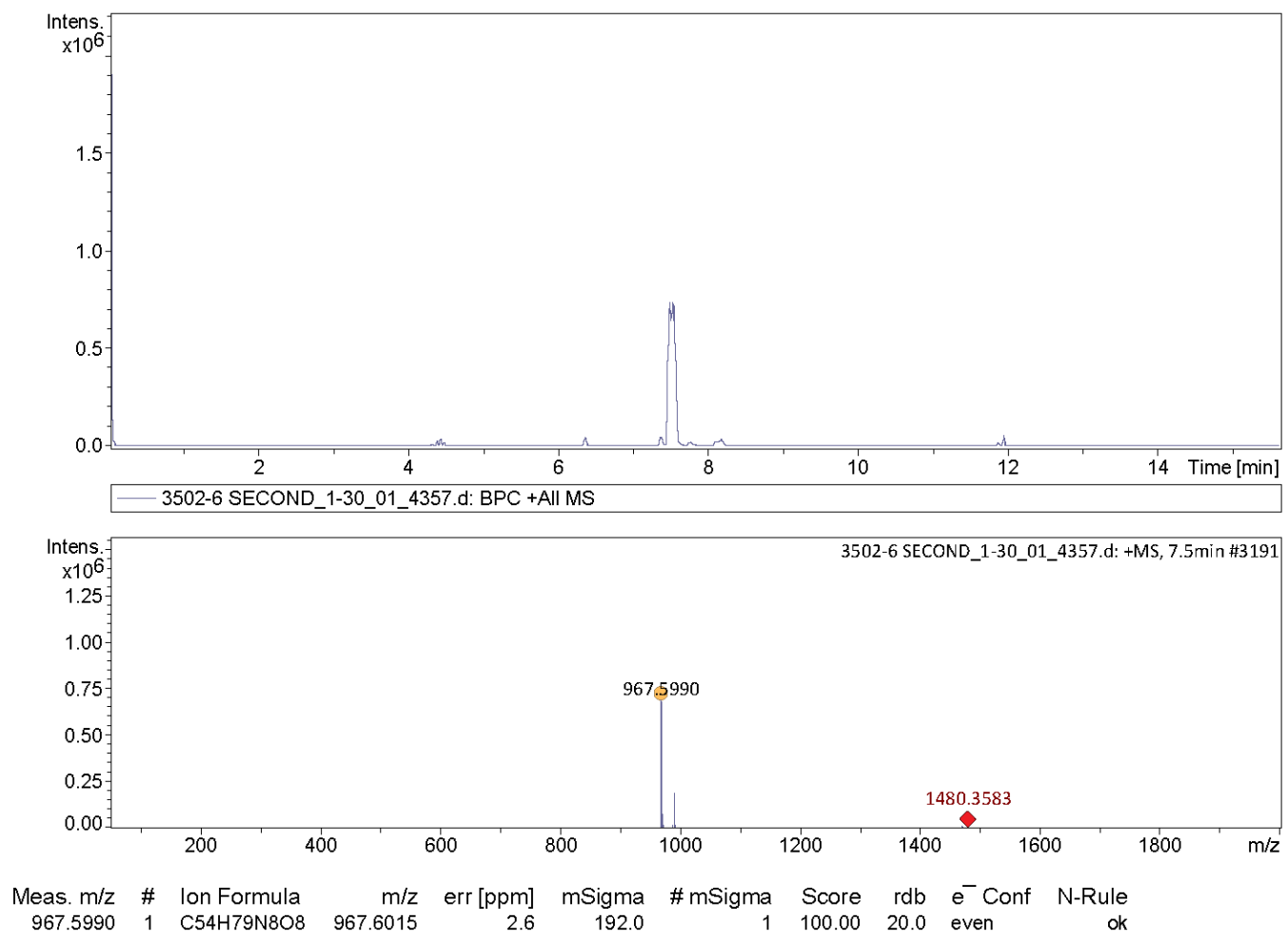

Figure S36. IR spectrum of 4

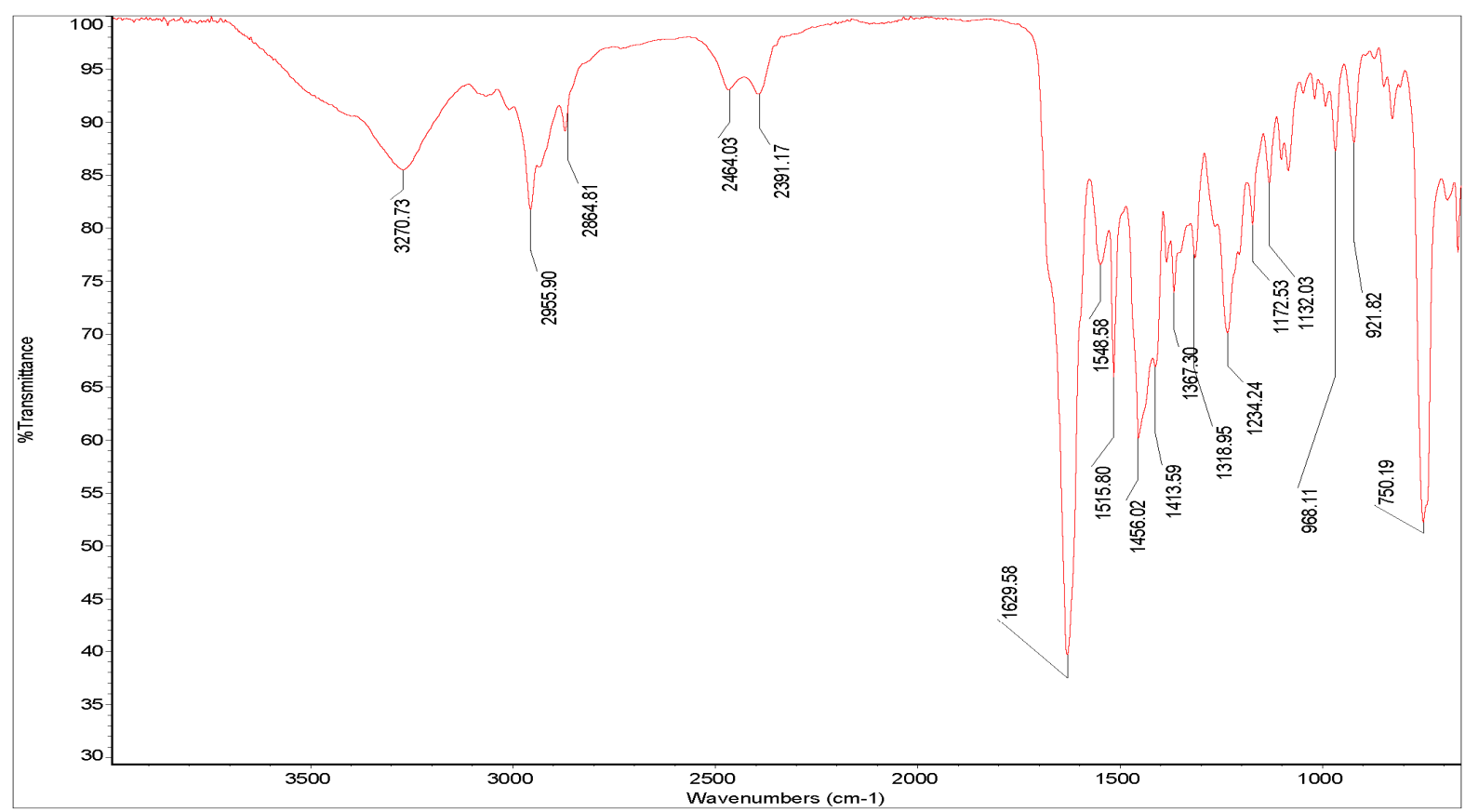


Figure S37. LC-ESIMS chromatograms of a total hydrolysate of 4 after derivatization with D/L-FDLA

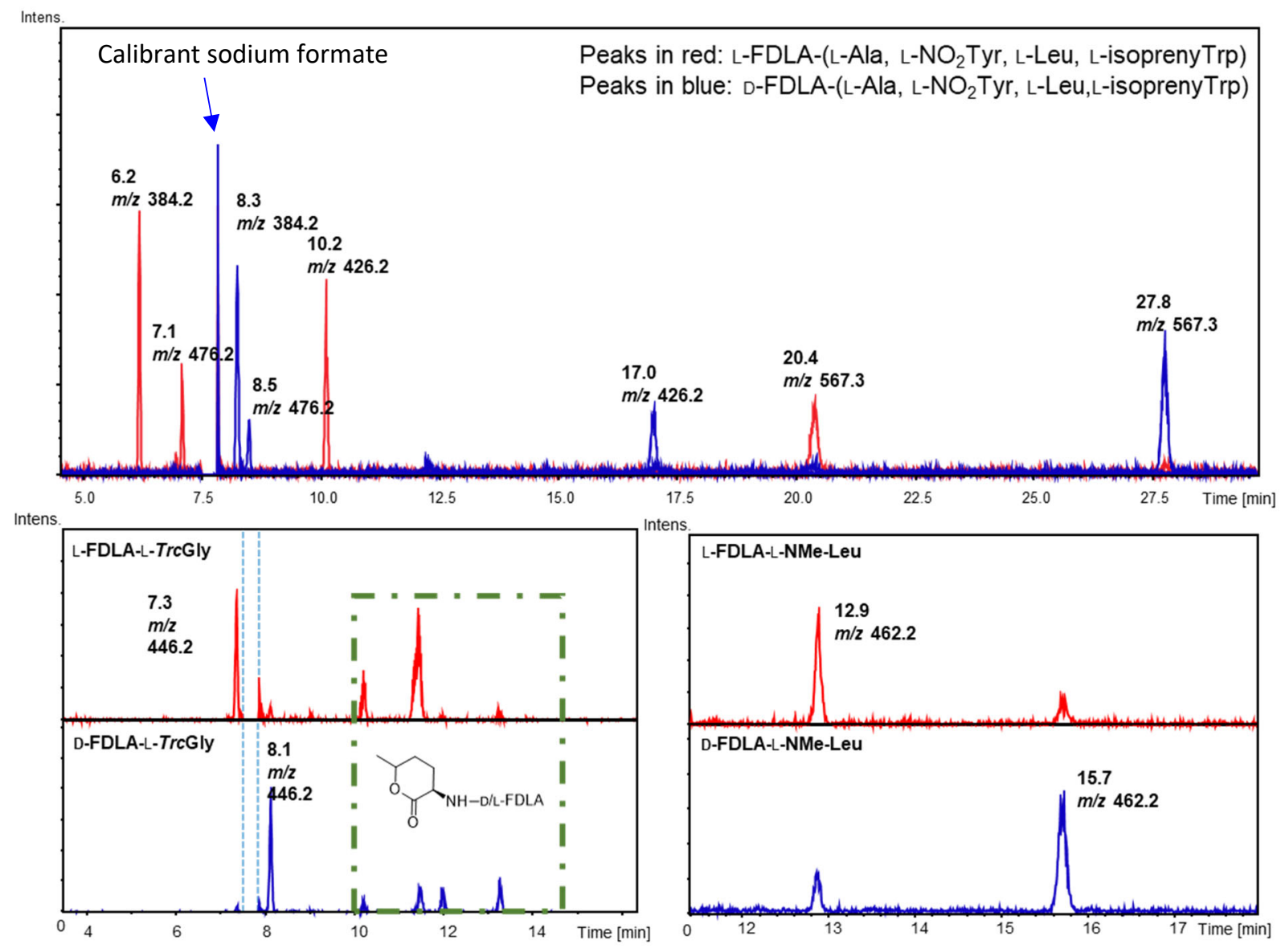




\section{Figure S38. ${ }^{1} \mathrm{H}$ NMR spectrum of 5 in $\mathrm{CD}_{3} \mathrm{OD}$ at $400 \mathrm{MHz}$}
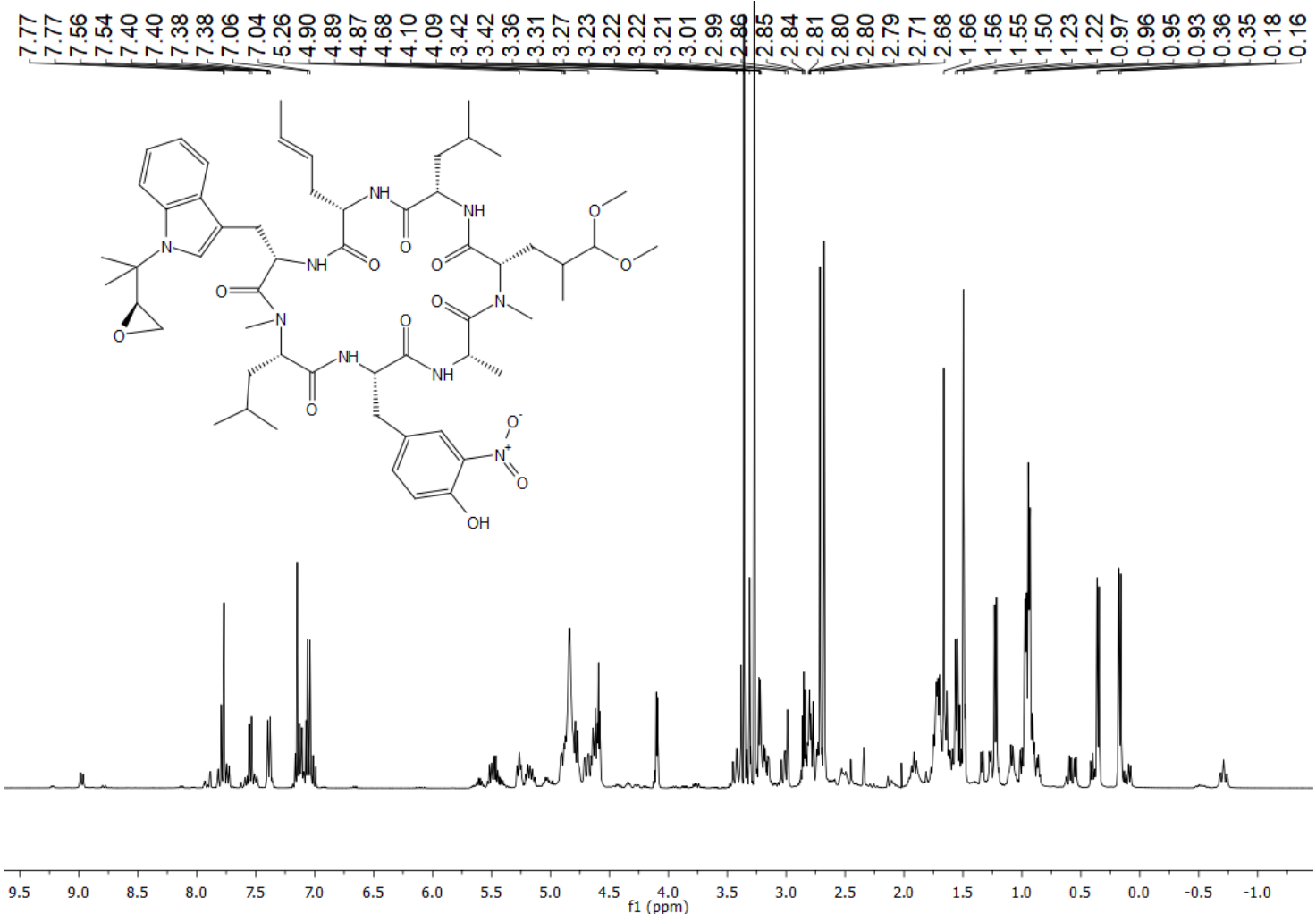

Figure S39. ${ }^{13} \mathrm{C}$ NMR spectrum of 5 in $\mathrm{CD}_{3} \mathrm{OD}$ at $100 \mathrm{MHz}$

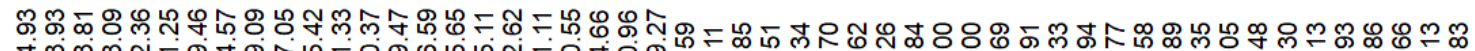

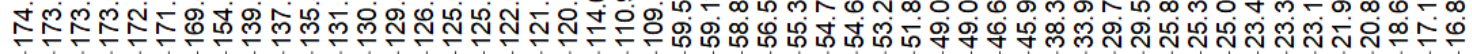

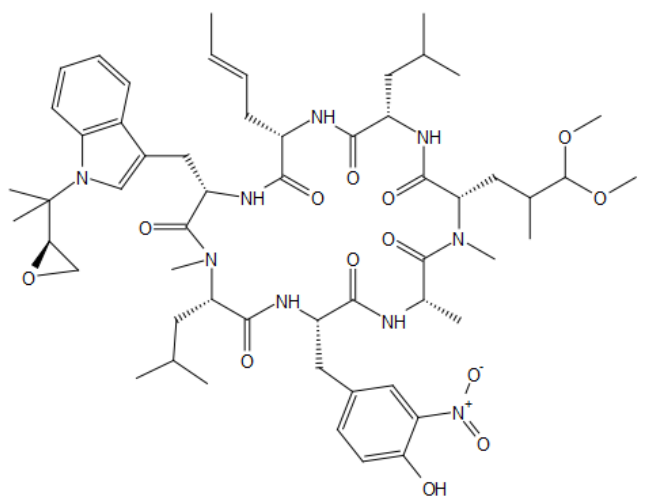

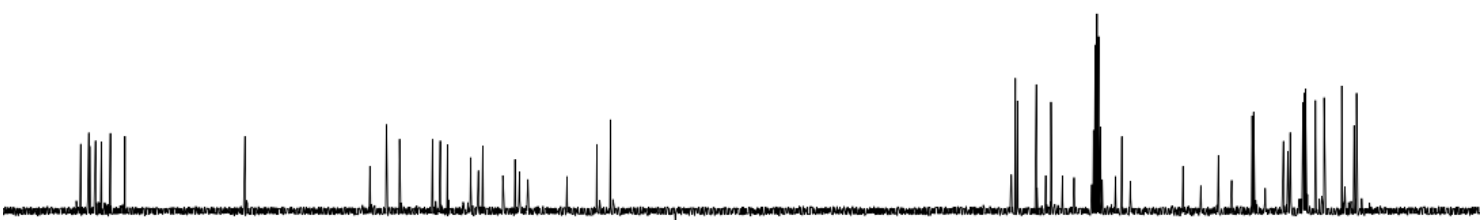

$\begin{array}{lllllllll}180 & 170 & 160 & 150 & 140 & 130 & 120 & 110 & 100\end{array} \begin{aligned} & 90 \\ & \mathrm{f} 1(\mathrm{ppm})\end{aligned}$ 
Figure S40. COSY spectrum of 5 in $\mathrm{CD}_{3} \mathrm{OD}(400 \mathrm{MHz})$

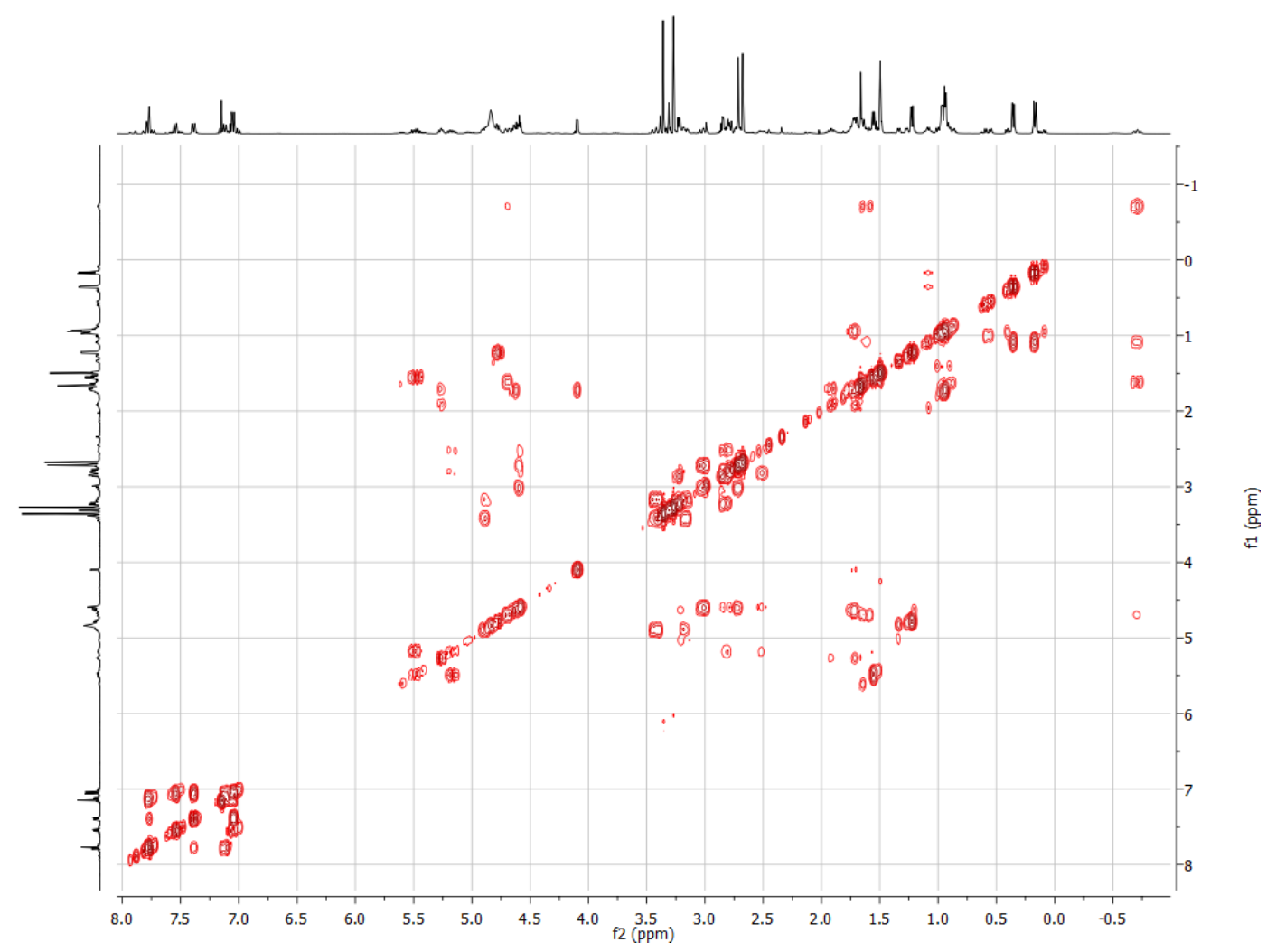

Figure S41. TOCSY spectrum of 5 in $\mathrm{CD}_{3} \mathrm{OD}(400 \mathrm{MHz})$

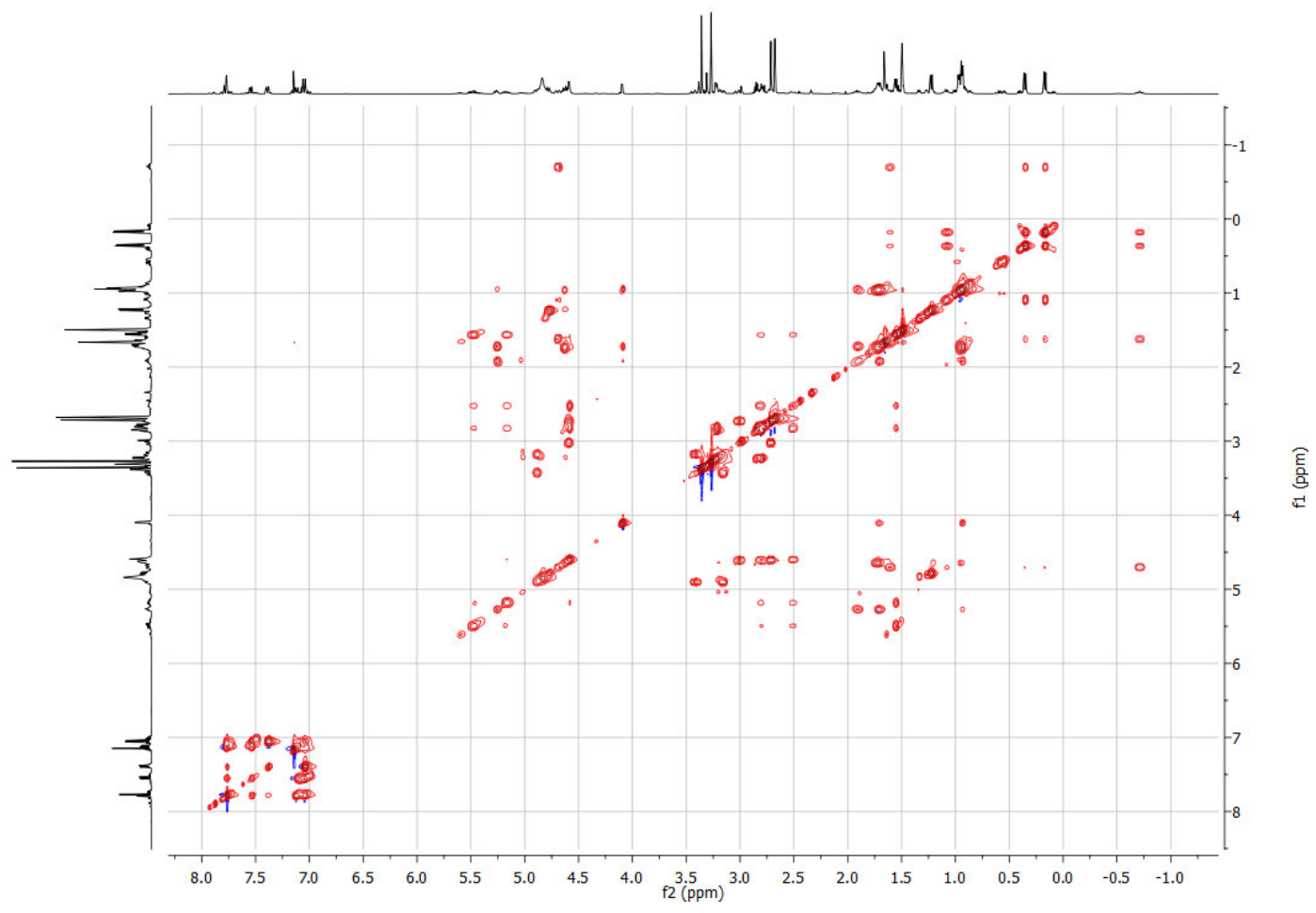


Figure S42. HSQC spectrum of 5 in $\mathrm{CD}_{3} \mathrm{OD}\left(400 \mathrm{MHz}^{1} \mathrm{H}\right)$

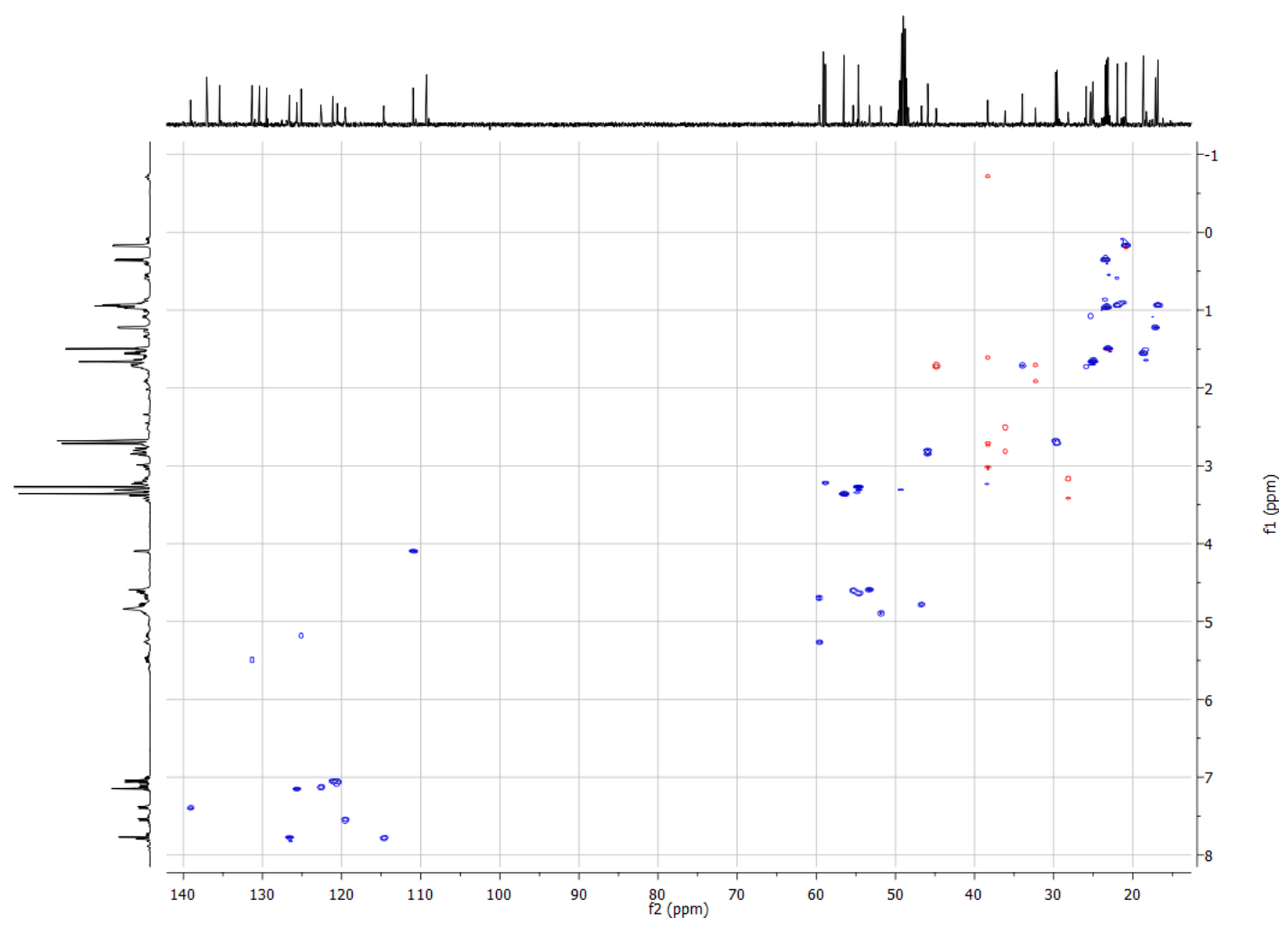

Figure S43. HMBC spectrum of 5 in $\mathrm{CD}_{3} \mathrm{OD}\left(400 \mathrm{MHz}^{1} \mathrm{H}\right)$

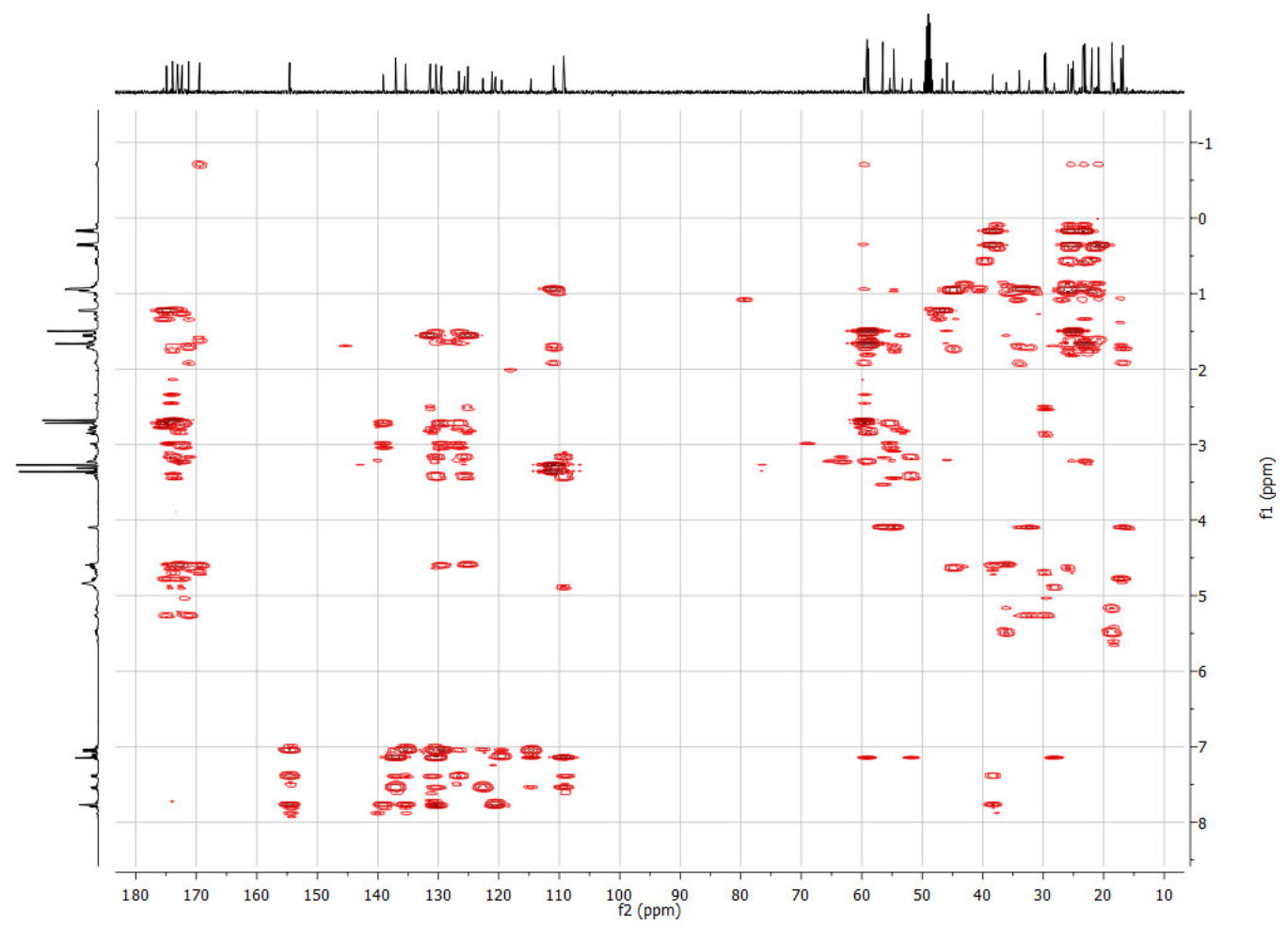


Figure S44. (+)-HRESIMS spectrum of 5

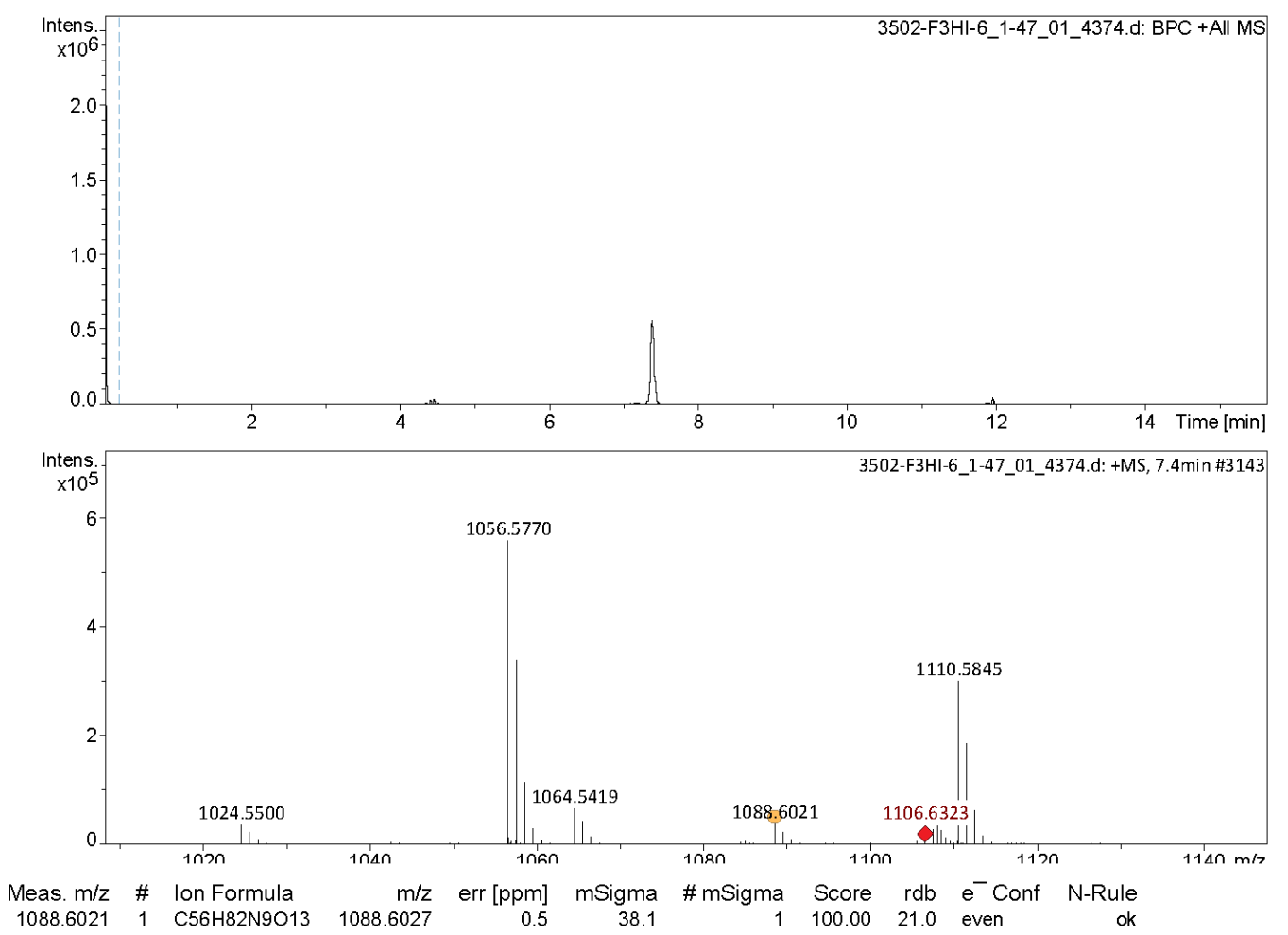

Figure S45. IR spectrum of 5

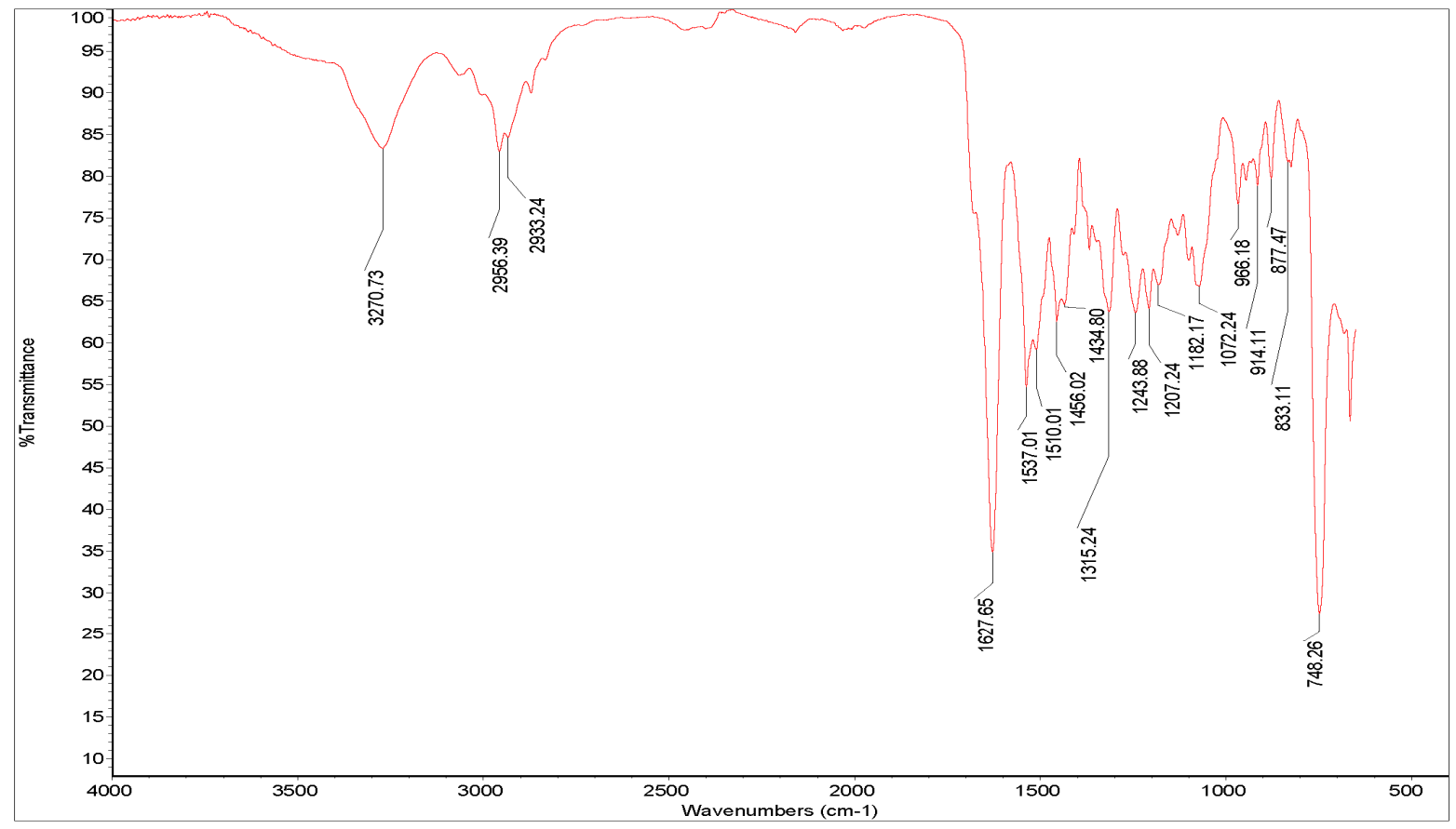


Figure S46. LC-ESIMS chromatograms of a total hydrolysate of 5 after derivatization with D/L-FDLA

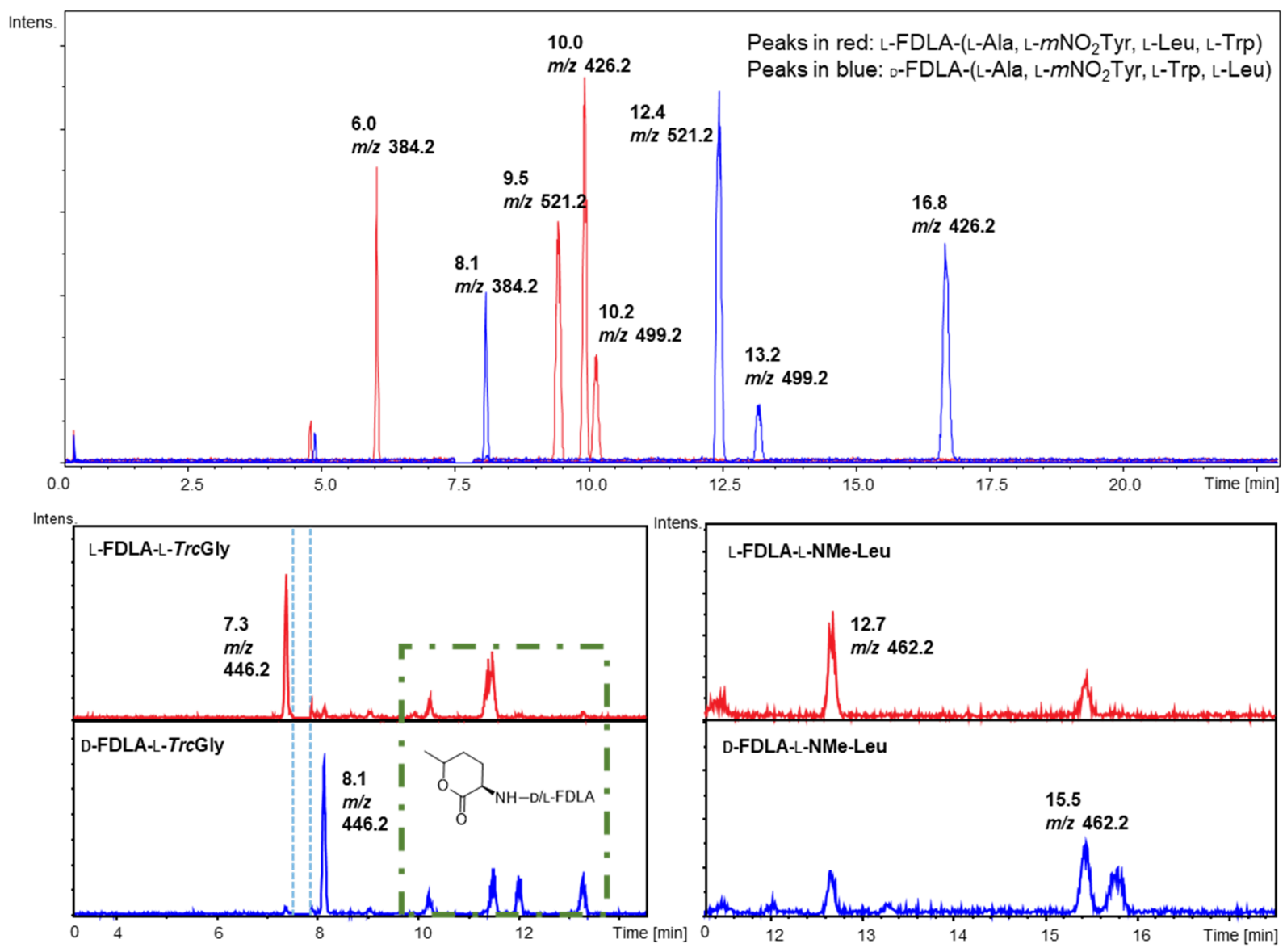


Figure S47. ${ }^{1} \mathrm{H}$ NMR spectrum of 6 in $\mathrm{CD}_{3} \mathrm{OD}$ at $400 \mathrm{MHz}$

ஜ

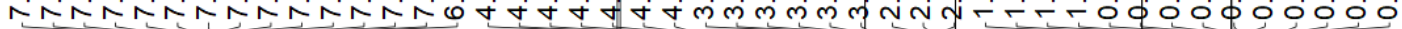
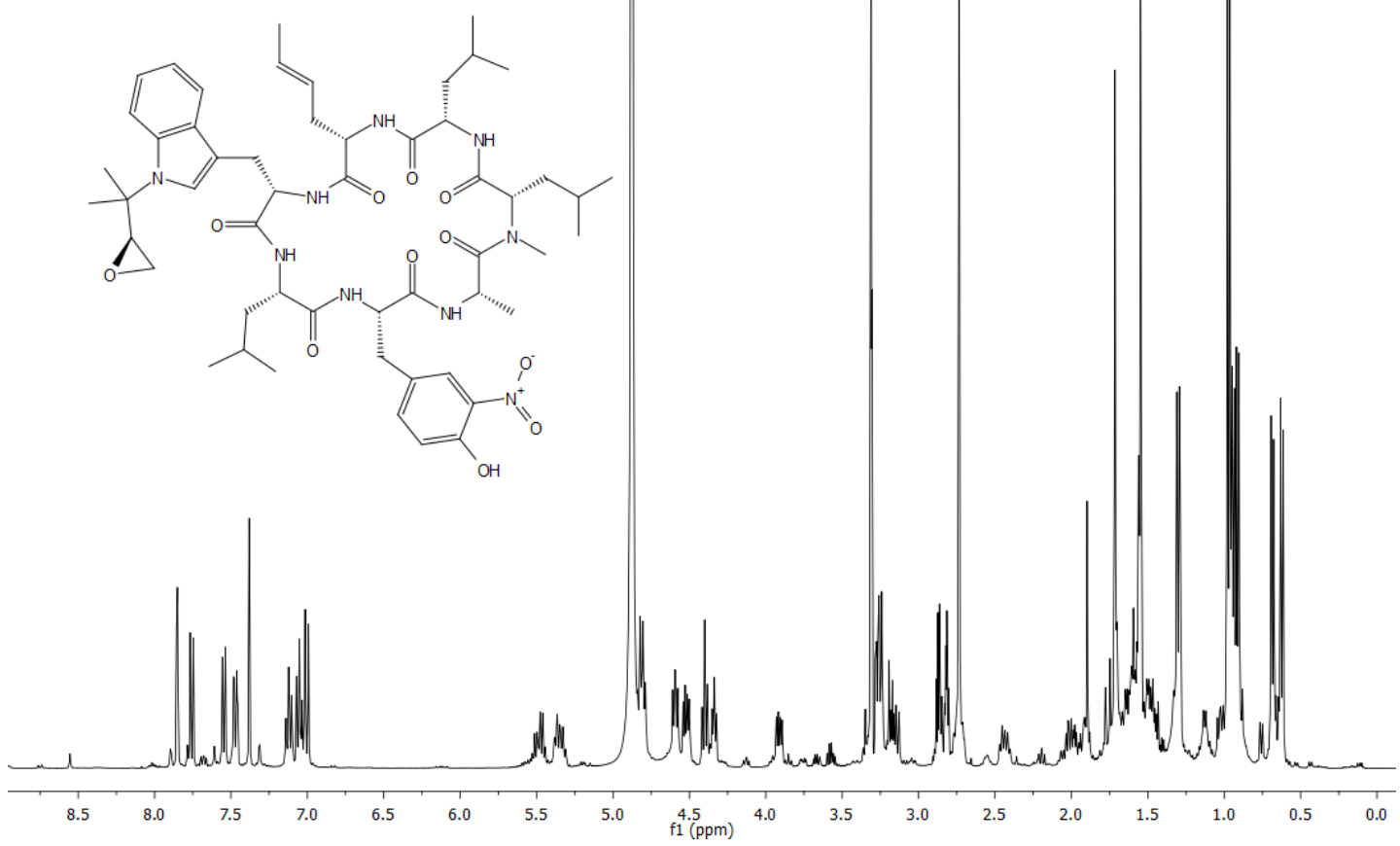

Figure S48. ${ }^{13} \mathrm{C}$ NMR spectrum of 6 in $\mathrm{CD}_{3} \mathrm{OD}$ at $100 \mathrm{MHz}$

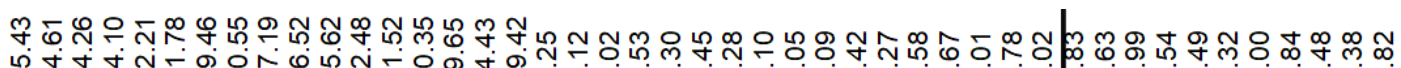

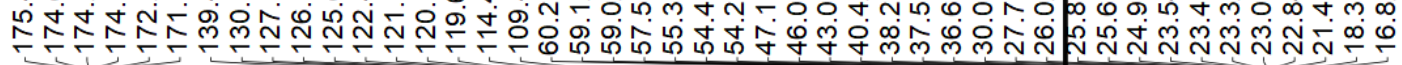

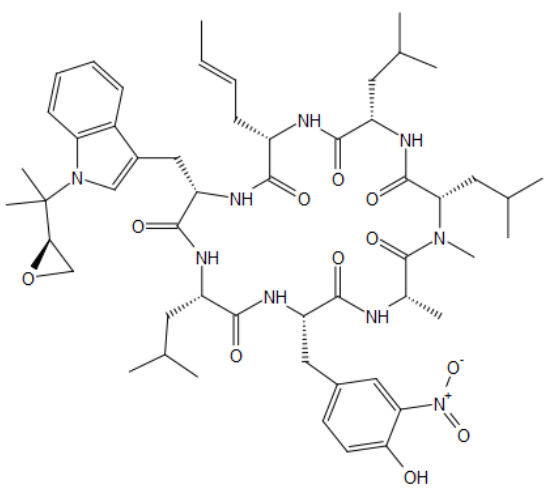

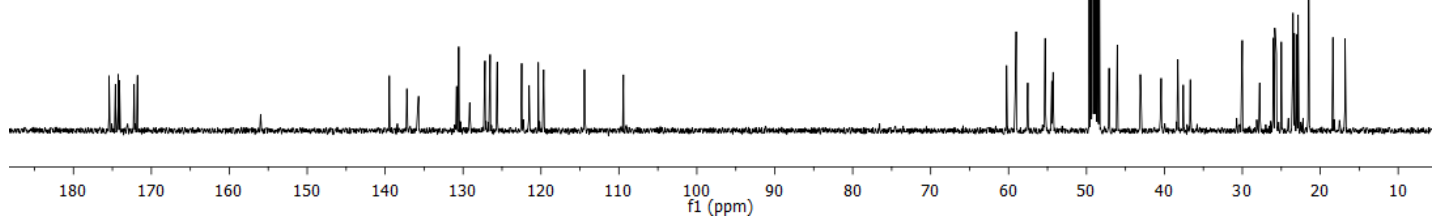


Figure S49. TOCSY spectrum of 6 in $\mathrm{CD}_{3} \mathrm{OD}(400 \mathrm{MHz})$

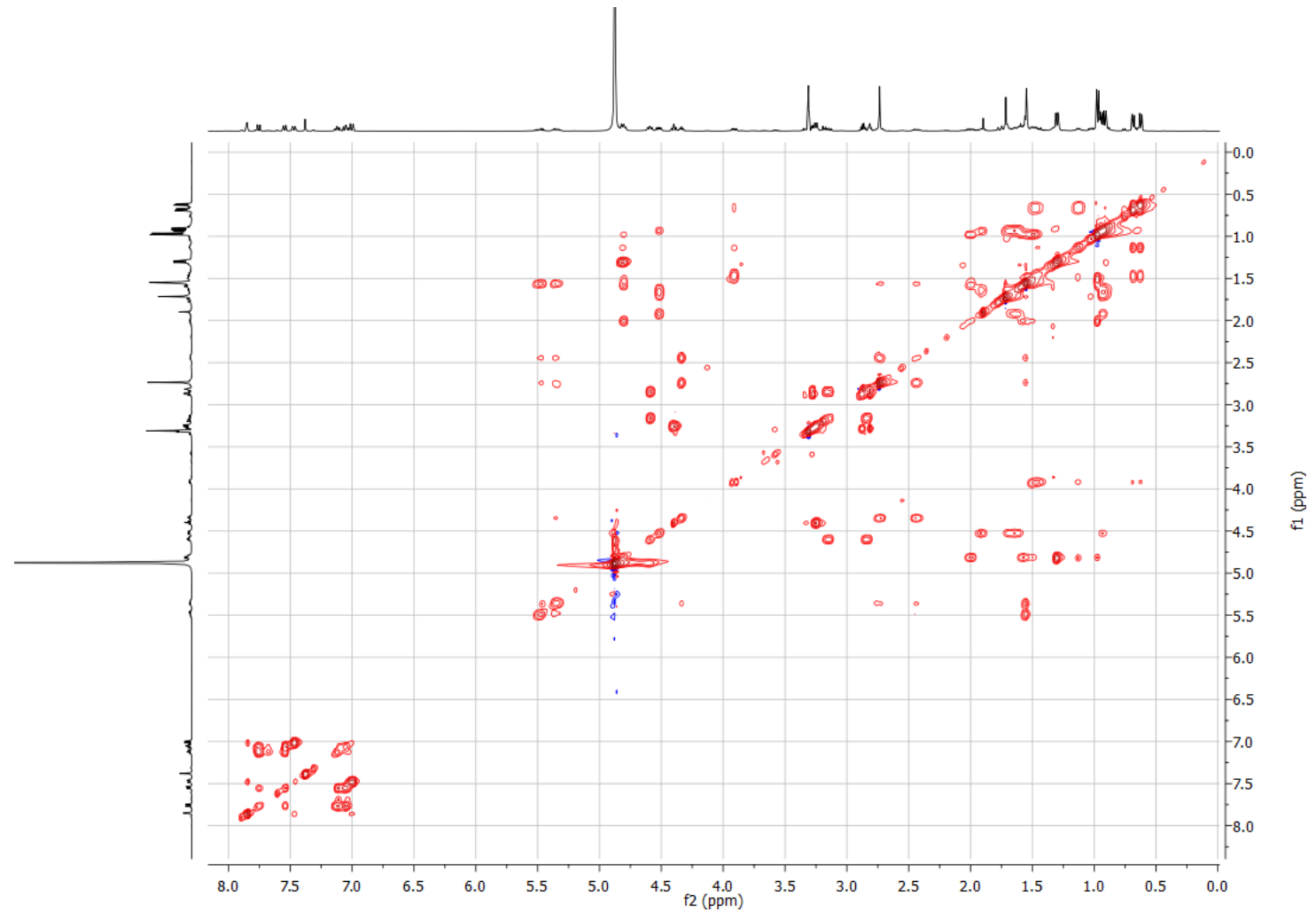

Figure S50. HSQC spectrum of 6 in $\mathrm{CD}_{3} \mathrm{OD}\left(400 \mathrm{MHz}{ }^{1} \mathrm{H}\right)$

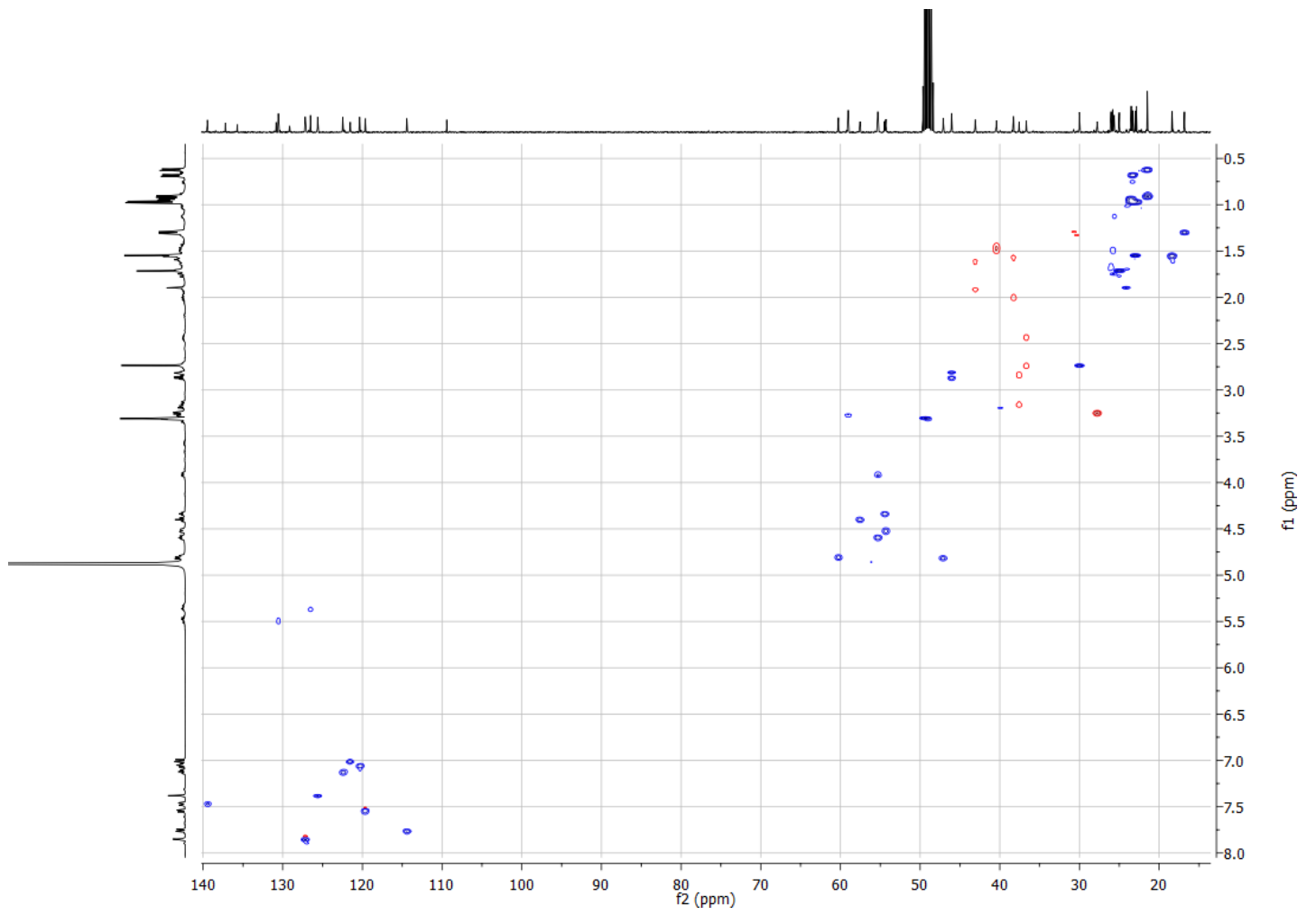


Figure S51. HMBC spectrum of 6 in $\mathrm{CD}_{3} \mathrm{OD}\left(400 \mathrm{MHz}^{1} \mathrm{H}\right)$

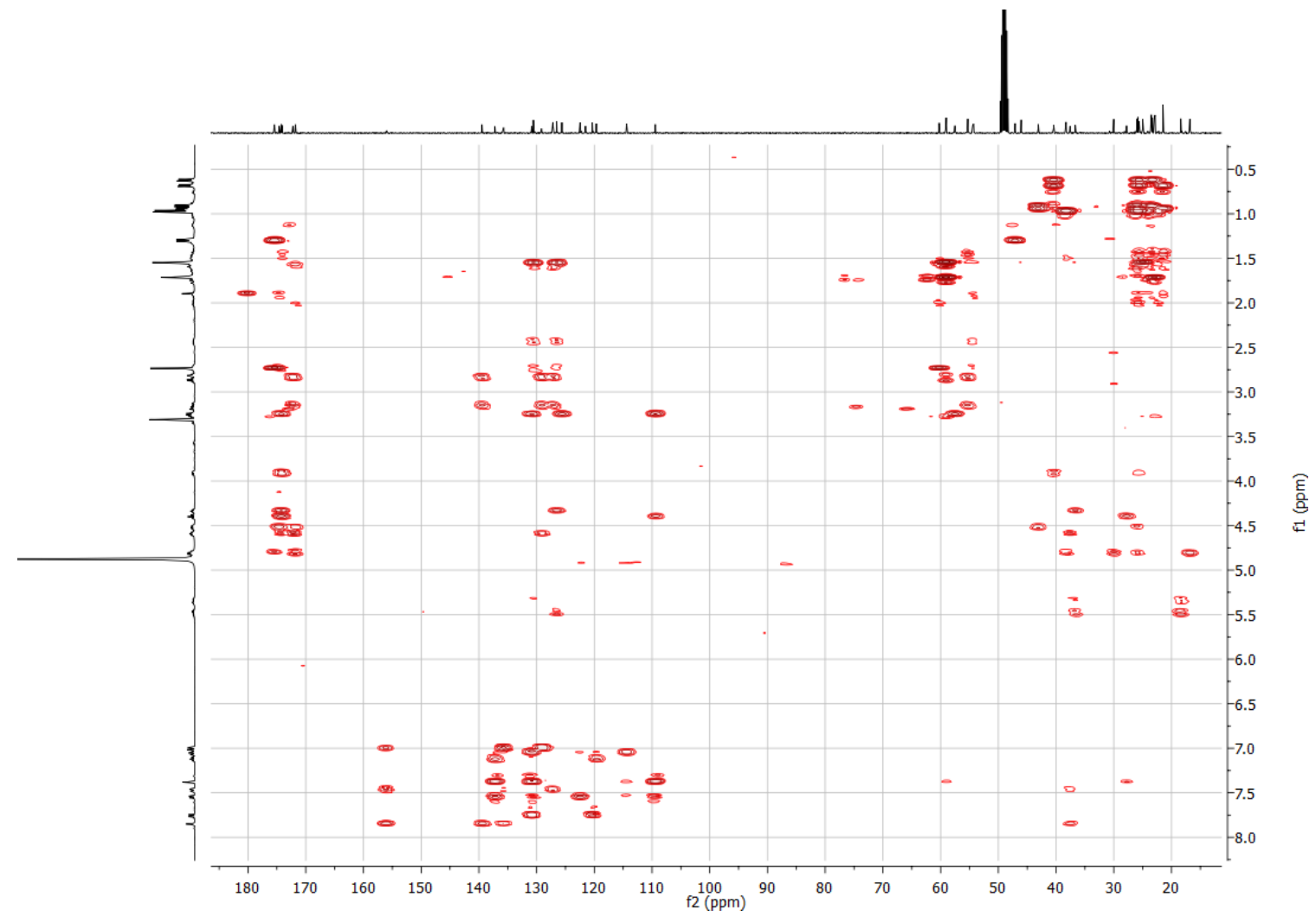

Figure S52. (+)-HRESIMS spectrum of 6

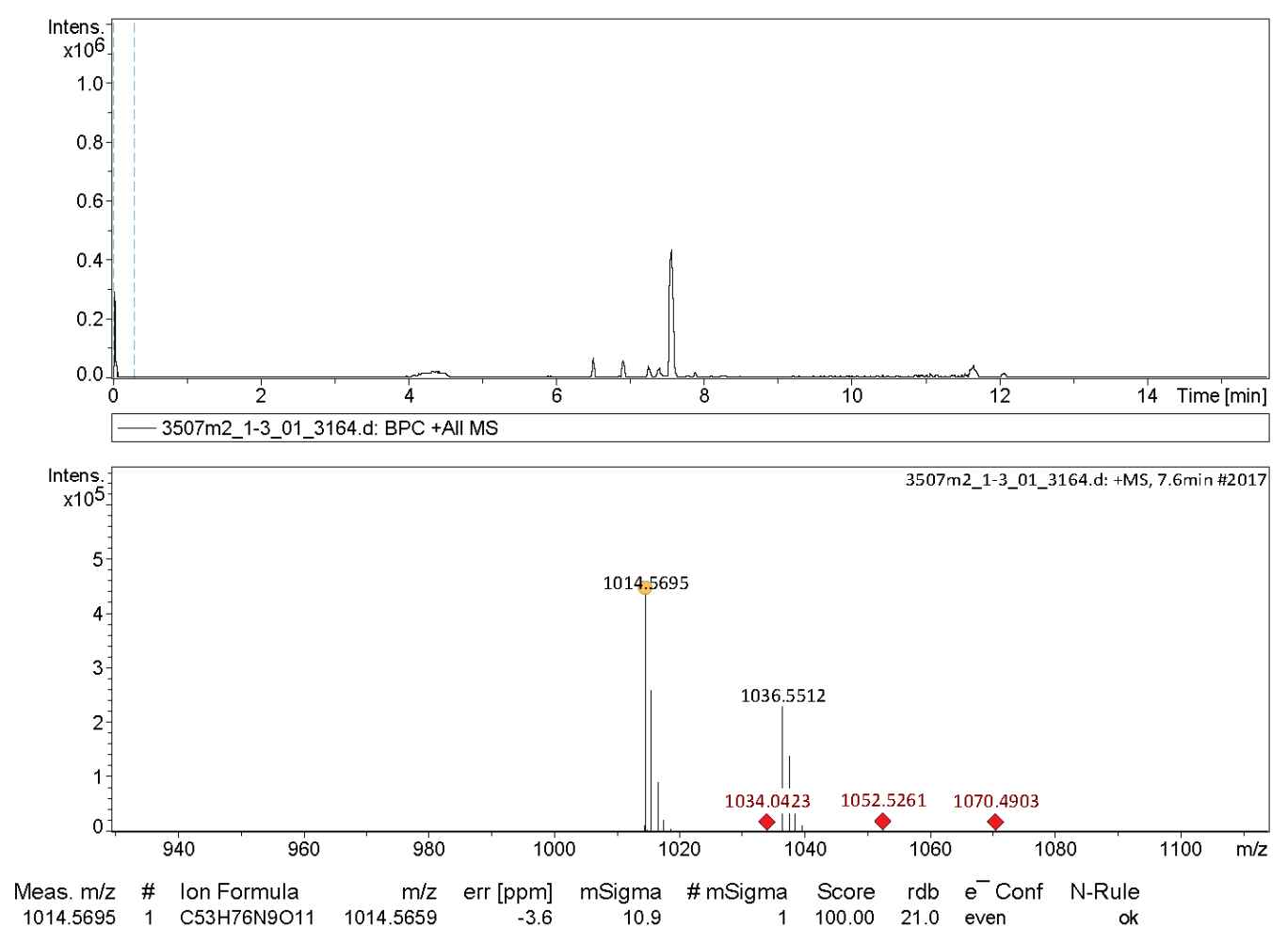


Figure S53. IR spectrum of 6

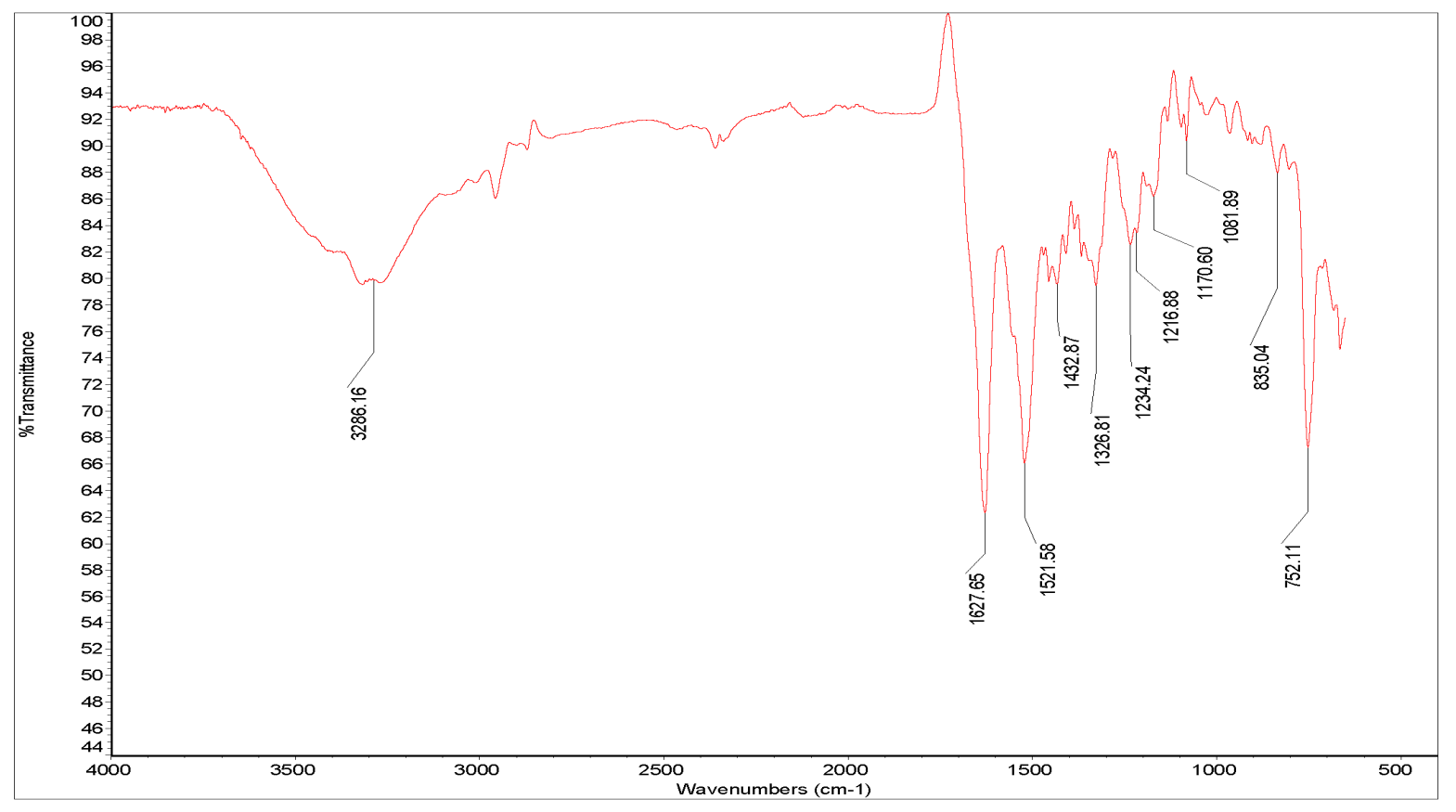

Figure S54. LC-ESIMS chromatograms of a total hydrolysate of 6 after derivatization with D/L-FDLA

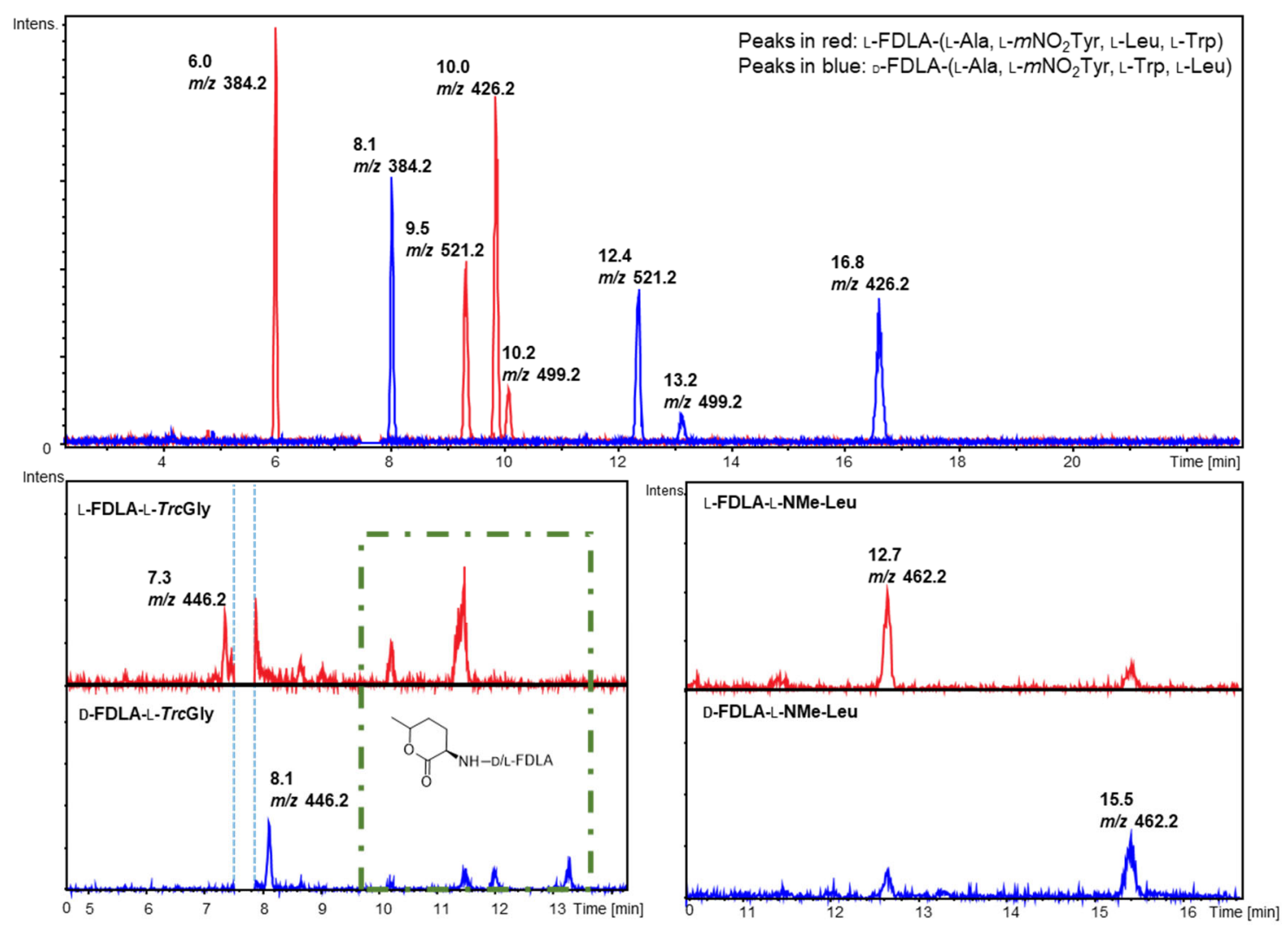




\section{Figure S55. ${ }^{1} \mathrm{H}$ NMR spectrum of 7 in $\mathrm{CD}_{3} \mathrm{OD}$ at $400 \mathrm{MHz}$}

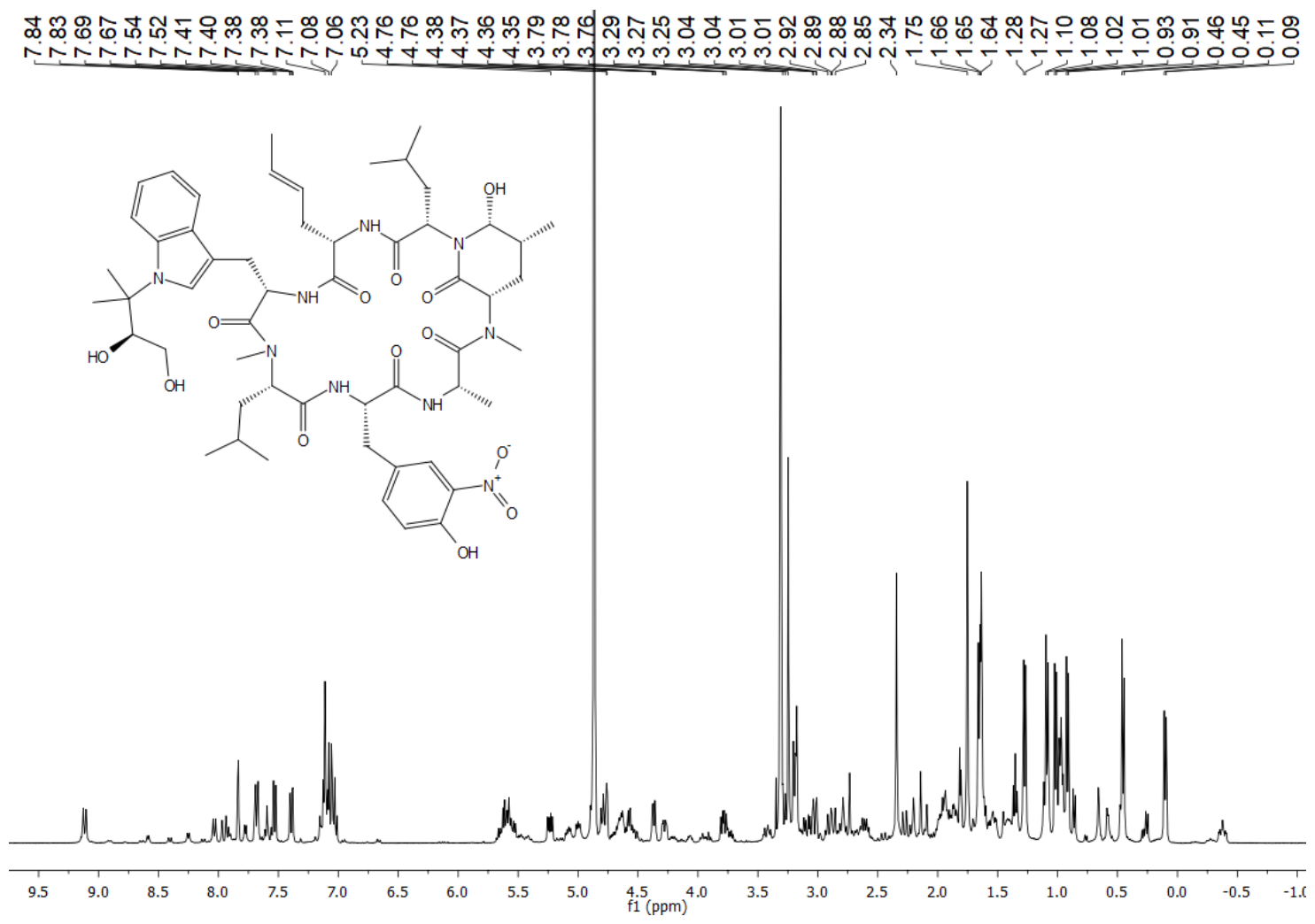

Figure S56. ${ }^{13} \mathrm{C}$ NMR spectrum of 7 in $\mathrm{CD}_{3} \mathrm{OD}$ at $100 \mathrm{MHz}$

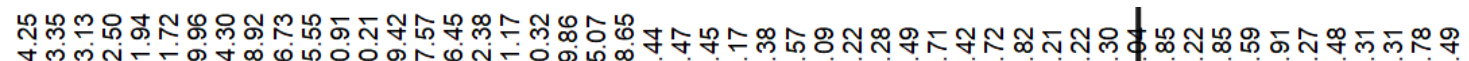

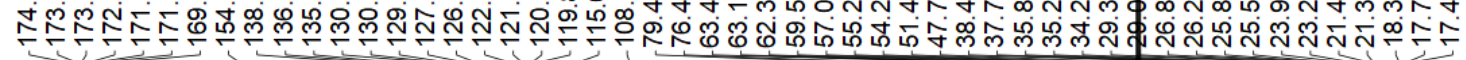
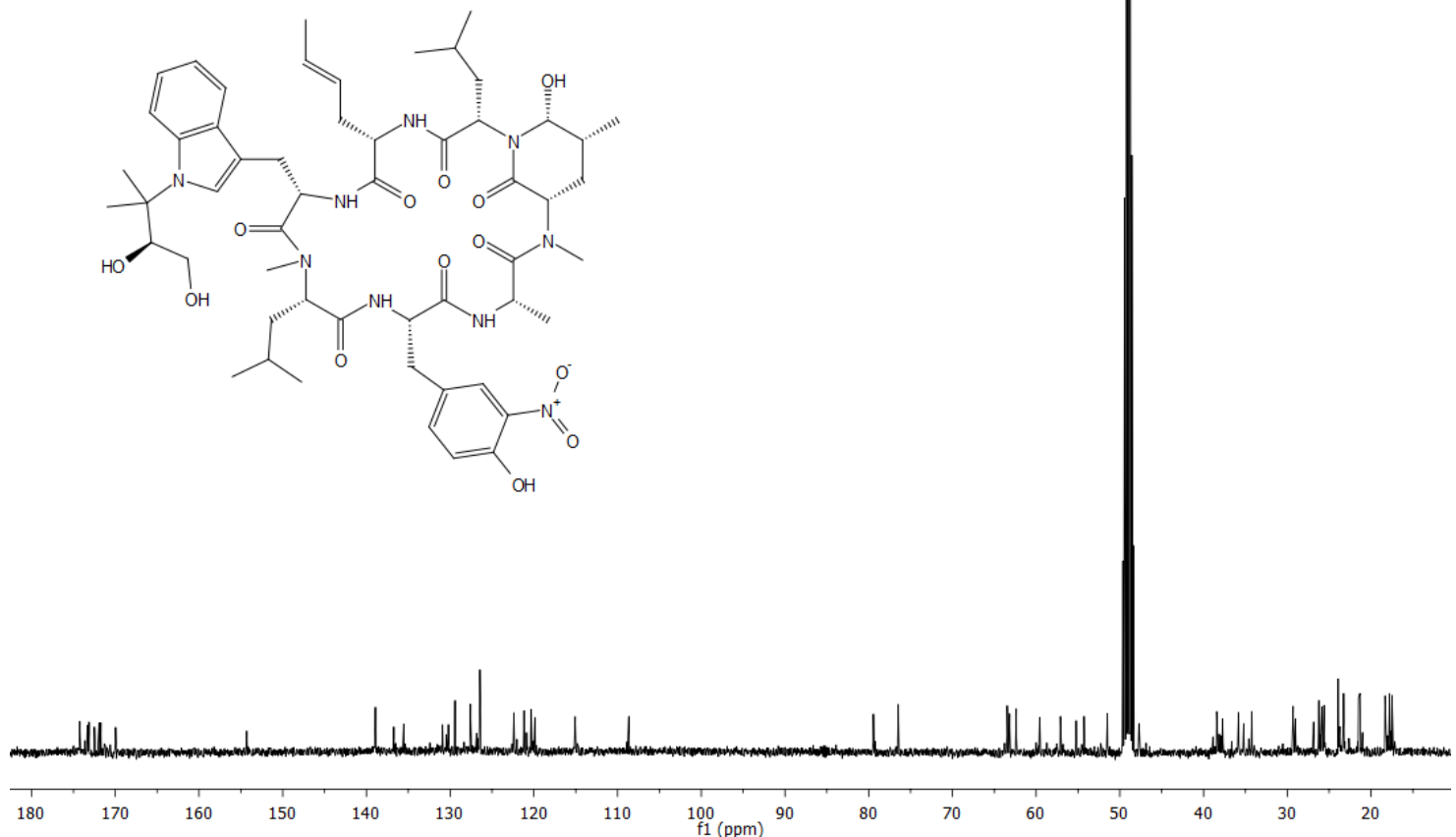
Figure S57. COSY spectrum of 7 in $\mathrm{CD}_{3} \mathrm{OD}(400 \mathrm{MHz})$

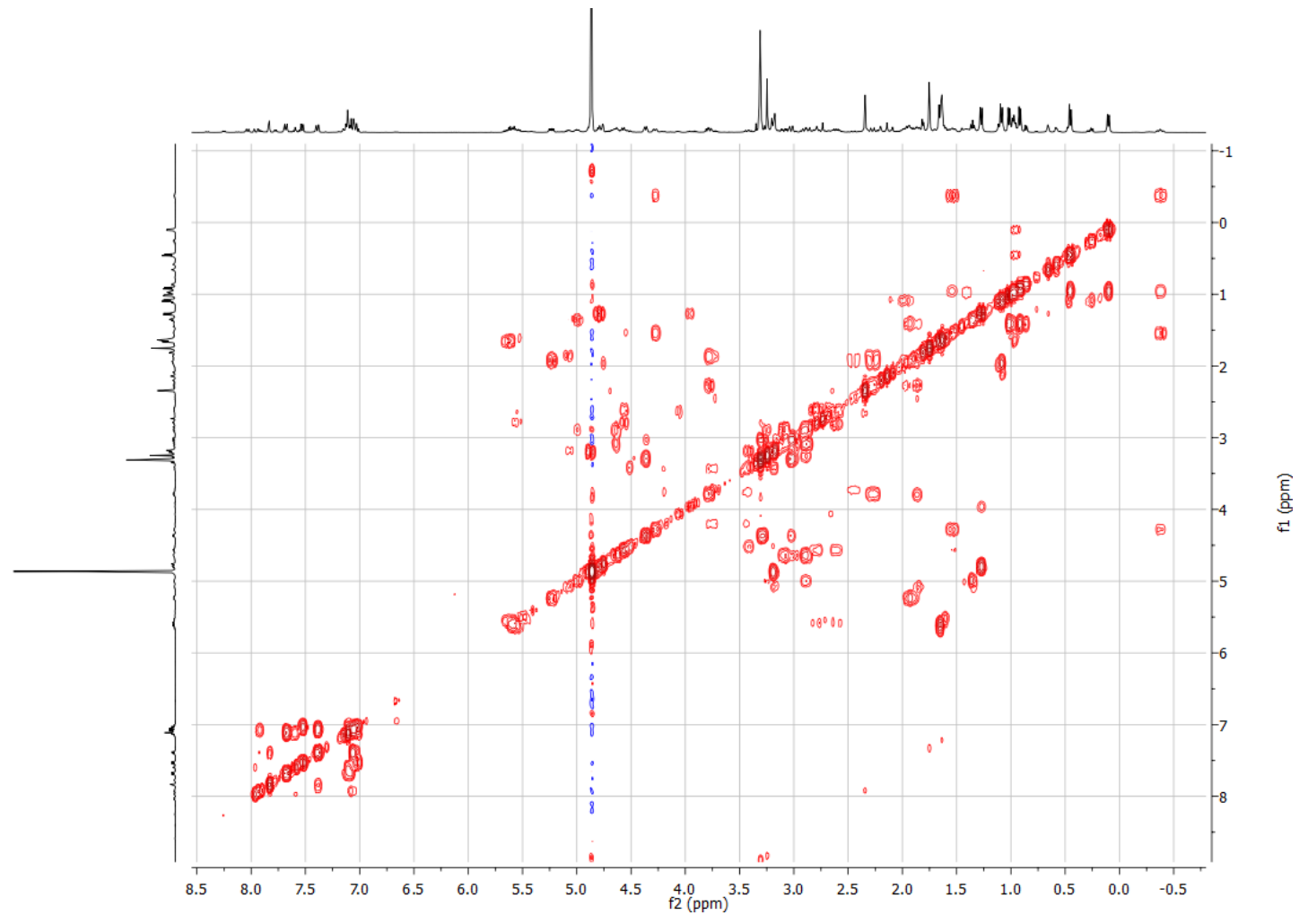

Figure S58. TOCSY spectrum of 7 in $\mathrm{CD}_{3} \mathrm{OD}(400 \mathrm{MHz})$

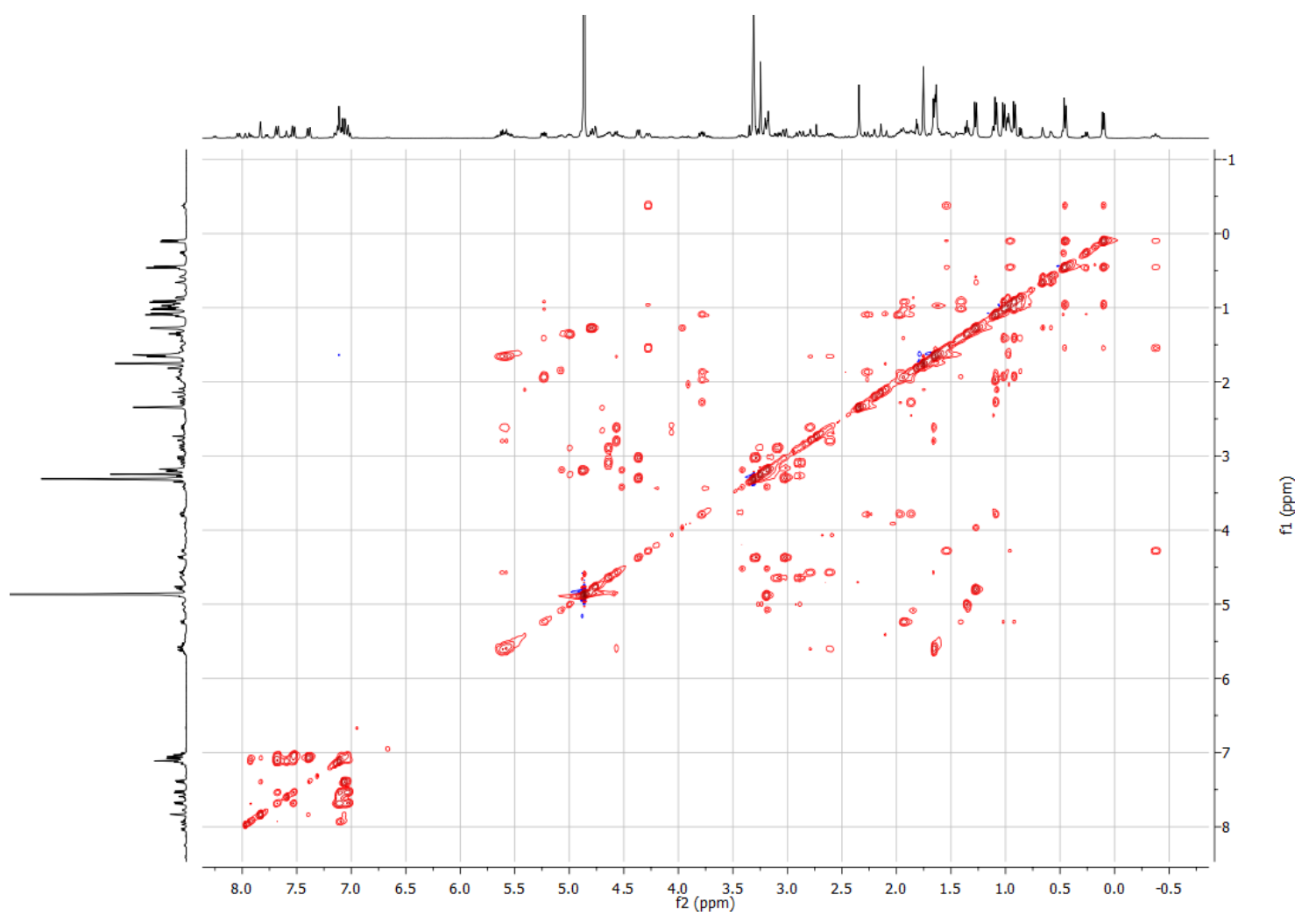


Figure S59. HSQC spectrum of 7 in $\mathrm{CD}_{3} \mathrm{OD}\left(400 \mathrm{MHz}{ }^{1} \mathrm{H}\right)$

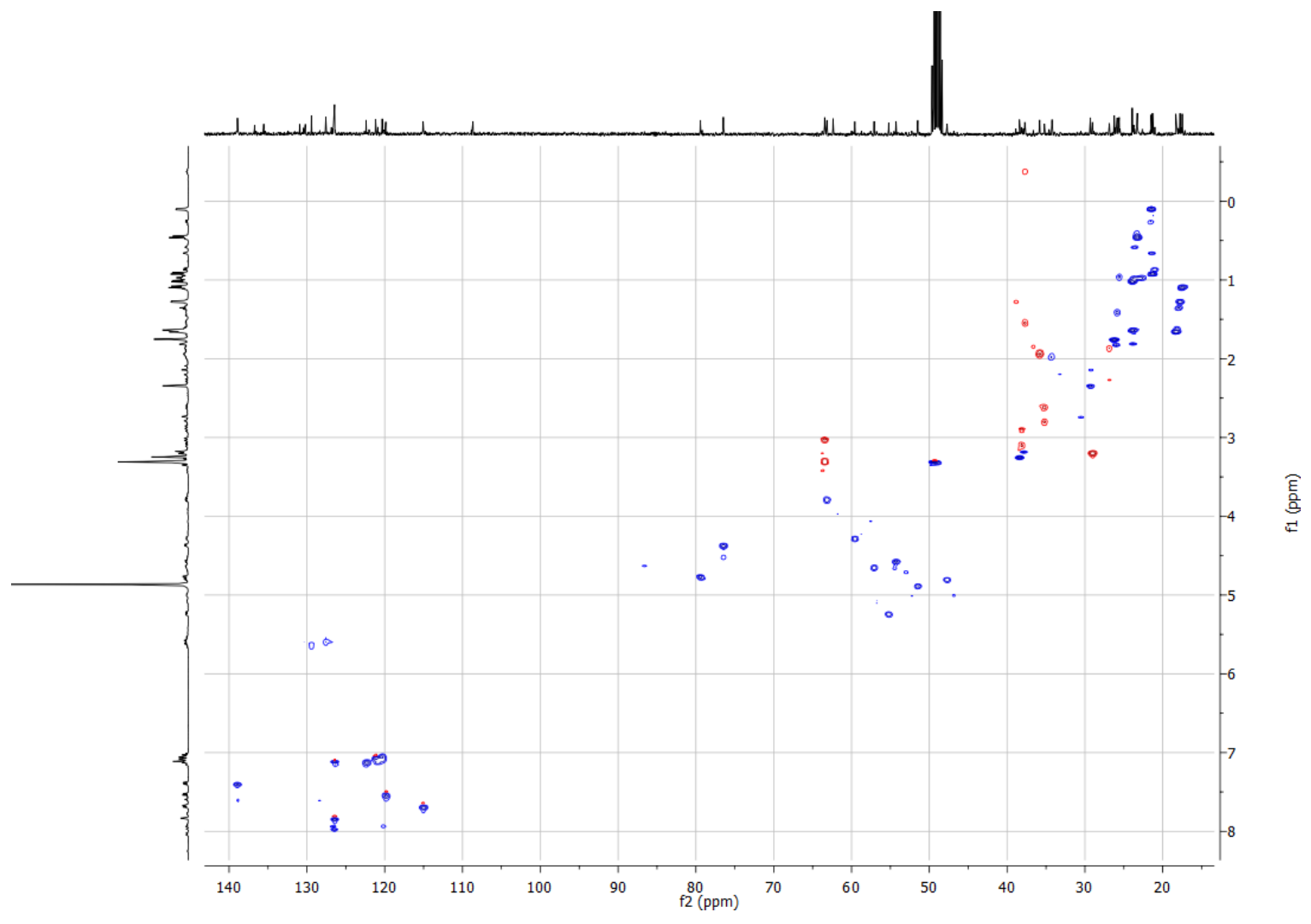

Figure S60. HMBC spectrum of 7 in $\mathrm{CD}_{3} \mathrm{OD}\left(400 \mathrm{MHz}^{1} \mathrm{H}\right)$

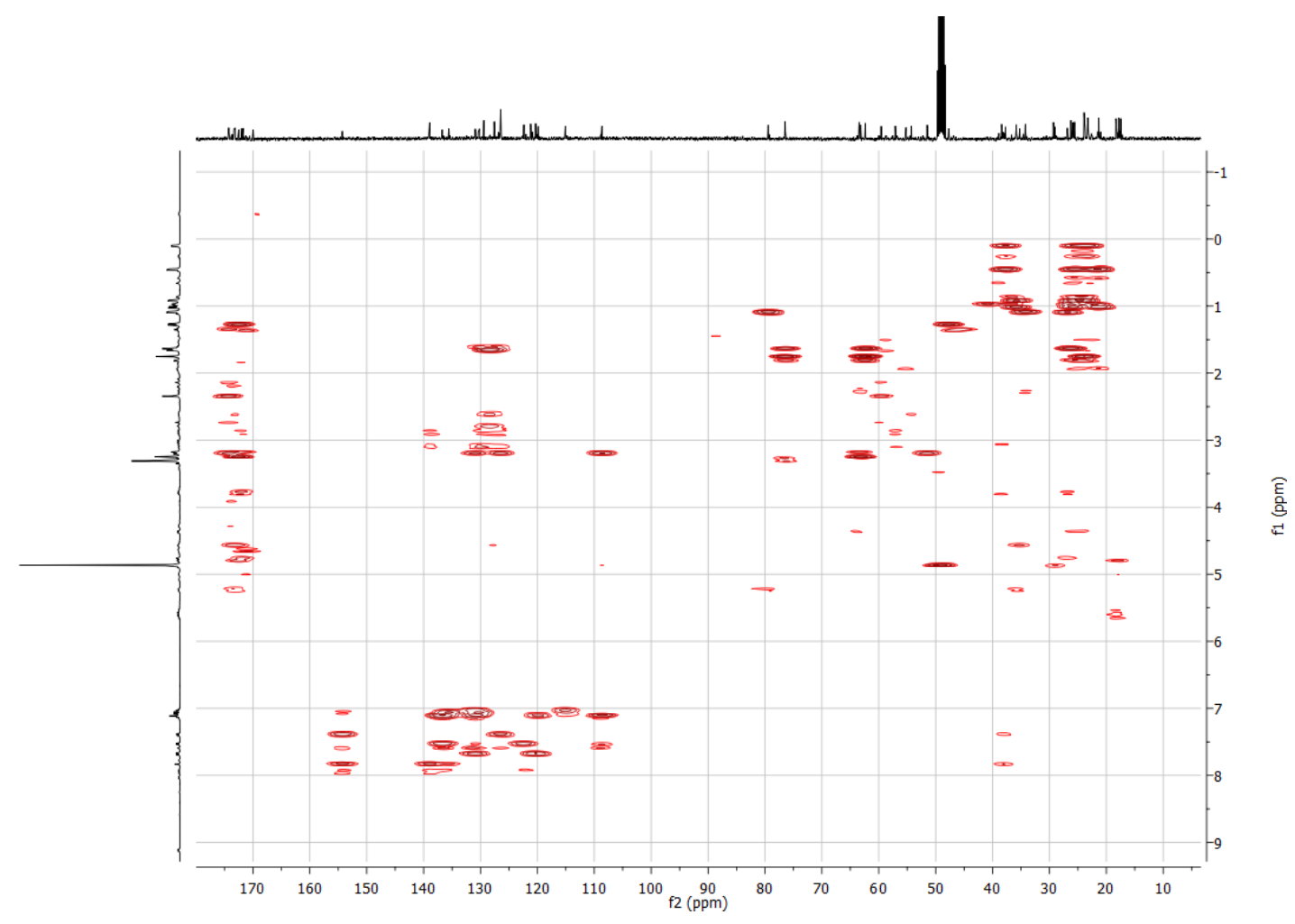


Figure S61. NOESY spectrum of 7 in $\mathrm{CD}_{3} \mathrm{OD}(400 \mathrm{MHz})$

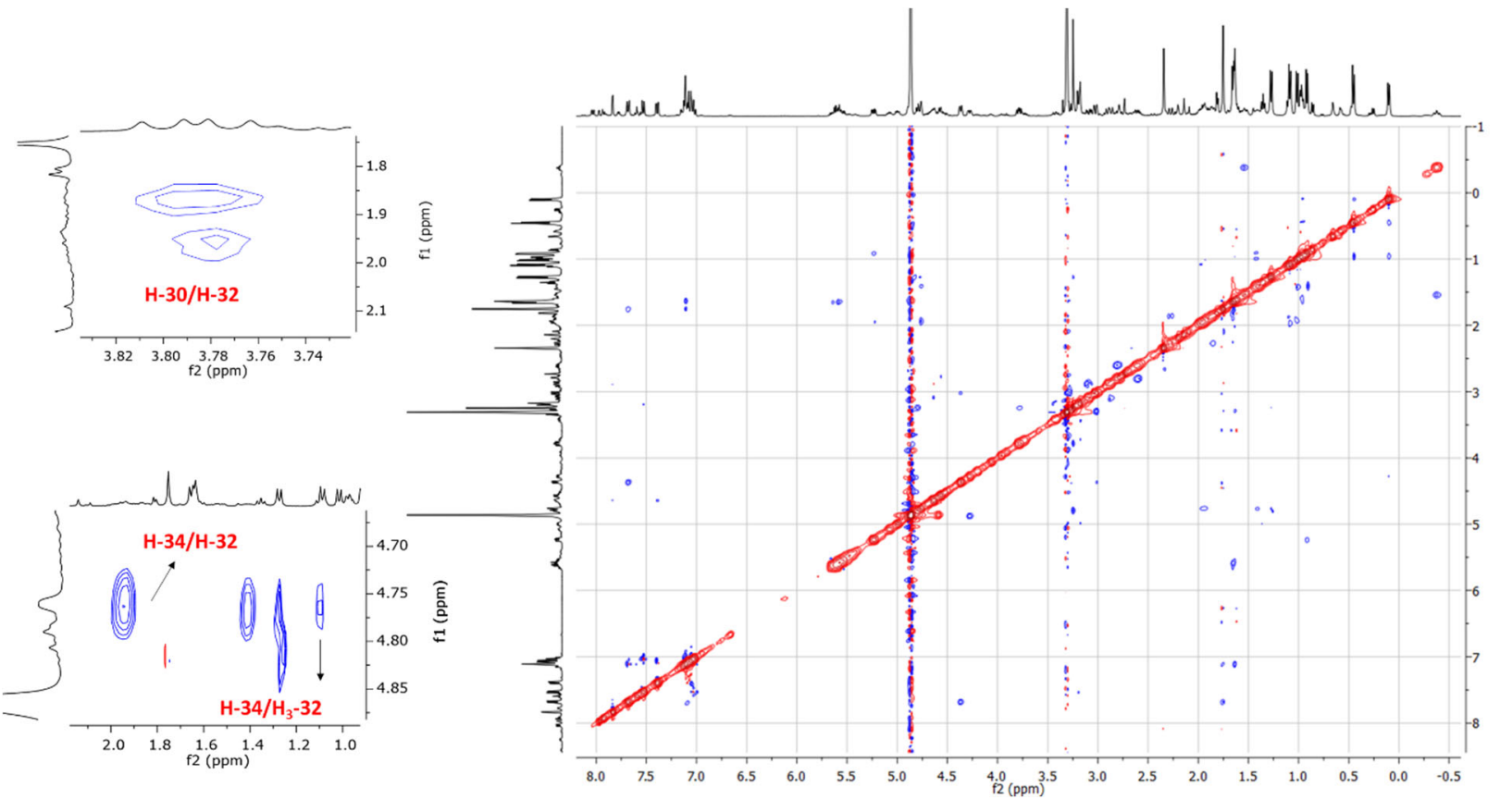

Figure S62. (+)-HRESIMS spectrum of 7

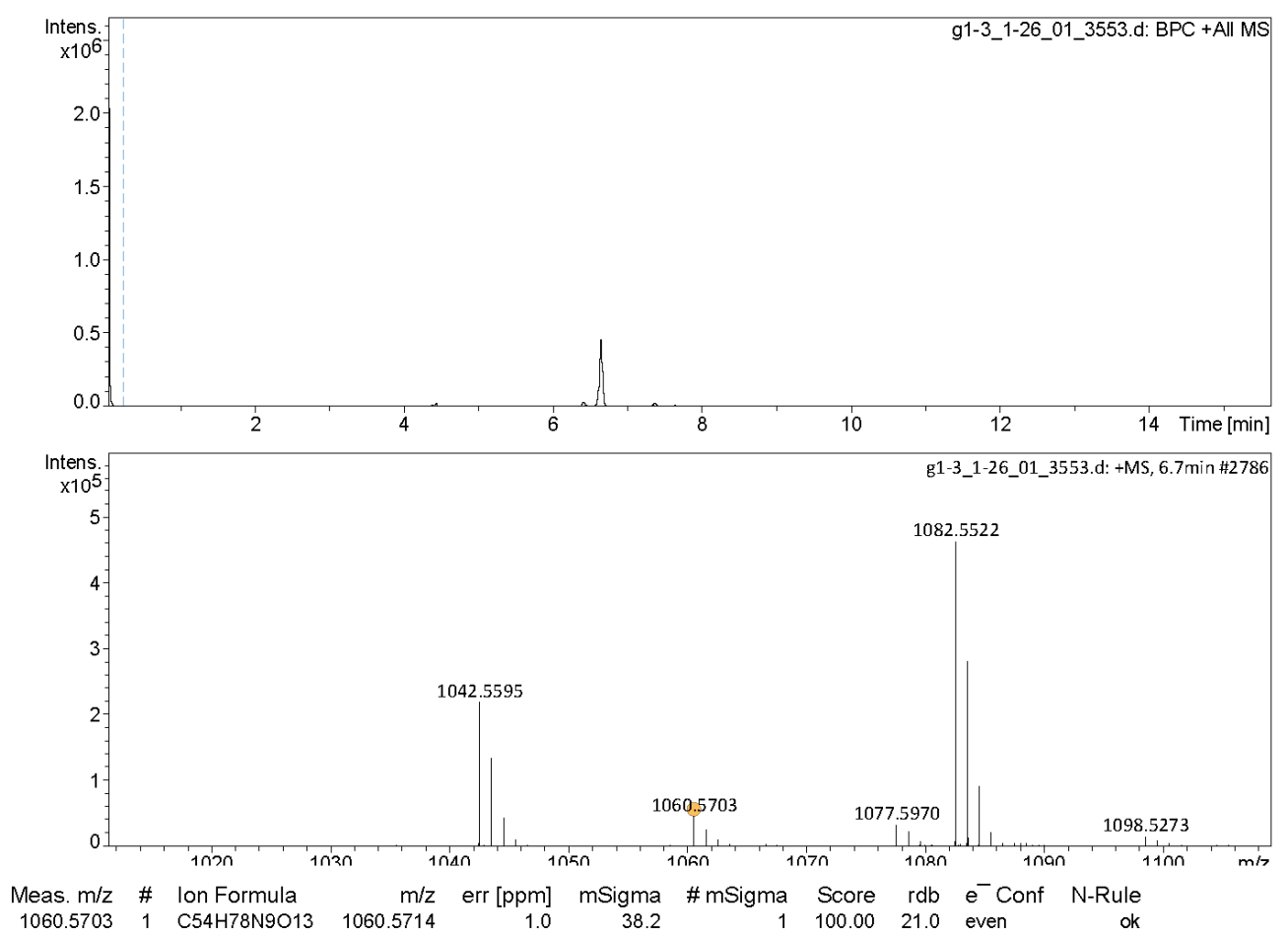




\section{Figure S63. IR spectrum of 7}

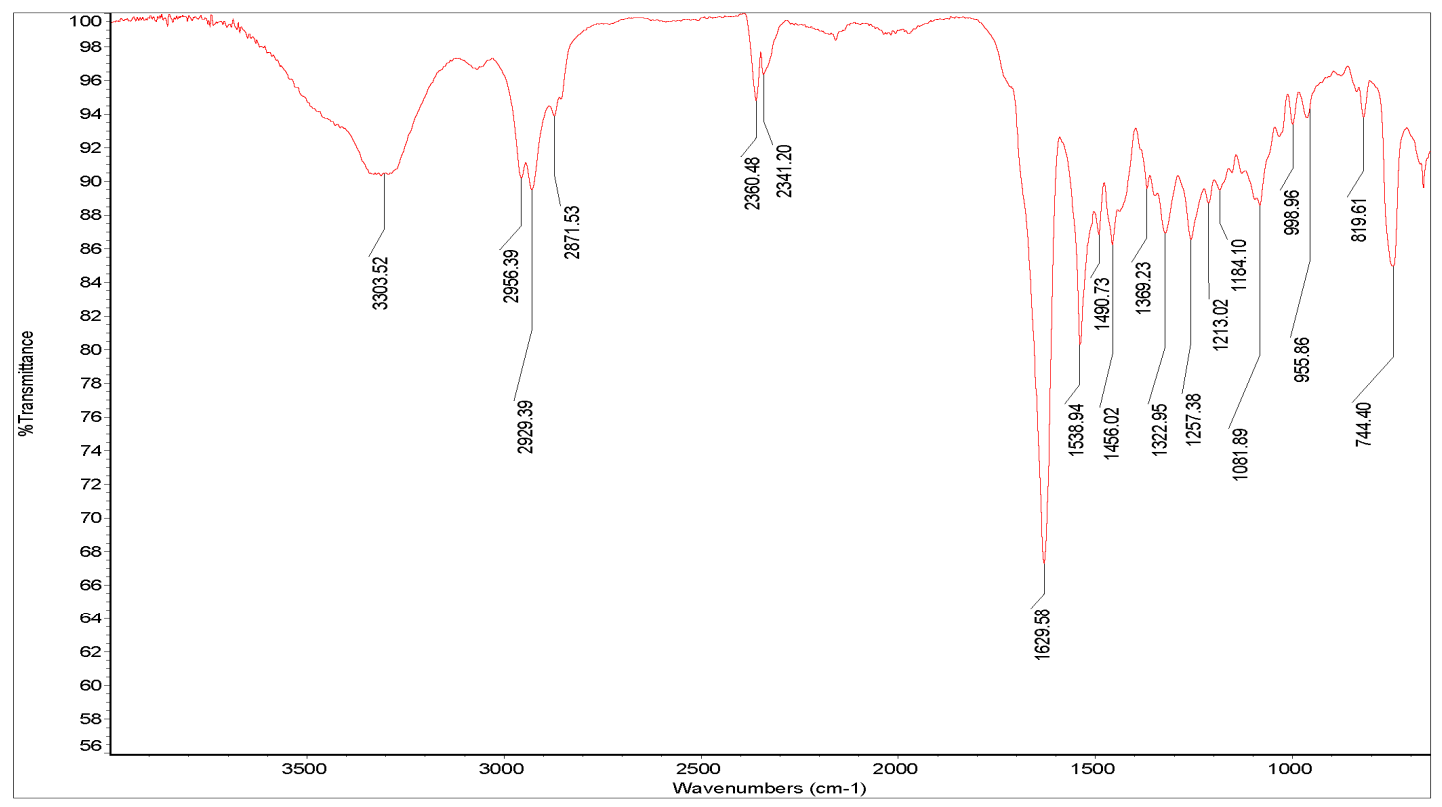

Figure S64. LC-ESIMS chromatograms of a total hydrolysate of 7 after derivatization with D/L-FDLA

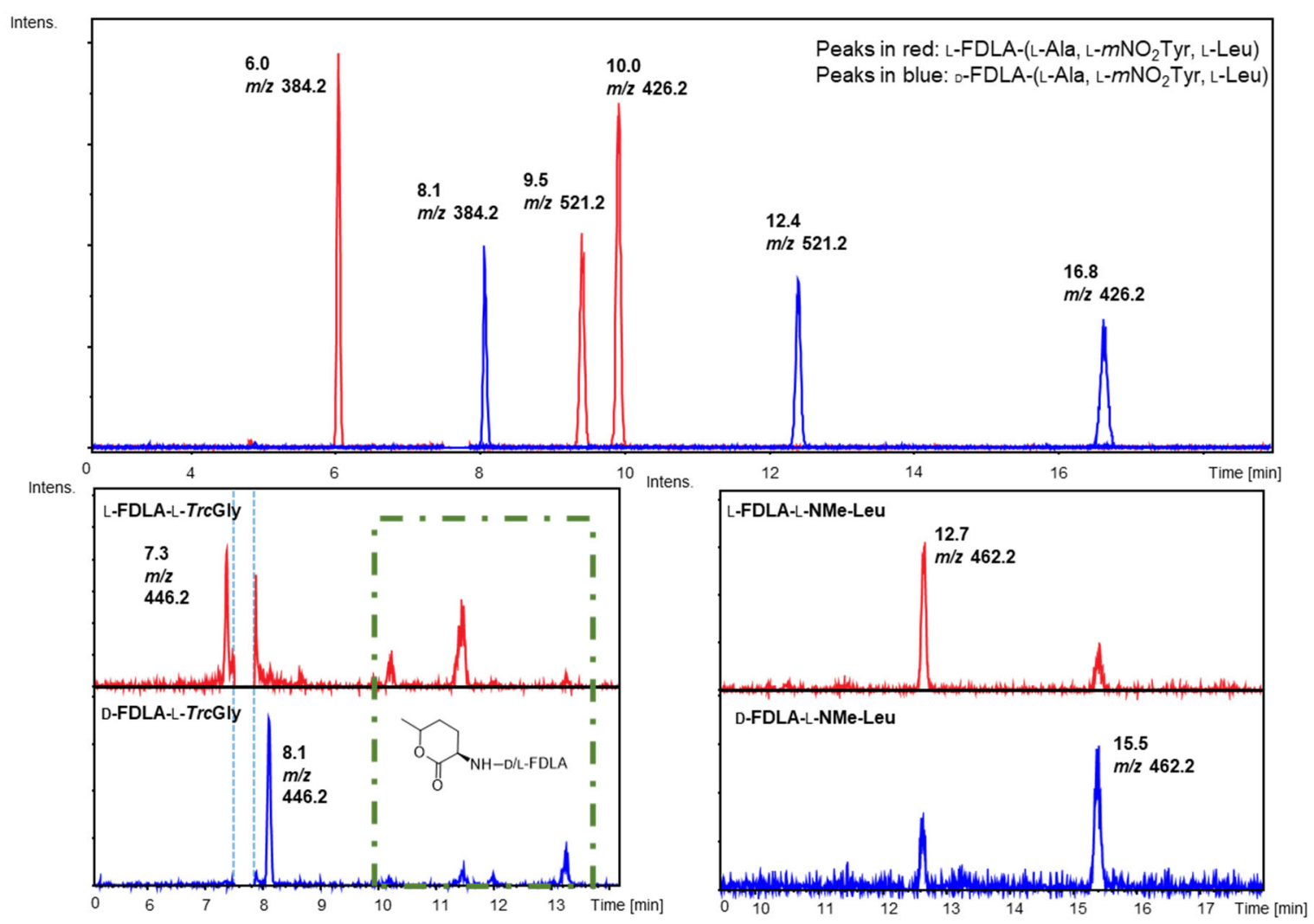

Note that Trp residues with 2-isopropyloxirane and 3-methylbutane-1,2-diol functionalities attached to the ring nitrogen are unstable during Marfey's reaction. 
Figure S65. ${ }^{1} \mathrm{H}$ NMR spectrum of 8 in $\mathrm{CD}_{3} \mathrm{OD}$ at $400 \mathrm{MHz}$
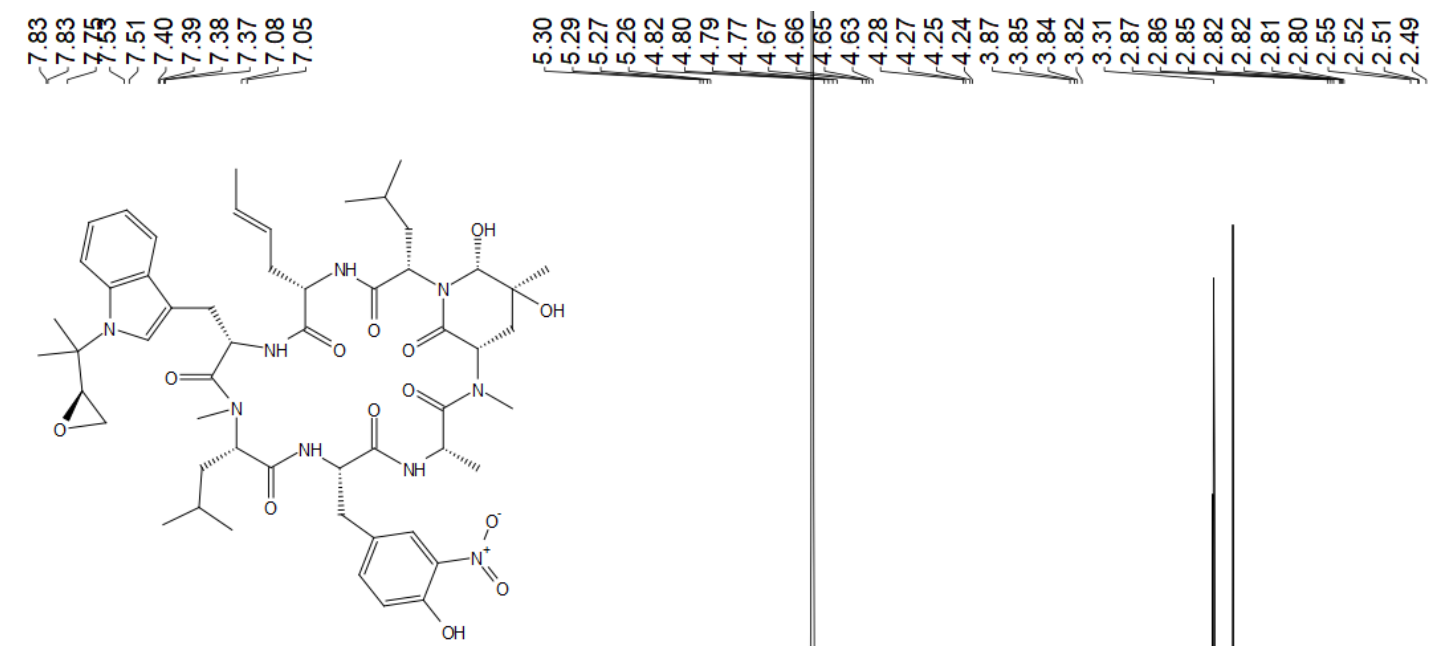

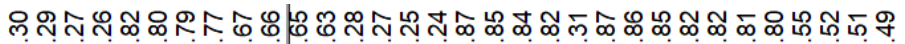
NTNNNNNN

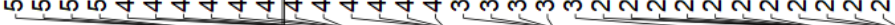

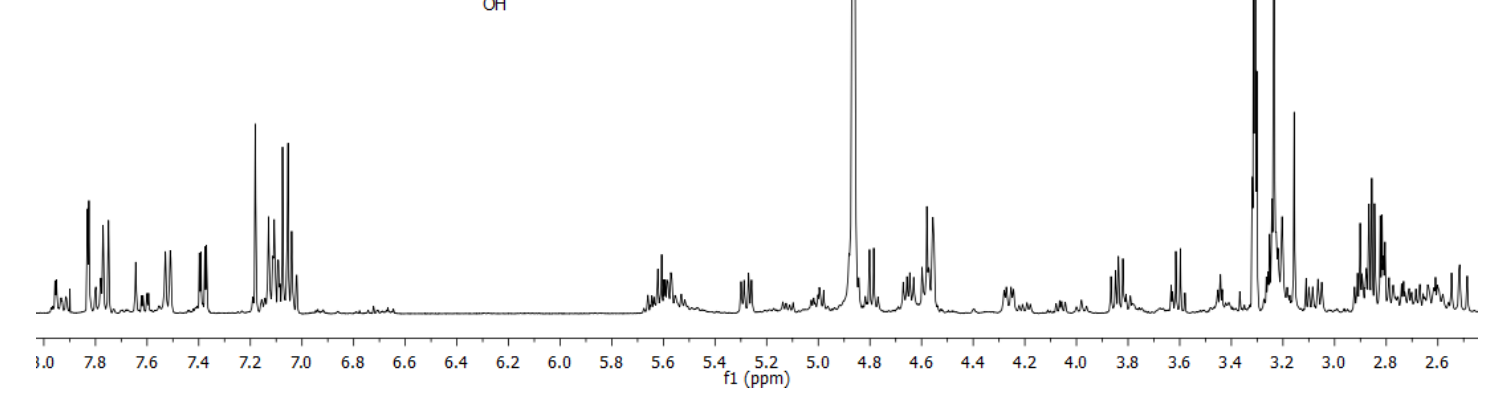

Figure S66. ${ }^{13} \mathrm{C}$ NMR spectrum of 8 in $\mathrm{CD}_{3} \mathrm{OD}$ at $100 \mathrm{MHz}$

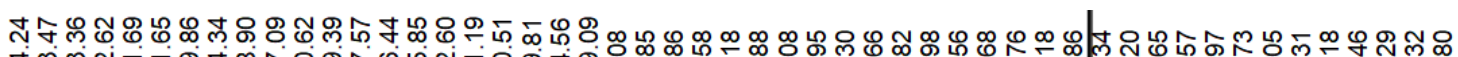

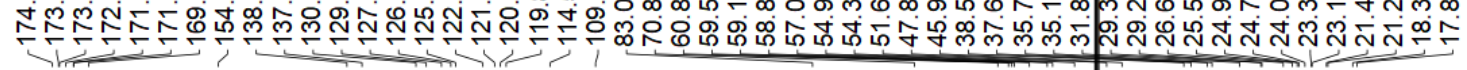

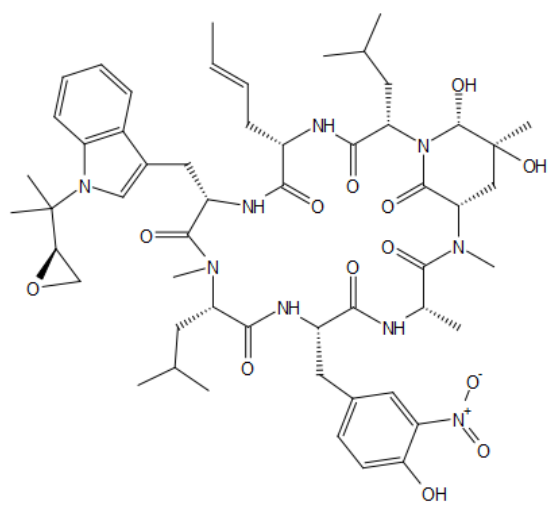

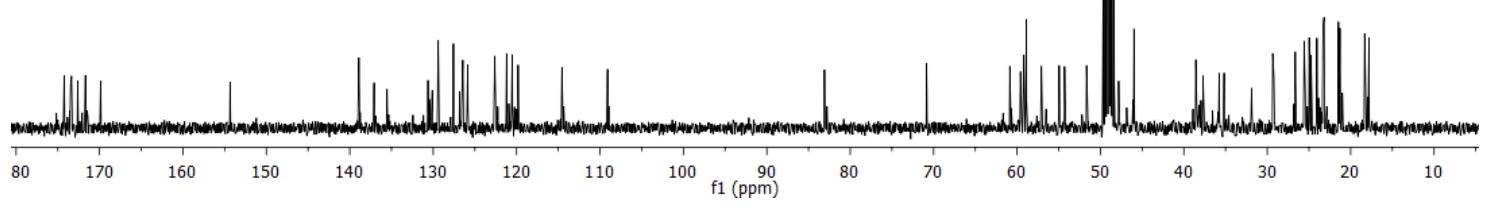


Figure S67. COSY spectrum of 8 in $\mathrm{CD}_{3} \mathrm{OD}(400 \mathrm{MHz})$

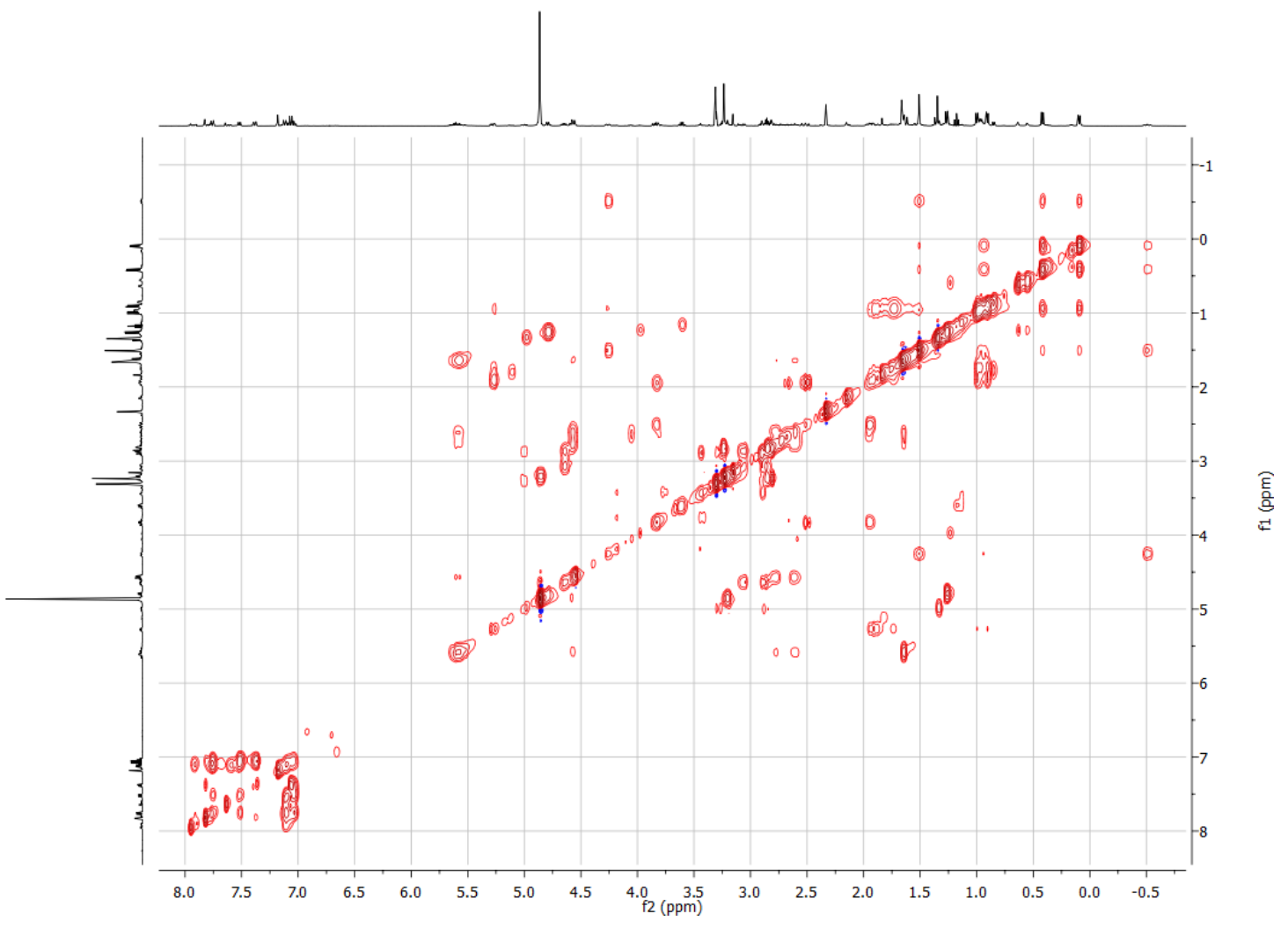

Figure S68. TOCSY spectrum of 8 in $\mathrm{CD}_{3} \mathrm{OD}(400 \mathrm{MHz})$

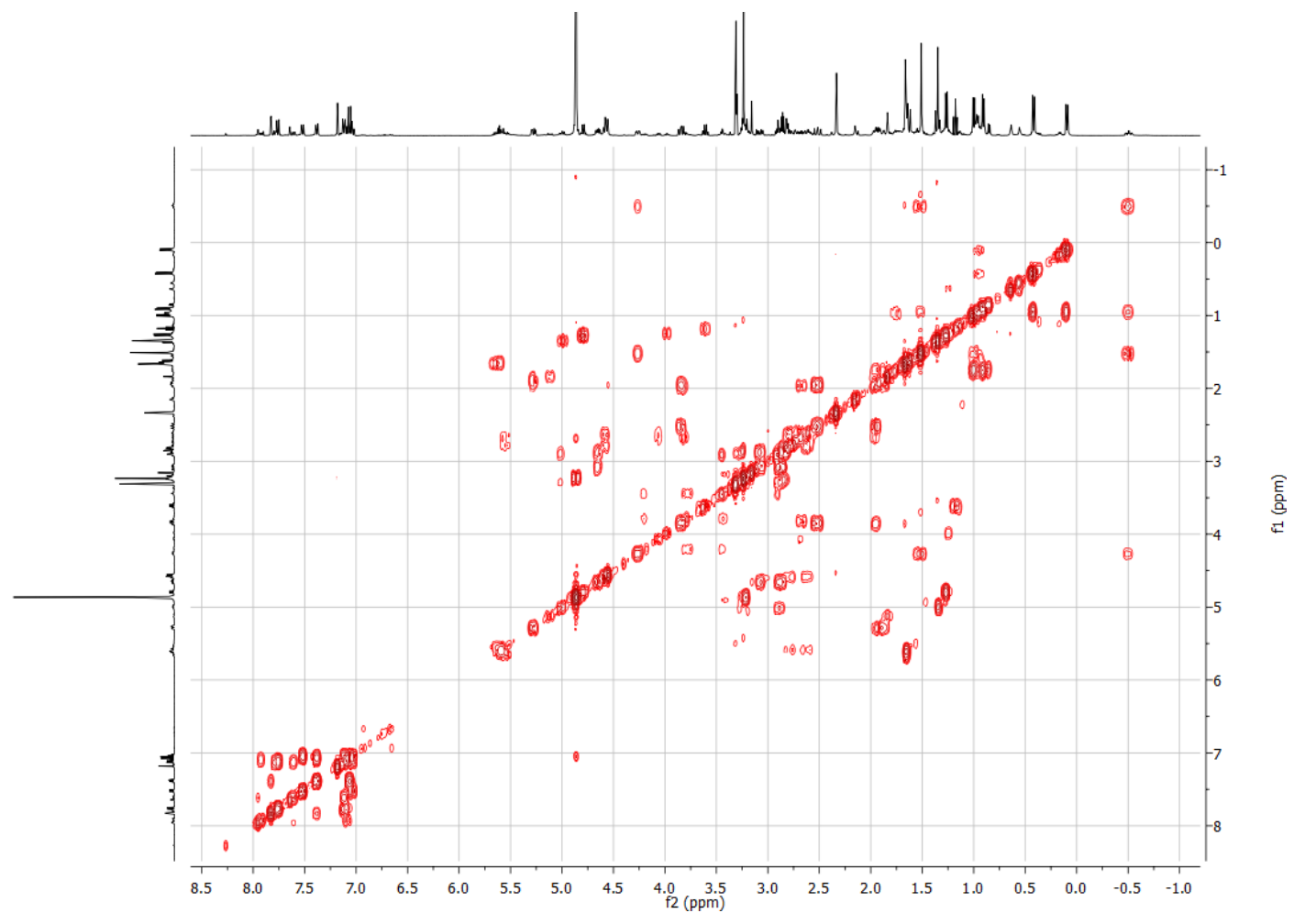


Figure S69. HSQC spectrum of 8 in $\mathrm{CD}_{3} \mathrm{OD}\left(400 \mathrm{MHz}{ }^{1} \mathrm{H}\right)$

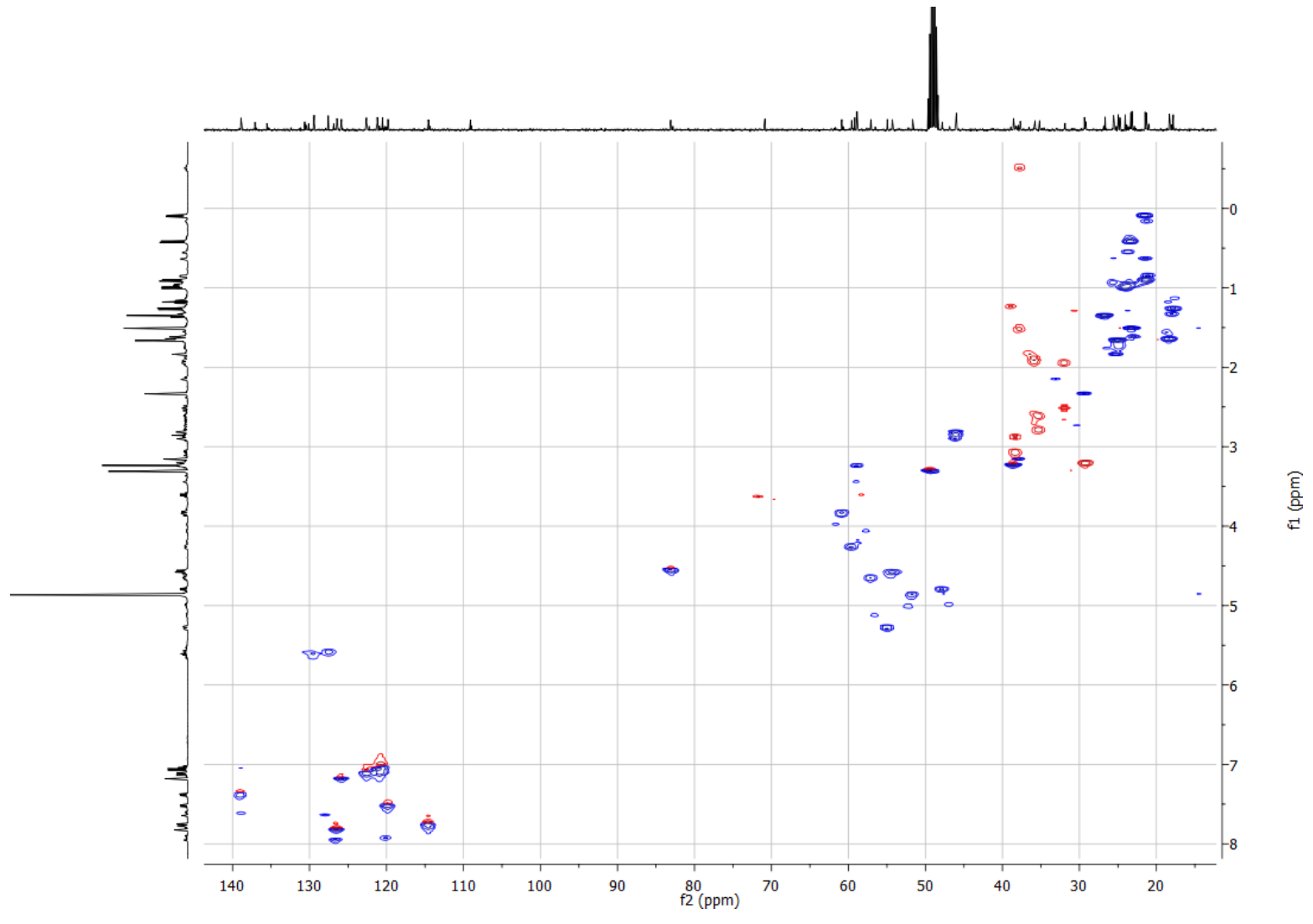

Figure S70. HMBC spectrum of 8 in $\mathrm{CD}_{3} \mathrm{OD}\left(400 \mathrm{MHz}^{1} \mathrm{H}\right)$

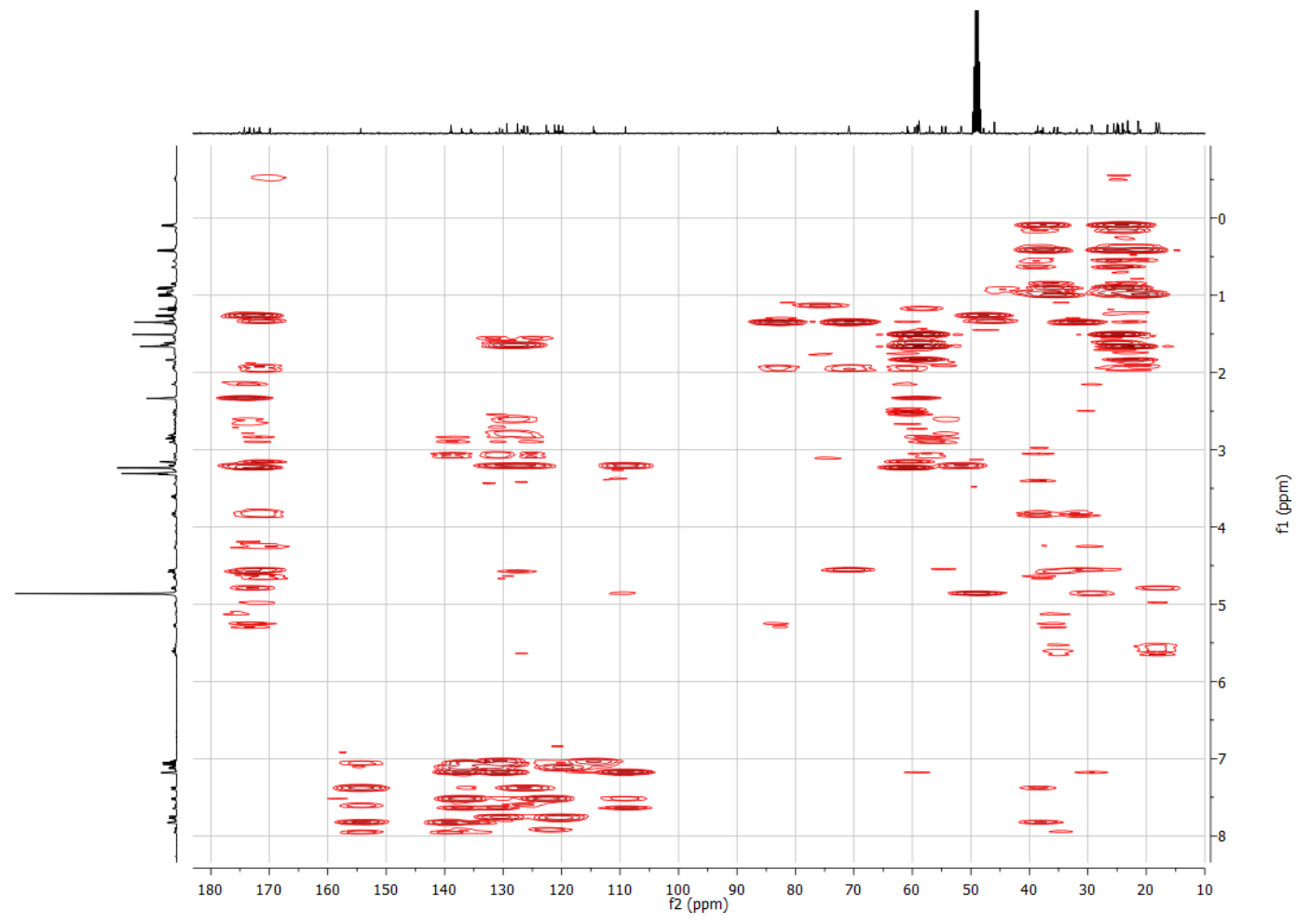


Figure S71. NOESY spectrum of $8(400 \mathrm{MHz})$

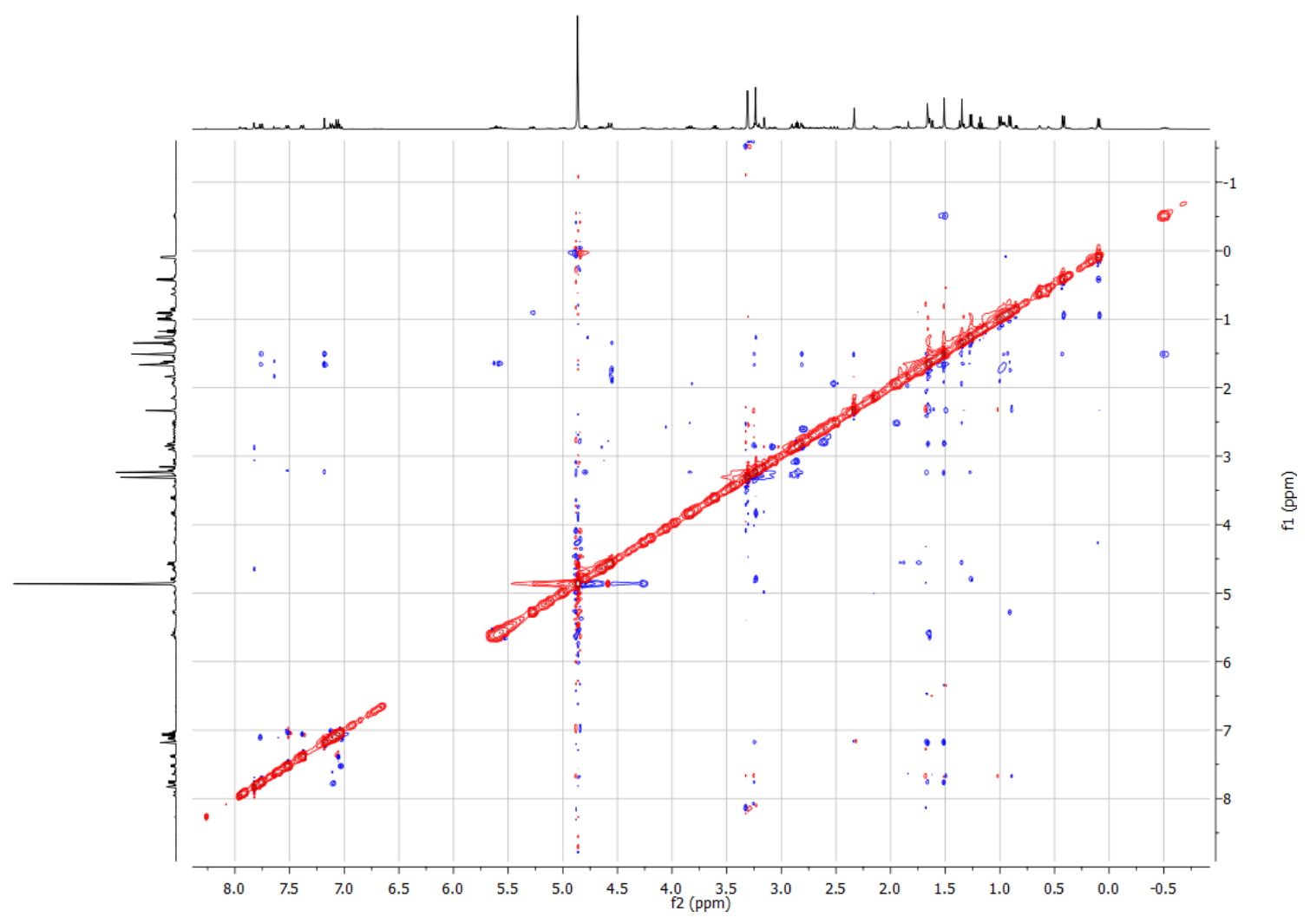

Figure S72. (+)-HRESIMS spectrum of 8
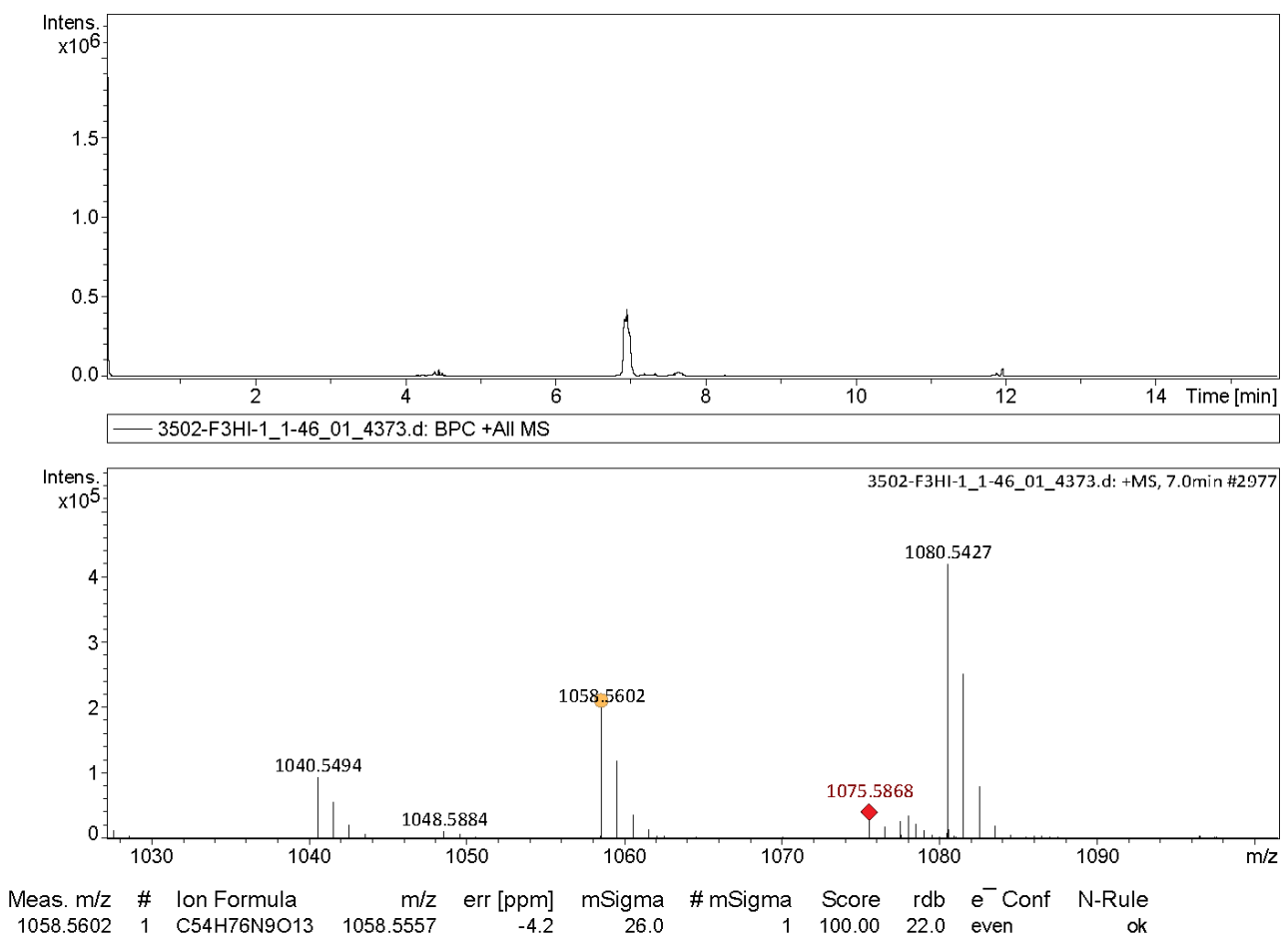


\section{Figure S73. IR spectrum of 8}

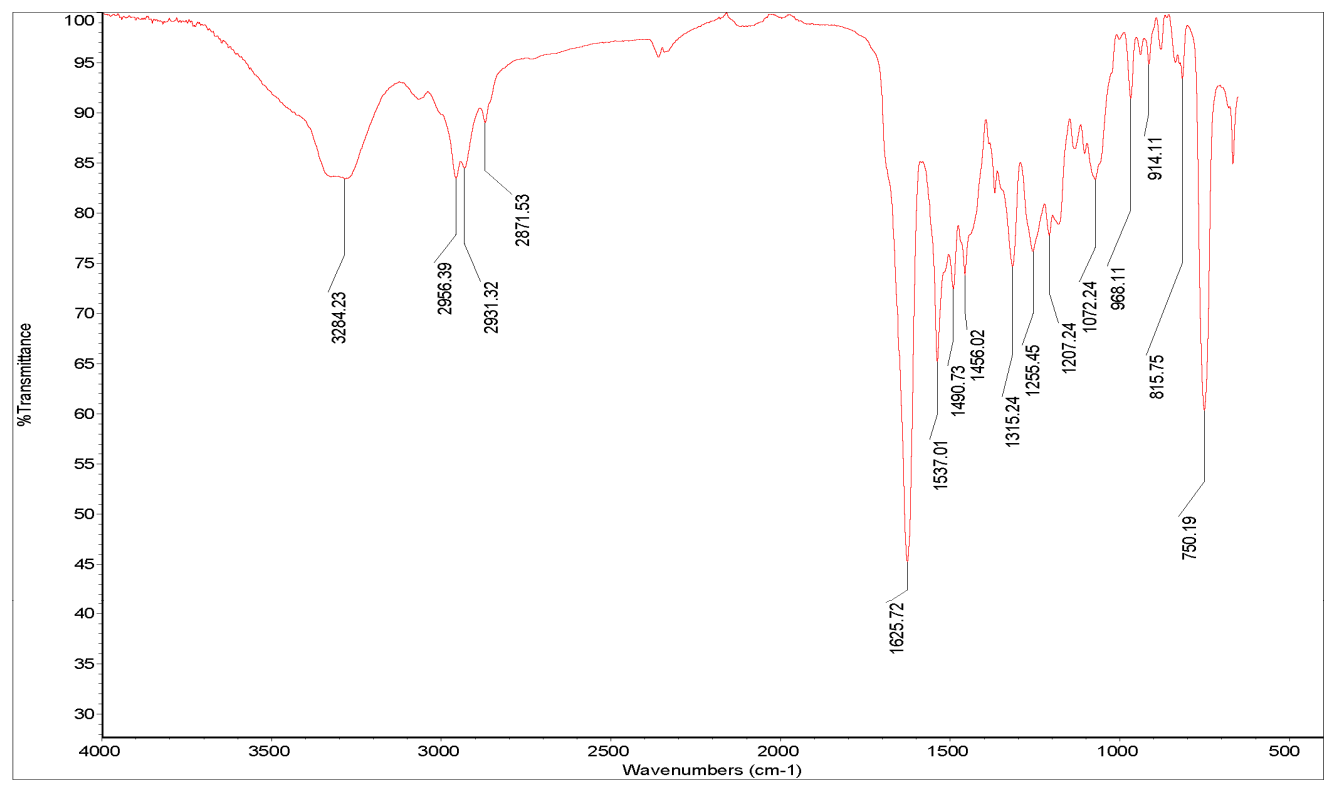

Figure S74. LC-ESIMS chromatograms of the hydrolysate of 8 after derivatization with D/L-FDLA

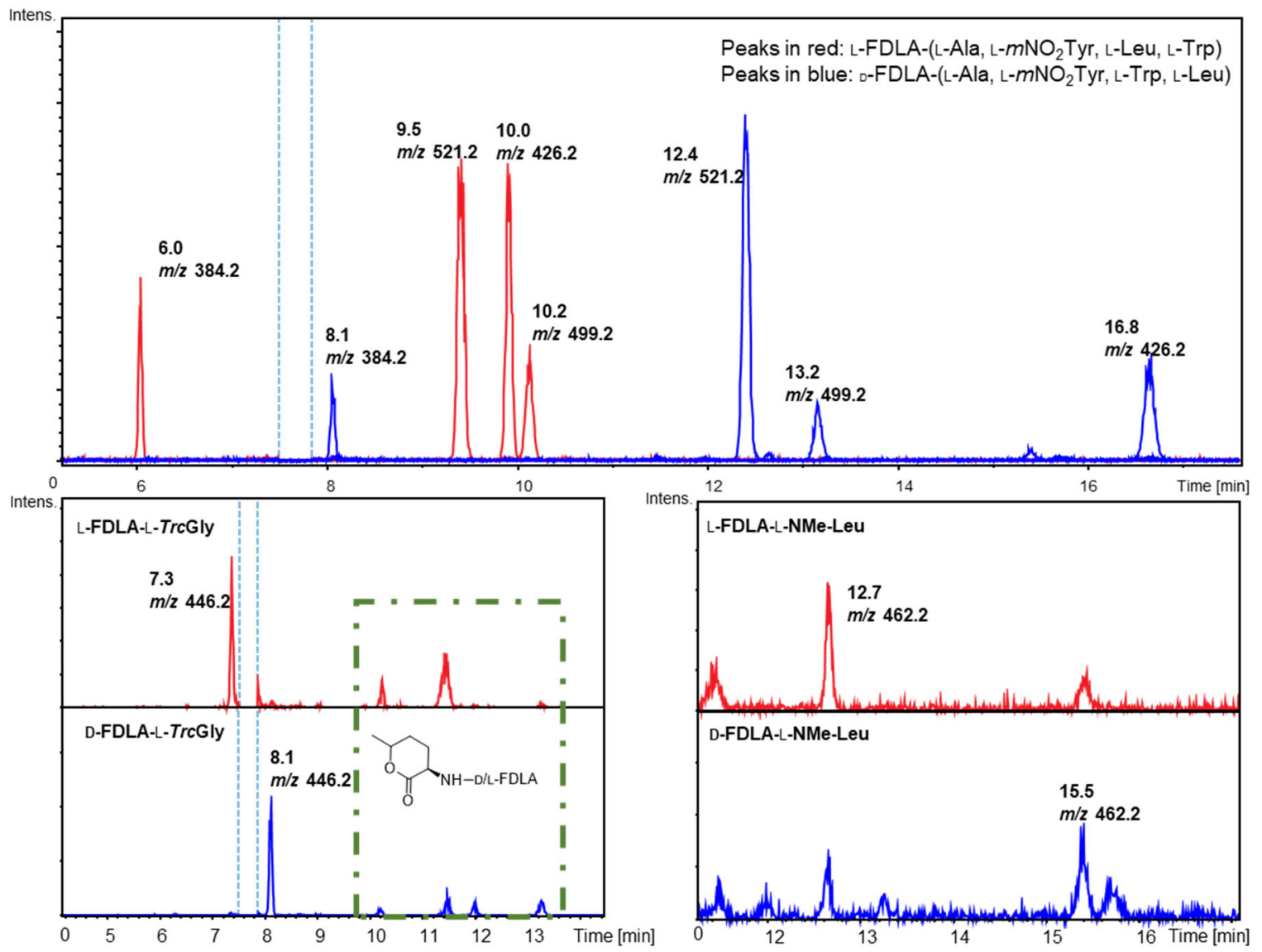


Figure S75.UHPLC chromatograms for isolates 1-13 (extracted at $254 \mathbf{n m})$

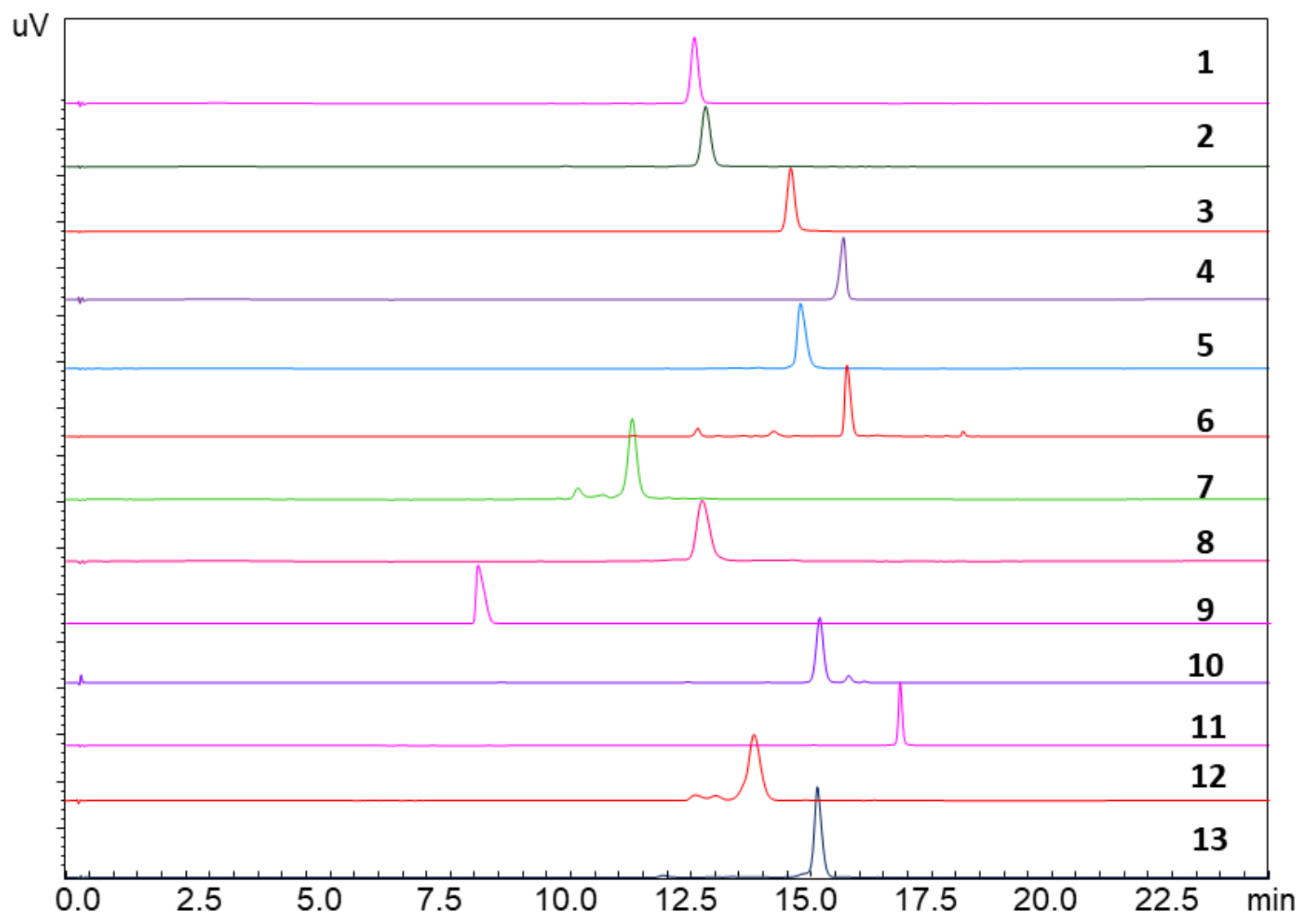

UHPLC Method. Column: Kinetex $1.7 \mu \mathrm{m}$ XB-C18 $100 \AA$ column $(50 \mathrm{~mm} \times 2.1 \mathrm{~mm})$. Gradient elution according to the following table, at a flow rate of $0.6 \mathrm{~mL} / \mathrm{min}$.

\begin{tabular}{ll}
\hline Time (min) & $\mathbf{~ \% C H}_{\mathbf{3}} \mathbf{C N}$ \\
\hline 0.01 & 20 \\
0.50 & 20 \\
15.0 & 55 \\
18.1 & 85 \\
21.0 & 100 \\
21.1 & 20 \\
25.0 & 20 \\
\hline
\end{tabular}


UV spectra for isolates 1-8 were obtained from corresponding UHPLC data. T (time, min) represent the retention time in UHPLC chromatograms.

Figure S76. UV spectrum of 1

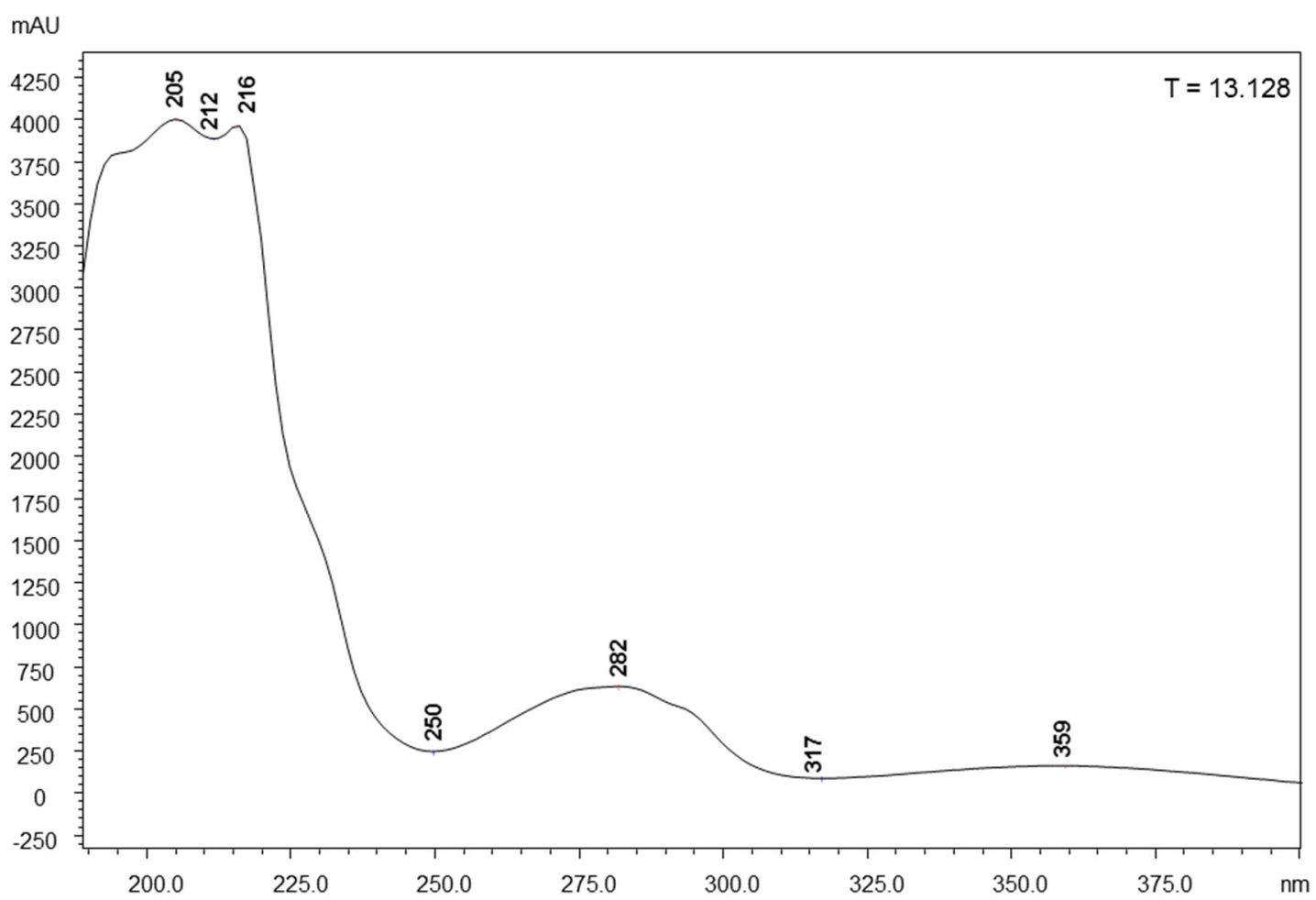

Figure S77. UV spectrum of 2

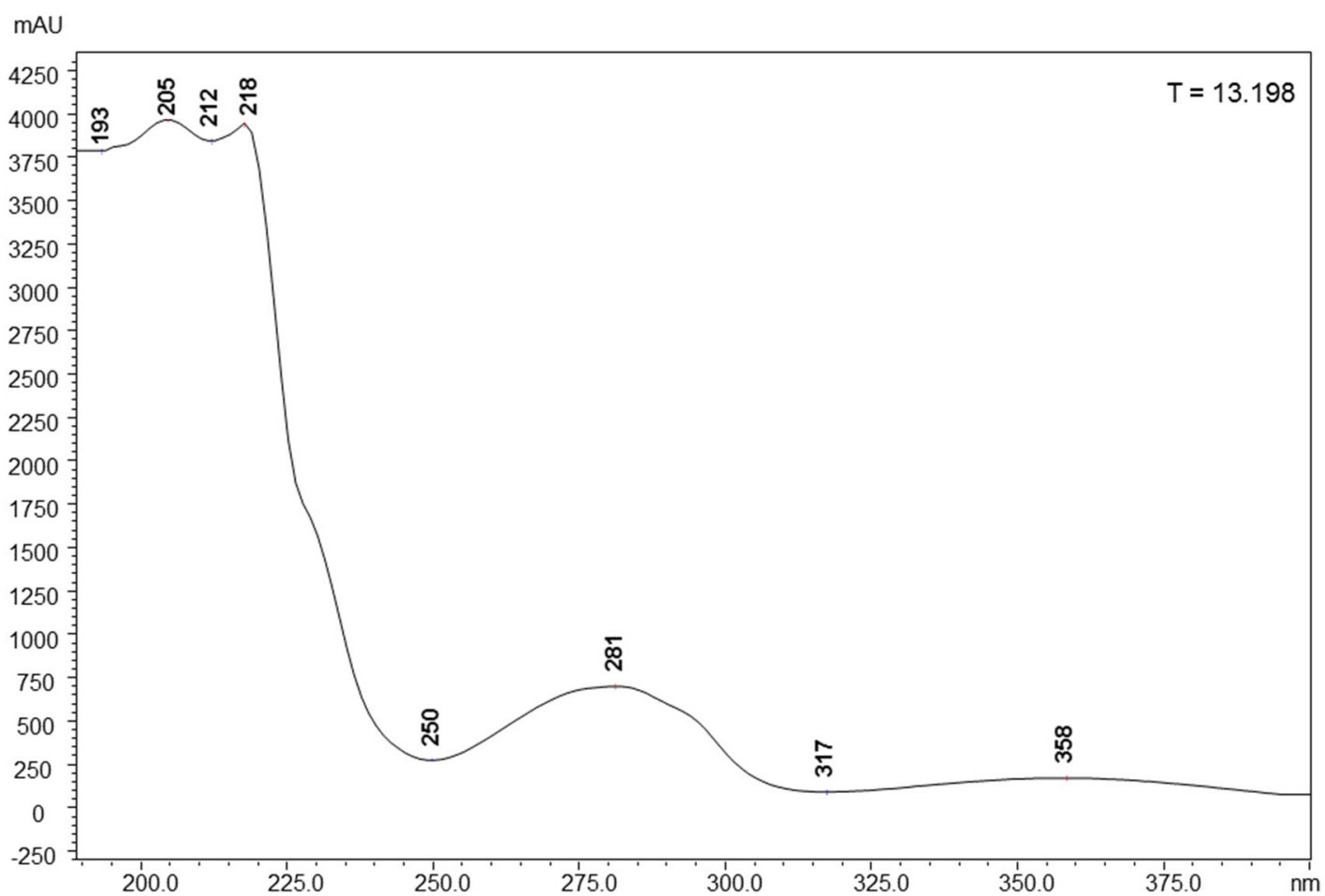


Figure S78. UV spectrum of 3

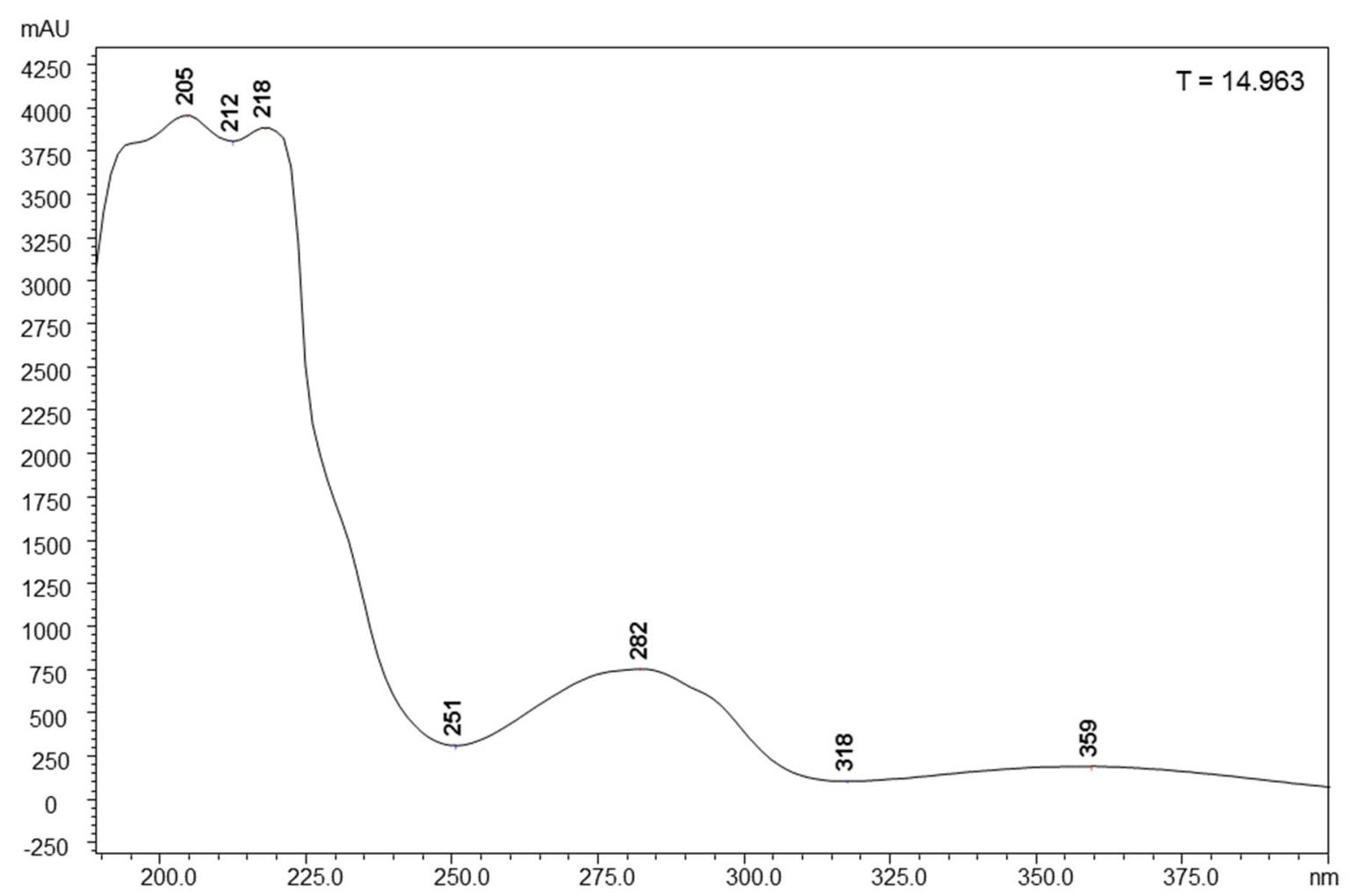

Figure S79. UV spectrum of 4

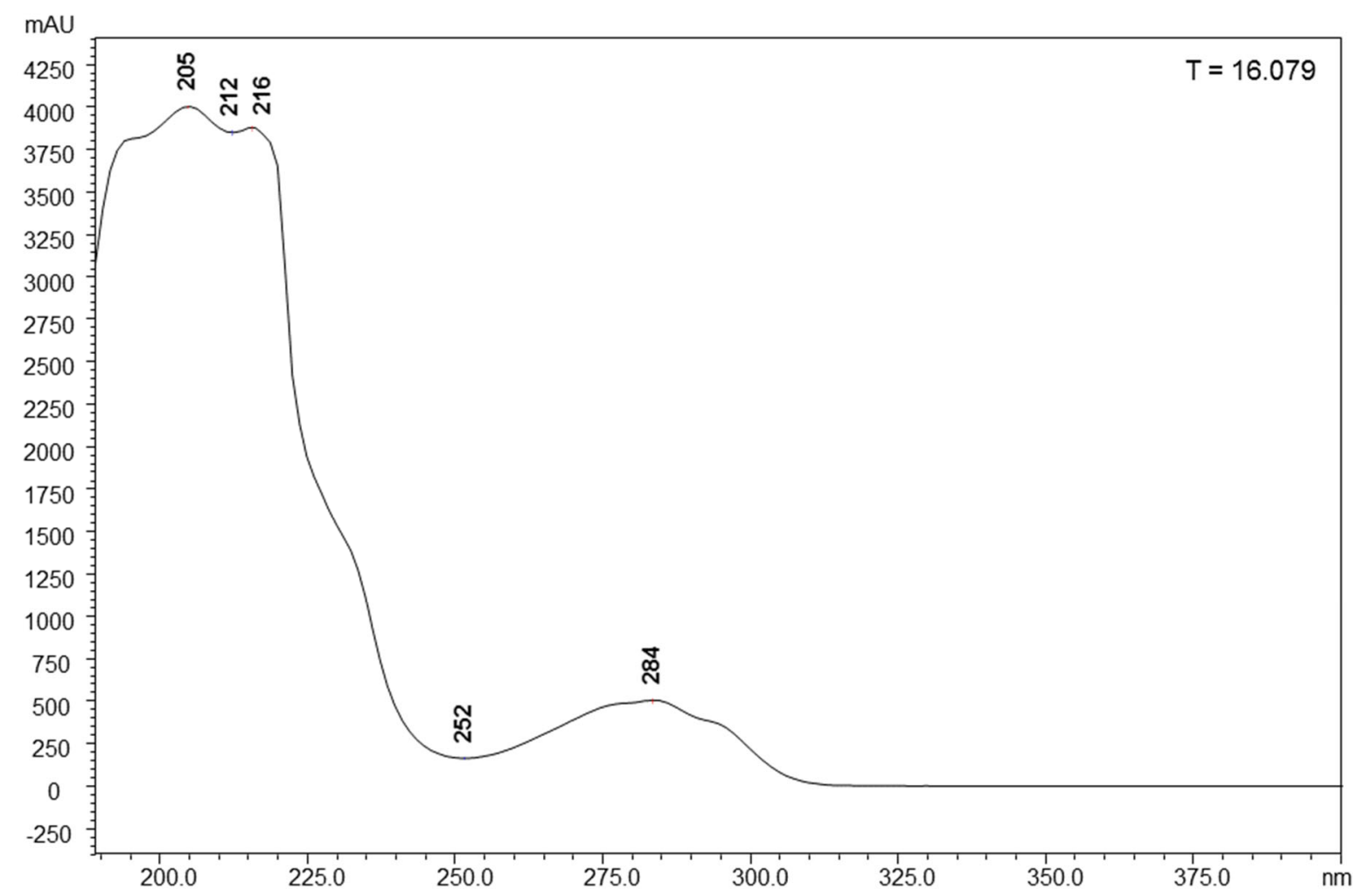


Figure S80. UV spectrum of 5

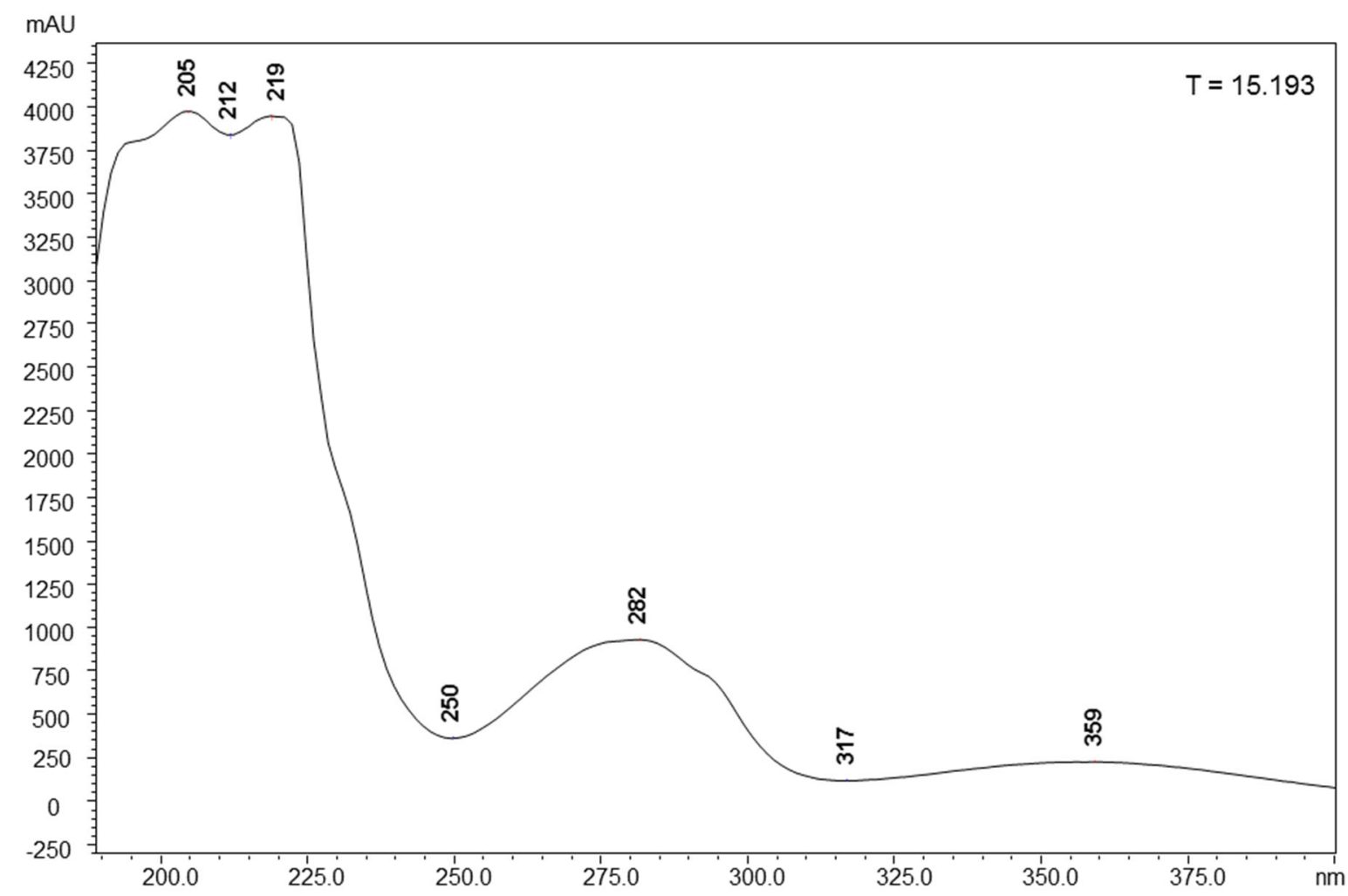

Figure S81. UV spectrum of 6

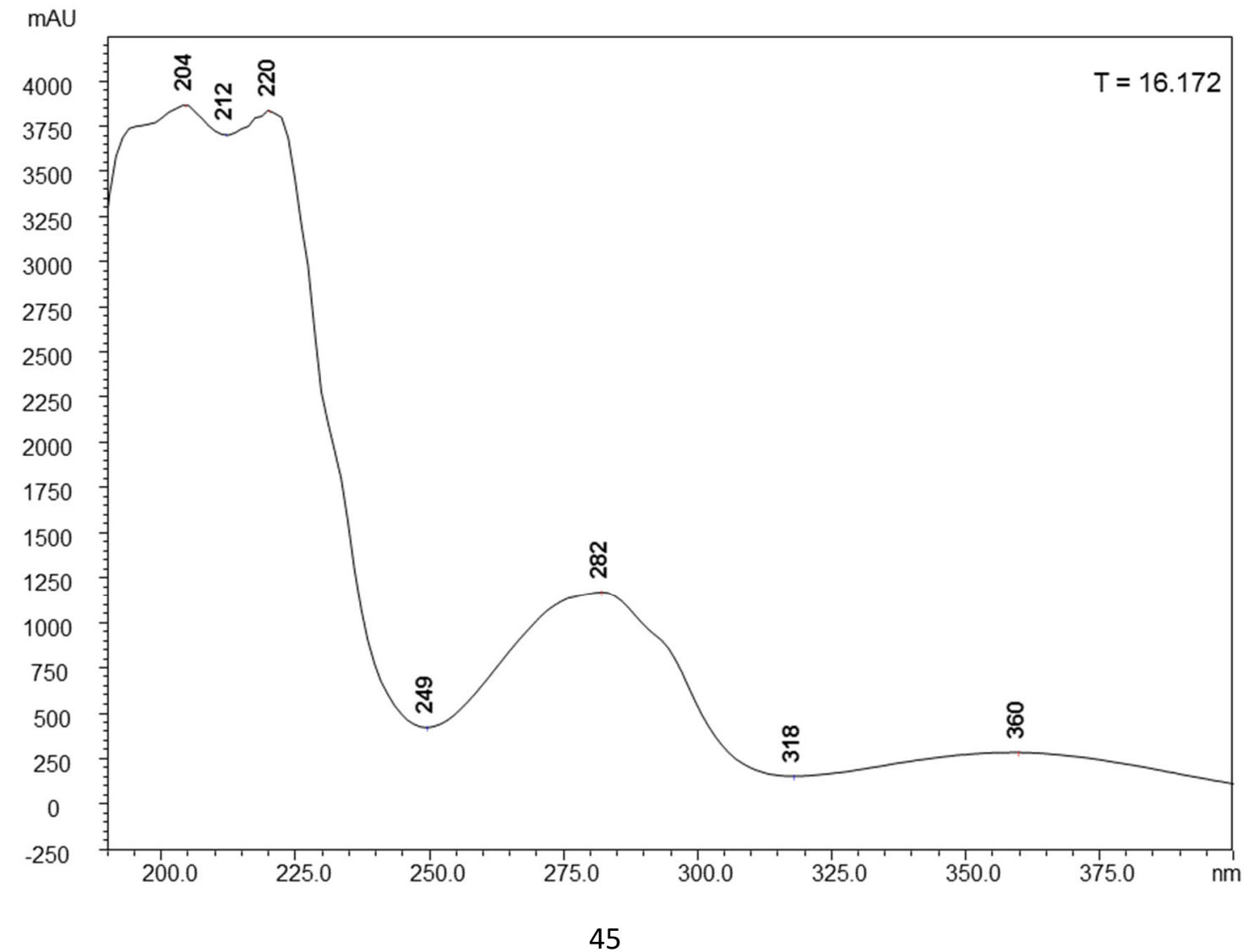


Figure S82. UV spectrum of 7

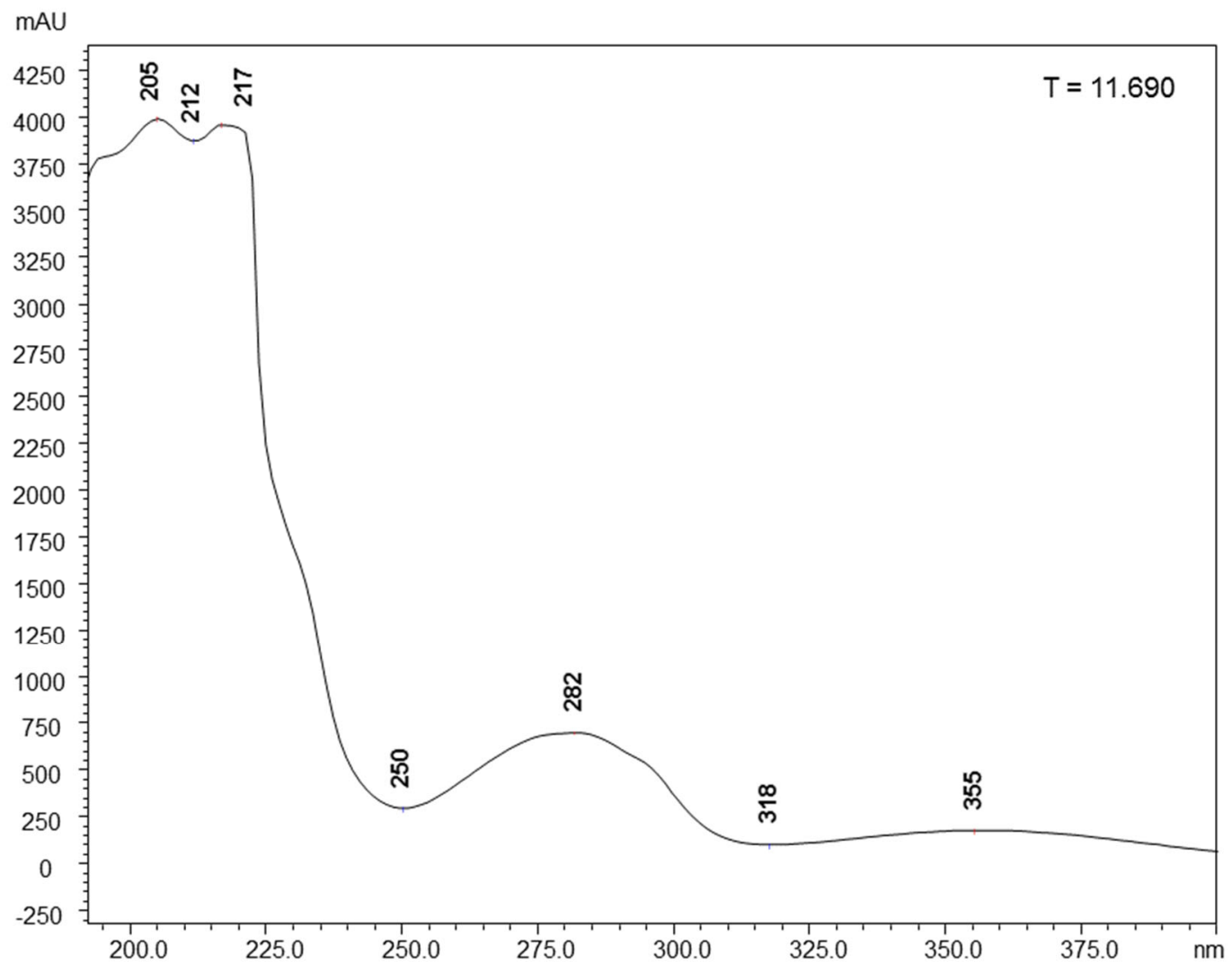

Figure S83. UV spectrum of 8

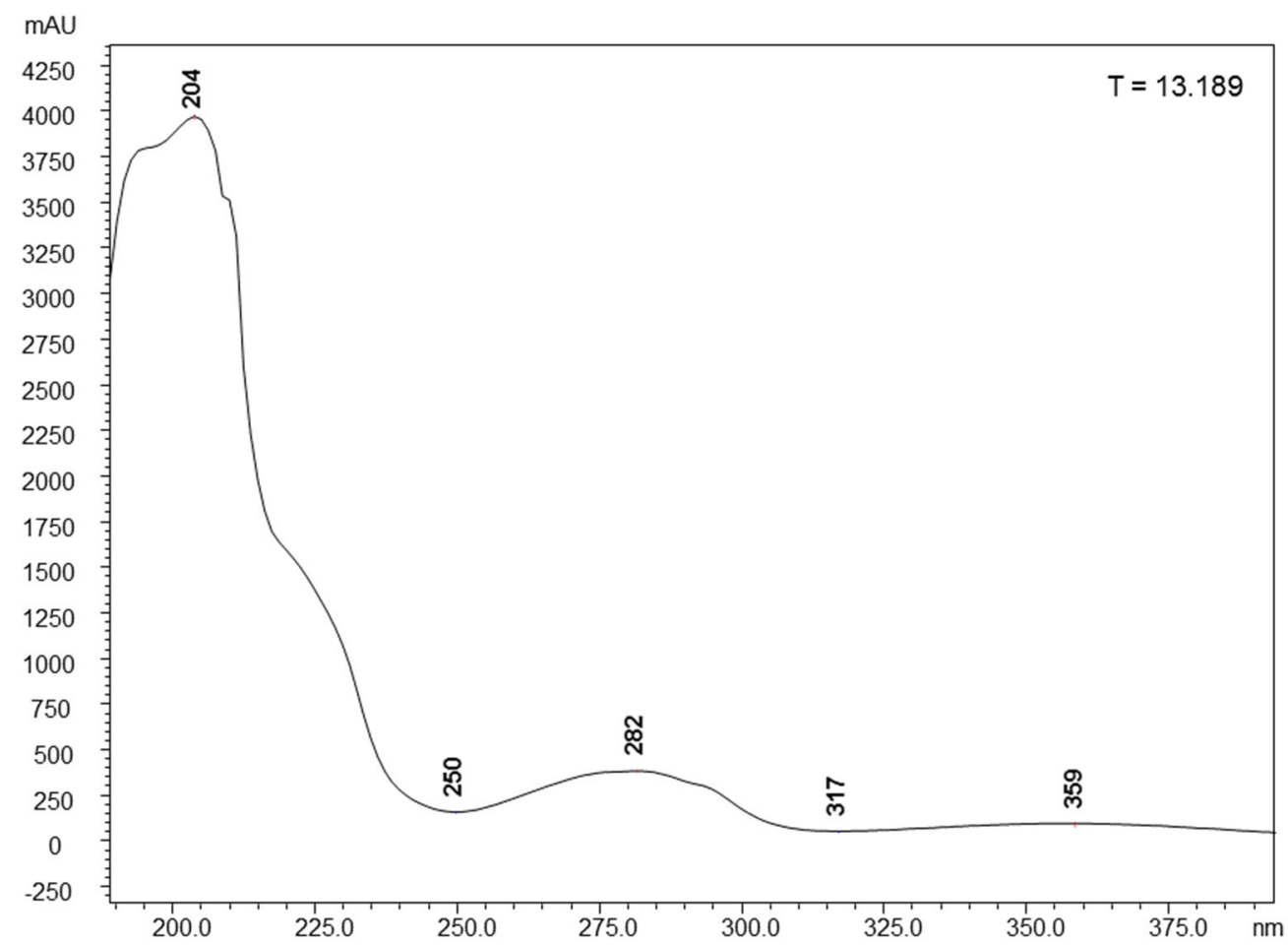

